\title{
Development of Trace Analysis Methods by
}

\section{Spectrofluorimetry}

\author{
by
}

Yu Yang, B.Sc.

A thesis submitted to the Faculty of Graduate Studies and Research in partial fulfillment of the requirements for the Degree of Master of Science

\author{
Department of Chemistry \\ Carleton University \\ Ottawa, Ontario, Canada
}

April 2011

C Copyright 2011, Yu Yang 
Library and Archives

Canada

Published Heritage Branch

395 Wellington Street Ottawa ON K1A ON4 Canada
Bibliothèque et

Archives Canada

Direction du

Patrimoine de l'édition

395 , rue Wellington

Ottawa ON K1A ON4

Canada
Your file Votre référence

ISBN: 978-0-494-81685-1

Our file Notre référence

ISBN: 978-0-494-81685-1
NOTICE:

The author has granted a nonexclusive license allowing Library and Archives Canada to reproduce, publish, archive, preserve, conserve, communicate to the public by telecommunication or on the Internet, loan, distribute and sell theses worldwide, for commercial or noncommercial purposes, in microform, paper, electronic and/or any other formats.

The author retains copyright ownership and moral rights in this thesis. Neither the thesis nor substantial extracts from it may be printed or otherwise reproduced without the author's permission.
AVIS:

L'auteur a accordé une licence non exclusive permettant à la Bibliothèque et Archives Canada de reproduire, publier, archiver, sauvegarder, conserver, transmettre au public par télécommunication ou par l'Internet, prêter, distribuer et vendre des thèses partout dans le monde, à des fins commerciales ou autres, sur support microforme, papier, électronique et/ou autres formats.

L'auteur conserve la propriété du droit d'auteur et des droits moraux qui protège cette thèse. $\mathrm{Ni}$ la thèse ni des extraits substantiels de celle-ci ne doivent être imprimés ou autrement reproduits sans son autorisation.
In compliance with the Canadian Privacy Act some supporting forms may have been removed from this thesis.

While these forms may be included in the document page count, their removal does not represent any loss of content from the thesis.
Conformément à la loi canadienne sur la protection de la vie privée, quelques formulaires secondaires ont été enlevés de cette thèse.

Bien que ces formulaires aient inclus dans la pagination, il n'y aura aucun contenu manquant. 


\section{Abstract}

An investigation of light scattering of non-imprinted PMAA-co-EGDMA particles (NIP) in aqueous suspension after 17ß-estradiol (E2) binding was conducted by spectrofluorimetry. This light scattering from NIP particles in aqueous suspension was increased by spiking E2 from 0.1 to $1.0 \mathrm{ppm}$. Thus, a new alternative method was found to determine $17 \beta$-estradiol (E2) by measurement of light scattering from NIP particles.

Molecularly imprinted PMAA-co-EGDMA particles (MIP) were synthesized in the presence of template E2 molecules. Fluorescence emission from E2 non-specifically bound onto the MIP particles was quenched by gold nanoparticles. The S-V plot was linear, with $\mathrm{K}_{\mathrm{sv}}=2.9 \times 10^{4} \mathrm{M}^{-1}$. Fluorescence emission from $\mathrm{E} 2$ specifically bound inside the MIP particles was quenched by nitrite anions. The S-V plot became non-linear, with $\mathrm{K}_{\mathrm{sv}}=2.1 \times 10^{2} \mathrm{M}^{-1}$ and $\mathrm{V}<1.0 \mathrm{M}^{-1}$. The difference between these two emission intensities varied with the initial E2 concentration in water, generating a Scatchard calibration curve from 0.1 to $10 \mathrm{ppb}$. 


\section{Publications}

Y. Yang, E. P. C. Lai and M. Liu, "Spectroscopic analysis of poly (methacrylic acid-coethylene glycol dimethacrylate) submicron particles by fluorescence emission and light scattering upon binding with $17 \beta$-estradiol in water treatment," The Open Colloid Science Journal, vol. 3, no. 8, pp. 1-8, 2010.

Y. Yang and E.P. C. Lai. "An investigation of porous structure in molecularly imprinted polymer for sensor development: Non-linear fluorescence quenching of $17 \beta$-estradiol bound inside MIP submicron particles by sodium nitrite and methacrylamide," Journal of Photochemistry and Photobiology A: Chemistry. vol. 213, no. 2-3, pp. 123-128, 2010.

Y. Yang and E. P. C. Lai, "Molecularly imprinted polymer particles for rapid determination of $17 \beta$-estradiol in water by fluorescence quenching," International Journal of Analytical Chemistry (submitted in January, 2011). 


\section{Acknowledgements}

My deepest appreciation and thanks go to my supervisor Professor Edward Lai for his support, guidance and inspiration helps throughout my graduate studies at Carleton University.

I would like to express my appreciation and thanks to my committee members who have provided me knowledge, insight, and experience helping throughout my work.

I would like to express my special thanks to Dr. Liu Min from chemistry department of Huazhong University of Science and Technology for our in-depth discussions on the light scattering and membrane filters.

Many thanks go to my lab mates: Zack DeMaleki, Negar Bahraini, Mark Pereira, Amy Hrdina, and Kevin Xia for their help, support, friendship, and for the many useful and interesting discussions.

This dissertation is dedicated to my beloved wife Yanwu Wang, my dear parents and uncle, for their love, support and patience. 


\section{Table of Contents}

Page

Title Page I

\begin{tabular}{ll|l} 
Abstract & II
\end{tabular}

$\begin{array}{lll}\text { Publications } & \text { III }\end{array}$

Acknowledgements IV

Table of Contents $\quad$ V

List of Tables

List of Figures $\quad$ X

List of Scheme $\quad$ XIII

List of Abbreviations and Symbols $\quad$ XIV 


\section{Chapter 1: Introduction}

1.1 Molecular sensors based on fluorescence quenching $\quad \mathbf{1}$

1.2 Scope of this work $\quad 3$

$\begin{array}{ll}\text { References } & 9\end{array}$

Chapter 2: Spectroscopic Analysis of Poly Methacrylic Acid-co-Ethylene Glycol Dimethacrylate Submicron Particles by Fluorescence Emission and Light Scattering upon Binding with 17ß-Estradiol in Water Treatment

\subsection{Introduction}

\subsection{Experimental}

2.2.1 Chemicals and reagents

2.2.2 Determination of the optimal Mie scattering excitation wavelength for NIP submicron particles in aqueous suspension

2.2.3 Determination of light scattering and fluorescence emission intensities of various concentrations of E2 spiked into aqueous suspension of NIP particles

2.2.4 Determination of light scattering and fluorescence emission intensities of various concentrations of NIP particles in aqueous suspensions spiked with E2 using excitation wavelengths of $279 \pm 1 \mathrm{~nm}$ and $725 \pm 1 \mathrm{~nm}$

\subsection{Results and Discussion}

2.3.1 Optimal Mie scattering wavelength for PMAA-co-EGDMA NIP submicron particles in aqueous suspension

2.3.2 Light scattering from NIP particles in aqueous suspension upon binding with E2

2.3.3 Comparison of fluorescence emissions from E2 added to NIP particles in aqueous suspension and E2 in aqueous solution

2.3.4 Fluorescence emission and light scattering from various concentrations of NIP in aqueous suspension at fixed 22 concentration 
Chapter 3: An investigation of porous MIP structure for sensor development: nonlinear fluorescence quenching of $17 \beta$-estradiol bound inside MIP particles by sodium nitrite and methacrylamide

3.1 Introduction

3.2 Experimental 34

3.2.1 Chemicals 34

3.2.2 Preparation of E2-MIP and NIP submicron particles

3.2.2.1 MIP particles 35

3.2.2.2 NIP particles 35

3.2.3 Characterization of particles 35

3.2.3.1 Particle size measurements by dynamic light scattering (DLS) 35

3.2.3.2 Fluorescence binding measurements 36

3.2.3.2.1 MIP particles 36

3.2.3.2.2 NIP particles 36

3.2.3.3 Fluorescence quenching measurements $\quad 36$

$\begin{array}{ll}\text { 3.3 Results and Discussion } & 37\end{array}$

3.3.1 Fluorescence property of E2-MIP and E2-NIP particles 37

3.3.2 Fluorescence quenching analysis $\quad 38$

$\begin{array}{ll}3.4 \text { Conclusion } & 48\end{array}$

References $\quad 51$

Chapter 4: Molecularly Imprinted Polymer Particles for Rapid Determination of 17ß-Estradiol in Water by Fluorescence Quenching

\subsection{Introduction}

4.2 Experimental 55

4.2.1. Chemicals 55

4.2.2. Preparation of MIP submicron particles and AuNPs 56 
4.2.3. Particle size analysis

4.3 Results and Discussion

4.3.1. Fluorescence quenching

4.3.2. Quencher sizes and efficiencies

4.3.3. Stern-Volmer plots 66

4.3.4. Determination of E2 in water 69

4.4 Conclusion 73

References

Chapter 5: Conclusion and future work

References

81

Appendix I Influence of E2 concentration on NIP particle size after binding

82 


\section{List of Tables}

Page

Table 2.1 Net fluorescence intensities of E2 spiked DDW and 0.1-ppm NIP submicron particles aqueous suspension

Table 4.1 Equilibrium binding constant $\left(\mathrm{K}_{\mathrm{d}}\right)$ values determined for three concentrations of MIP particles in aqueous suspension, after $5 \mathrm{~min}$ of incubation. 


\section{List of Figures}

Page

Figure 1.1 Organization of this thesis in Chapters 1-4.

Figure 2.1 Molecular structures of estrogenic compounds.

Figure 2.2 Mie scattering spectra of 0.5-ppm NIP particles in aqueous suspension, by scanning the incident light from $750 \pm 1 \mathrm{~nm}$ to $200 \pm 1 \mathrm{~nm}$.

Figure 2.3 Light scattering spectra from 0.1-ppm NIP particles in aqueous suspension upon binding with $\mathrm{E} 2$ (from $0.1 \mathrm{ppm}$ to $1.0 \mathrm{ppm}$ ), by scanning the incident light around $700 \mathrm{~nm}, 725 \mathrm{~nm}$ and $750 \mathrm{~nm}$.

Figure 2.4 Light scattering spectra from 0.1-ppm NIP particles in aqueous suspension upon binding with bisphenol A $(0.5 \mathrm{ppm})$, by scanning the incident light around $700 \mathrm{~nm}, 725 \mathrm{~nm}$ and $750 \mathrm{~nm}$.

Figure 2.5 Fluorescence emission spectra of 0.1 to 1.0-ppm E2 added to 0.1-ppm NIP particles in aqueous suspension, using excitation wavelength $=279 \pm 1 \mathrm{~nm} . \mathbf{2 1}$

Figure 2.6 Fluorescence emission spectra of 0.1 to 1.0-ppm E2 added to DDW, using excitation wavelength $=279 \pm 1 \mathrm{~nm}$.

Figure 2.7 Fluorescence emissions and light scattering spectra of 1.0-ppm E2 aqueous solution spiked with various concentrations of NIP submicron particles, using excitation wavelengths of $279 \pm 1 \mathrm{~nm}$ and $725 \pm 1 \mathrm{~nm}$.

Figure 2.8 FTIR spectra of (a) poly MAA-co-EGDMA particles before E2 binding,

(b) poly MAA-co-EGDMA particles after binding with E2,

(c)poly MAA-co-EGDMA and E2 particles in mixture, and (d) E2 particles.26

Figure 3.1 Molecular structures of estrone (E1), $\beta$-estradiol (E2) and estriol (E3)

Figure 3.2 Fluorescence determination of E2 binding with MIP and NIP particles $\left(\lambda_{\text {ex }}=\right.$ $280 \pm 1 \mathrm{~nm}$ ): (a) fluorescence emission of E2-MIP particles suspended in DDW, (b) fluorescence emission of E2-NIP particles suspended in DDW, (c) fluorescence emission of $3.5 \mathrm{ppm} \mathrm{E} 2$ in aqueous solution. 
Figure 3.3 Fluorescence emission spectra of (a) $4.5 \mathrm{ppm}$ E2 aqueous solution, (b) 2.5 $\mathrm{mg} / \mathrm{mL}$ E2-MIP particles in aqueous suspension, and (c) $2.5 \mathrm{mg} / \mathrm{mL}$ E2-NIP particles in aqueous suspension, during titration with sodium nitrite up to a final concentration of $0.19 \mathrm{M}$ (without causing any significant dilution effects, $\sim 6 \%$ ).

Figure 3.4 Stern-Volmer plots of $F_{0} / F$ versus concentration of sodium nitrite for (a) 4.5 ppm E2 aqueous solution, (b) $2.5 \mathrm{mg} / \mathrm{mL}$ E2-MIP particles in aqueous suspension, and (c) $2.5 \mathrm{mg} / \mathrm{mL}$ E2-NIP particles in aqueous suspension. The solid lines indicate the best fittings from nonlinear regression.

Figure 3.5 Fluorescence emission spectra of (a) $4.5 \mathrm{ppm}$ E2 aqueous solution, (b) 2.5 $\mathrm{mg} / \mathrm{mL}$ E2-MIP particles in aqueous suspension, and (c) $2.5 \mathrm{mg} / \mathrm{mL}$ E2-NIP particles in aqueous suspension, during titration with methacrylamide up to a final concentration of $0.07 \mathrm{M}$ (without causing any significant dilution effects).

Figure 3.6 Stern-Volmer plots of $F_{0} / F$ versus concentration of methacrylamide for (a) 4.5 ppm E2 aqueous solution, (b) $2.5 \mathrm{mg} / \mathrm{mL}$ E2-MIP particles in aqueous suspension, and (c) $2.5 \mathrm{mg} / \mathrm{mL}$ E2-NIP particles in aqueous suspension. The solid lines indicate the best fittings from nonlinear regression.

Figure 4.1 Fluorescence emission spectra of (a) $3.5 \mathrm{ppm}$ E2 aqueous solution, (b) 2.5 $\mathrm{mg} / \mathrm{mL}$ E2-MIP particles in aqueous suspension, and (c) $2.5 \mathrm{mg} / \mathrm{mL}$ E2bound NIP particles in aqueous suspension, during fluorescence quenching by AuNPs from $0 \mathrm{M}$ to $5.88 \times 10^{-4} \mathrm{M}$. $\left(\lambda_{\mathrm{ex}}=280 \mathrm{~nm}\right)$

Figure 4.2 (a) Fluorescence excitation spectrum of AuNPs aqueous suspension $\left(\lambda_{\mathrm{em}}=\right.$ $310 \mathrm{~nm}$ ), (b) fluorescence emission spectrum ( $1^{\text {st }}$ and $2^{\text {nd }}$ orders $)$ of AuNPs aqueous suspension $\left(\lambda_{\mathrm{ex}}=280 \mathrm{~nm}\right.$ ), (c) fluorescence emission spectrum of E2 aqueous solution ( $\lambda_{\mathrm{ex}}=280 \mathrm{~nm}$ ), and (d) fluorescence emission spectrum of $\mathrm{E} 2$ aqueous solution in presence of trisodium citrate dihydrate $(1 \% \mathrm{w} / \mathrm{w})$. $\left(\lambda_{\mathrm{ex}}=280 \mathrm{~nm}\right)$

Figure 4.3 Fluorescence emission spectra during titration of sodium nitrite (up to a final concentration of $6.5 \times 10^{-2} \mathrm{M}$ ) into a mixture of $2.5 \mathrm{mg} / \mathrm{mL}$ E2-MIP particles and $5.88 \times 10^{-4} \mathrm{M}$ AuNPs. The titration consisted of fifteen $10-\mu \mathrm{L}$ spikes of $100 \mathrm{mg} / \mathrm{mL}$ sodium nitrite to minimize any dilution effect $(\sim 6 \%)$.

Figure 4.4 Fluorescence emission intensity at $310 \mathrm{~nm}$ versus concentration of quencher: (a) $2.5 \mathrm{mg} / \mathrm{mL}$ E2-MIP particles in aqueous suspension quenched with AuNPs, (b) $3.5 \mathrm{ppm}$ E2 aqueous solution quenched with AuNPs, (c) $2.5 \mathrm{mg} / \mathrm{mL}$ E2bound NIP particles in aqueous suspension quenched with AuNPs, (d) 2.5 
$\mathrm{mg} / \mathrm{mL}$ E2-MIP particles in aqueous suspension going through two steps of fluorescence quenching, first with AuNPs and next with sodium nitrite.

(Standard error bars, approximately three times the size of each data point symbol, are omitted here for the sake of clarity).

Figure 4.5 Correlation of light scatting intensity with time for measuring the size of AuNPs on a nanoDLS particle size analyzer.

Figure 4.6 Quenching efficiency $(\theta)$ versus concentration of quencher: (a) $2.5 \mathrm{mg} / \mathrm{mL}$ E2-bound NIP particles in aqueous suspension quenched with AuNPs, (b) 2.5 $\mathrm{mg} / \mathrm{mL}$ E2-MIP particles in aqueous suspension quenched with AuNPs, (c) $3.5 \mathrm{ppm}$ E2 aqueous solution quenched with AuNPs, (d) $2.5 \mathrm{mg} / \mathrm{mL}$ E2-MIP particles in aqueous suspension quenched first with AuNPs and next with sodium nitrite. (e) $2.5 \mathrm{mg} / \mathrm{mL}$ E2-MIP particles in aqueous suspension quenched with sodium nitrite (up to $0.128 \mathrm{M}$ ).

Figure 4.7 Stern-Volmer plots of $F_{0} / F$ versus concentration of AuNPs for 3.5 ppm E2 aqueous solution, $2.5 \mathrm{mg} / \mathrm{mL}$ E2-MIP particles in aqueous suspension, and $2.5 \mathrm{mg} / \mathrm{mL}$ E2-bound NIP particles in aqueous suspension. Each solid line indicates the best possible linear regression.

Figure 4.8 Stern-Volmer plots of $F_{0} / F$ versus concentration of sodium nitrite. Sodium nitrite was titrated stepwise into $2.5 \mathrm{mg} / \mathrm{mL}$ E2-MIPs in aqueous suspension containing $5.88 \times 10^{-4} \mathrm{M}$ AuNPs. Each solid line indicates the best possible linear regression.

Figure $4.9 \mathrm{I}_{\max }$ for $3.5 \mathrm{mg} / \mathrm{mL}, 2.5 \mathrm{mg} / \mathrm{mL}, 1.5 \mathrm{mg} / \mathrm{mL}$ and $0.5 \mathrm{mg} / \mathrm{mL}$ E2-MIP particles in aqueous suspension.

Figure $4.10 \% \mathrm{E} 2$ binding (with imprinted cavities) as a function of E2 concentration after incubation for (a) $5 \mathrm{~min}$, and (b) $35 \mathrm{~min}$. (Standard error bars, approximately three to five times the size of each data point symbol, are omitted here for the sake of clarity). 


\section{List of Schemes}

Page

Scheme 4.1: Larger AuNPs were used in the first step of fluorescence quenching to quench E2 molecules non-specifically bound throughout the porous MIP particle, while small nitrite anions were easily penetrate the MIP particle to quench the fluorescence emission from E2 molecules specifically bound inside imprinted cavities in the second step of fluorescence quenching. The attenuated fluorescence emission intensity between step 1 and step 2 varies as a function of E2 concentration. 


\section{List of Abbreviations and Symbols}

4-VP

$5 \mathrm{FU}$

AA

AIBN

APTMS

AuNP

BPA

DDW

DLS

DVB

E1

E2

E3

EDCs

EGDMA

EGMA

EE2

FTIR

FQ

HPLC-FD

IC

$\mathrm{K}_{\mathrm{d}}$

$\mathrm{K}_{\mathrm{sv}}$

MAA
4-Vinylpyridine

5-fluorouracil

Acrylic acid

Azobisisobutyronitrile

3-(2-aminoethylamino) propyltrimethoxysilane

Gold nano-particle

Bisphenol A

Distilled deionized water

Dynamic light scattering

Divinylbenzene

Estrone

$17 \beta$-estradiol

Estriol

Endocrine disrupting contaminants

Ethylene glycol dimethacrylate

Ethylene glycol methacrylate

$17 \alpha$-ethinylestradiol

Fourier transform infrared

Fluorescence quenching

High performance liquid chromatography with fluorescence detection

Ion chromatography

Equilibrium binding constant

Dynamic quenching constant

Methacrylic acid 


$\begin{array}{ll}\text { MIP } & \text { Molecularly imprinted polymer } \\ \text { MPS-PPV } & \text { Poly (2-methoxy-5-propyloxy sulfonate phenylene vinylene } \\ \text { MV } & \text { Methyl viologen } \\ \text { NICA } & \text { Non-ideal competitive adsorption } \\ \text { NIP } & \text { Non-imprinted polymer } \\ \text { PETRA } & \text { Pentaerythritol trimethylacrylate } \\ \text { PTFE } & \text { Polytetrafluoroethylene } \\ \text { Py } & \text { Pyrrole } \\ \text { [Q] } & \text { Concentration of fluorescence quencher } \\ S_{0} & \text { Ground state } \\ S_{1} & \text { Excited state } \\ \text { S-V } & \text { Stern-Volmer } \\ \text { TEOS } & \text { Tetraethyl orthosilicate } \\ \text { TRIM } & \text { Trimethylolpropane trimethacrylate } \\ \text { UV } & \text { Ultraviolet } \\ \text { V } & \text { Static quenching constant }\end{array}$




\section{Chapter 1}

\section{Introduction}

Spectrofluorimetry is a highly sensitive instrumental method of analysis that is widely applied in chemistry, biochemistry, environmental science and forensic science $[1,2,3,4]$. The spectrofluorimeter has frequently been employed to determine molecules and particles by their fluorescence emission and light scattering properties $\left[{ }^{5,6,7,8}\right]$. Fluorescence occurs when an excited molecule emits photons, accompanying its relaxation from excited state $\left(S_{1}\right)$ to ground state $\left(S_{0}\right)$. Light scattering is based on another physical property how light interacts with particles or large molecules $\left[{ }^{9}\right]$. Both fluorescence and light scattering are denoted as direct detection methods. Indirect detection by fluorescence quenching is another valuable method to quantitative chemical analysis.

\subsection{Molecular sensors based on fluorescence quenching}

Fluorescence quenching refers to any event which decreases the fluorescence intensity of a given chemical compound or particle. This decrease in fluorescence intensity is described as loss of energy from $S_{1}$ to non-radiative pathways instead of $S_{0}$. Two pathways are predominantly due to collision (dynamic quenching) and complexation (static quenching) between the fluorophore and quencher molecules. Based on these essential non-radiative pathways, molecular sensors can successfully be designed and developed. 
By using fluorescence quenching, molecular sensors are widely used in analytical chemistry. Nitro-aromatic compounds were detected by an optical sensor involving benzo-fluoranthene fluorescence quenching $\left[{ }^{10}\right]$. A sensitive lead ion sensor based on $\mathrm{Pb}^{2+}$-induced quenching of fluorescent PPE polymers $\left[{ }^{11}\right]$. In biochemistry, fluorescent polyanionic conjugated polymer biosensor for ultrafast $(650 \mathrm{fs})$ detection of avidin and streptavidin via amplified fluorescence quenching $\left[{ }^{12}\right]$. Proteins (rubredoxin) were successfully detected by a water-soluble cationic ammonium-functionalized polymer $\left[{ }^{13}\right]$. In medicine, gold nanoparticles were used as a fluorescence quenching probe to detect anticancer drug 5-fluorouracil $\left[{ }^{14}\right]$. In environment science, mercury(II) was detected in water samples by using functionalized gold nanoparticles with a rhodamine 6G-based fluorescent sensor $\left[{ }^{15}\right]$. Essentially, each molecular sensor has an analyte responsive unit consisting of a fluorophore. This fluorophore acts as a transducer that converts the presence of analyte into an optical signal due to changes in fluorescence characteristics $\left[{ }^{16}\right]$. Three fluorescence quenching mechanisms have utility as molecular sensors: i) collision between fluorophore and quencher $\left[{ }^{17,18,19}\right]$, ii) interaction (complexation) between fluorophore and quencher $\left[{ }^{20,21,22}\right]$, iii) conduction between fluorophore and quencher via a fluorophore linked receptor $\left[{ }^{23,24,25}\right]$.

During the last decade, many scientific papers have been published about molecularly imprinted polymer (MIP) materials as molecular sensors for the detection of nonfluorescent analytes (quencher) by fluorescence quenching $\left[{ }^{26}\right]$. These MIPs were used as artificial biomimetic receptors with high affinity to bind analytes. These materials are easier to prepare and more stable than natural receptors (antibodies) in solution. They can be produced in different formats (beads, films, wires) to facilitate integration into various 
types of sensing devices $\left[{ }^{27}\right]$. Once the quencher analyte specifically or non-specifically bind with the fluorescent MIP, the emission intensity is significantly decreased. The main advantages of this technology are good selectivity, high sensitivity and minimal interference by other compounds. However, one major limitation is that analytes with strong fluorescence emission are hard to detect by this quenching technology. In addition, the specific binding between MIP and analyte is difficult to investigate by this method. Theoretically, both specific and non-specific interactions between MIPs and analytes all cause of fluorescence quenching which is limited further investigation on newly synthesized MIP material.

In this thesis research, a new molecular sensor was specifically designed with nonfluorescent MIP submicron particles binding with a fluorescent analyte. A unique twostep fluorescence quenching method with different quencher sizes will benefit specific analyte detection, with no side effects due to non-specific binding.

\subsection{Scope of this work}

Highly selective MIPs for estrogenic compounds had been successfully developed in our research group $\left[{ }^{28}\right]$. These MIPs demonstrated over $90 \%$ binding efficiency for selective removal of $17 \beta$-estradiol in water $\left[{ }^{29}\right]$. Binding between MIPs and E2 was observed via capillary electrophoresis (CE) with UV detection, and verified by high performance liquid chromatography (HPLC) with fluorescence detection. A key advantage of MIP is that many imprinted cavities are built during the polymerization process. These imprinted cavities contribute significantly to the selectivity of analyte recognition. However, it was 
hard to find a method that quantifies E2 binding in the MIP cavities. So far this quantity was estimated by subtracting the amount of E2 binding with NIP from that with MIP. This is, however, not an accurate determination of E2 binding with imprinted cavities because the particle size and porosity could be very different between MIP and NIP. Different particle size and porosity would affect the specific surface area (and hence change the binding percentage). For instance, if MIP particles are $100 \mathrm{~nm}$ larger in diameter than NIP particles, the high binding capacity of MIP is due to a larger surface area but not the imprinted cavities. A clear and unequivocal verification of specific analyte binding with imprinted cavities is crucial for MIP characterization. Hence, the aim of this thesis was to develop a two-step fluorescence quenching method that would demonstrate E2 binding with the imprinted cavities of MIP particles. Furthermore, a quenching scheme was also designed to benefit trace level detection of fluorescent E2 with non-fluorescent MIP as a promising molecular sensor material.

\section{Original contributions of this thesis:}

- A new method was developed for the determination of E2 in a water sample by measuring the intensity of light scattering (after NIP particles are added to bind with E2) on a spectrofluorimeter. (Chapter 2)

- The sizes of MIP and NIP particles were determined by a nano-dynamic light scattering (DLS) analyzer. The spectral characteristics of E2 bound with naturally nonfluorescent MIP and NIP were determined. (Chapter 2, 3 and 4)

- The fluorescence quenching of E2, bound with MIP and NIP particles, by two different ionic/molecular quenchers was investigated thoroughly. The hypothesis of a 
porous structure in MIP particles was tested for the development of a novel E2 sensing scheme. (Chapter 3)

- Gold nano particles (AuNPs) were synthesized and used as a large-size quencher. These AuNPs were characterized by spectrometric techniques, in particular UV-visible absorption, fluorescence excitation/emission, and nanoDLS. (Chapter 4)

- An E2 fluorescence sensing scheme was established by a two-step fluorescence quenching of E2 bound with MIP using first AuNPs and next sodium nitrite as quenchers. (Chapter 4)

This thesis is organized as follows: 


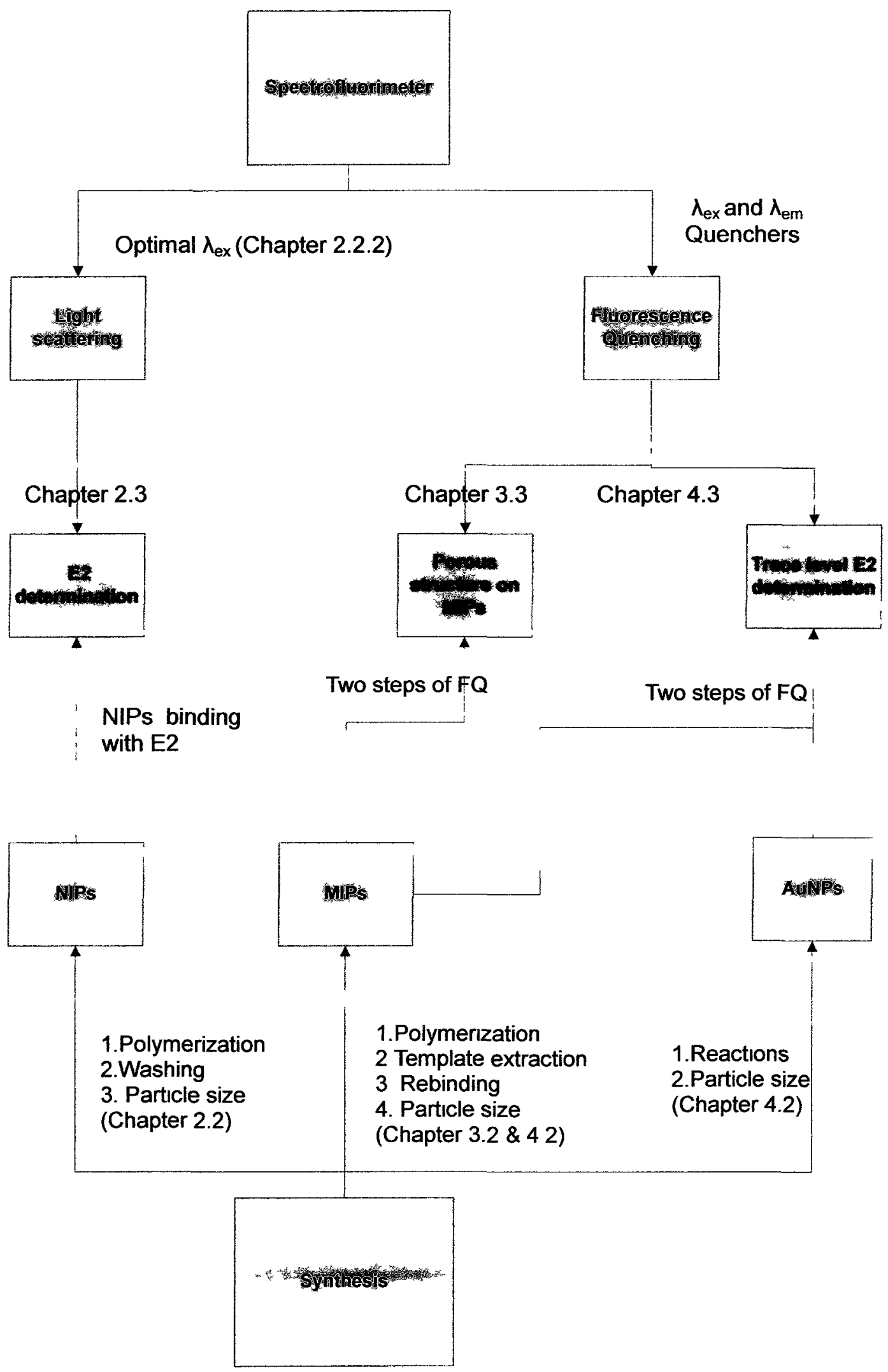

Figure 1.1 Organization of this thesis in Chapters 1-4.

$$
\sim 6 \sim
$$


Chapter 2 of this thesis describes an investigation of light scattering by NIP submicron particles in aqueous suspension before and after E2 binding using a spectrofluorimeter. A feasibility study of this new method for rapid E2 detection is discussed. The reverse effect of NIP particles on E2 fluorescence emission was investigated.

Chapter 3 focuses on utilizing the porous structure in MIP particles for the development of a novel E2 sensing scheme. The strong fluorescence intensity from E2-MIP particles was quenched with two quenchers of different sizes. Fluorescence quenching abilities of these quenchers were successfully analyzed by Stern-Volmer (S-V) plots. The calculated fluorescence quenching constants demonstrated the exact fitting of imprinted cavities for E2. The larger quencher was sterically hindered in penetrating the porous MIP particles. Furthermore, the fluorescence of E2 bound inside an imprinted cavity was observed after fluorescence quenching of E2 bound outside with the larger quencher.

Chapter 4 proposes a rapid method for the determination of trace E2 based on the sensing scheme established in Chapter 3 . The fluorescence quenching efficiency of carefully selected large and small quenchers were determined by S-V plots. The fluorescence emission intensity from E2 specifically bound with the imprinted cavities in MIP particles was probed (or examined) by two quenching steps. Moreover, the normalized percentage binding of E2 with the imprinted cavities was computationally analyzed. Experimental conditions, such as MIP concentration and binding time, were optimized. Finally a Scatchard calibration curve was constructed for monitoring trace levels of E2 in water. 
Chapter 5 summarizes the contributions of the present studies, and provides an outlook for future investigations. 


\section{References:}

11]. L. H. Lutz and A. A. Yayanos, "Spectrofluorometric determination of bacterial DNA base composition," Anal Biochem, vol. 144, no. 1, pp. 1-5, 1985.

[2]. A. B. Moreira . H. P. M. Oliveira, T. D. Z. Atvars, I. L. T. Dias, G. O. Neto, E. $\wedge$. G. Zagatto and L. T. Kubota, "Direct determination of paracetamol in powdered pharmaceutical samples by fluorescence spectroscopy," Analytica Chimica Acta, vol. 539, no. 1-2, pp. 257-261, 2005.

[3]. M. N. Poglazova, I. N. Mitskevich and V. A. Kuzhinovsky. "A spectrofluorimetric method for the determination of total bacterial counts in environmental samples." Journal of Microbiological Methods, vol. 24, no. 3, pp. 211-218. 1996.

[4]. N. S. Soukos , K. Crowley, M. P. Bamberg, R. Gillies, A. G. Doukas . R. Evans and N. Kollias, "A rapid method to detect dried saliva stains swabbed from human skin using fluorescence spectroscopy." Forensic Science International, vol. 114. no. 3. pp. $133-138,2000$.

[5]. K. Yano and 1. Karube, "Molecularly imprinted polymers for biosensor applications," TrAC Trends in Analytical Chemistry, vol. 18, no. 3, pp. 199-204, 1999.

[6]. Y.-C. Chen . J. J. Brazier . M. Yan, P. R. Bargo and S. A. Prahl, "Fluorescencebased optical sensor design for molecularly imprinted polymers," Sensors and Actuators B: Chemical, vol. 102, no. 1, pp. 107-116, 2004.

[7]. S. Manju , P. R. Hari and K. Sreenivasan, "Fluorescent molecularly imprinted polymer film binds glucose with a concomitant changes in fluorescence," Biosensors and Bioelectronics, vol. 26, no. 2, pp. 894-897, 2010.

[8]. E. L. Holthoff, D. N. Stratis-Cullum and M. E. Hankus, "A nanosensor for TNT detection based on molecularly imprinted polymers and surface enhanced raman scattering," Sensors vol. 11, no. 3, pp. 2700-2714, 2011.

[9]. M. Jonasz and G. R. Fournier, In Light Scattering by Particles in Water, Academic Press: Amsterdam, 2007; pp 1-32.

[10]. D. Patra and A. K. Mishra, "Fluorescence quenching of benzo[k]fluoranthene in poly(vinyl alcohol) film: a possible optical sensor for nitro aromatic compounds," Sensors and Actuators B: Chemical, vol. 80, no. 3, pp. 278-282, 2001.

[11]. I.-B. Kim, A. Dunkhorst, J. Gilbert and U. H. F. Bunz, "Sensing of lead ions by a carboxylate-substituted PPE: multivalency effects," Macromolecules, vol. 38, no. 11, pp. 4560-4562. 2005. 
[12]. L. Chen, D. W. McBranch, H. L. Wang, R. Helgeson, F. Wudl and D. G. Whitten, "Highly sensitive biological and chemical sensors based on reversible fluorescence quenching in a conjugated polymer," Proc Natl Acad Sci US A, vol. 96, no. 22, pp. 12287-92, 1999.

[13]. F. Cheng, G.-W. Zhang, X.-M. Lu , Y.-Q. Huang, Y. Chen, Y. Zhou, Q.-L. Fan and W. Huang, "A cationic water-soluble poly(p-phenylenevinylene) derivative: Highly sensitive biosensor for iron-sulfur protein detection," Macromolecular Rapid Communications, vol. 27, no. 10, pp. 799-803, 2006.

[14]. V. Selvaraj and M. Alagar, "Analytical detection and biological assay of antileukemic drug 5-fluorouracil using gold nanoparticles as probe," International Journal of Pharmaceutics, vol. 337, no. 1-2, pp. 275-281, 2007.

[15]. J. Chen, A. Zheng, A. Chen, Y. Gao, C. He, X. Kai , G. Wu and Y. Chen, "A functionalized gold nanoparticles and Rhodamine $6 \mathrm{G}$ based fluorescent sensor for high sensitive and selective detection of mercury(II) in environmental water samples," Analytica Chimica Acta, vol. 599, no. 1, pp. 134-142, 2007.

[16]. B. Valeur, Molecular Fluorescence: Principles and Applications. Wiley, 2001.

[17]. B. J. Basu , A. Thirumurugan , A. R. Dinesh , C. Anandan and K. S. Rajam, "Optical oxygen sensor coating based on the fluorescence quenching of a new pyrene derivative," Sensors and Actuators B: Chemical, vol. 104, no. 1, pp. 15-22, 2005.

[18]. V. K. Sharma, D. Mohan and P. D. Sahare, "Fluorescence quenching of 3-methyl 7-hydroxyl Coumarin in presence of acetone," Spectrochimica Acta Part A: Molecular and Biomolecular Spectroscopy, vol. 66, no. 1, pp. 111-113, 2007.

[19]. M. Koneswaran and R. Narayanaswamy, "l-Cysteine-capped $\mathrm{ZnS}$ quantum dots based fluorescence sensor for Cu2+ ion," Sensors and Actuators B: Chemical, vol. 139, no. 1, pp. 104-109, 2009.

[20]. M. H. Noiré and B. Duréault, "A ferrous ion optical sensor based on fluorescence quenching," Sensors and Actuators B: Chemical, vol. 29, no. 1-3, pp. 386-391, 1995.

[21]. M. D. P. De Costa and W. A. P. A. Jayasinghe, "Detailed studies on complexation behaviour and mechanism of fluorescence quenching of naphthalene linked hydroxamic acid with transition metal ions by UV-visible and fluorescence spectra," Journal of Photochemistry and Photobiology A: Chemistry, vol. 162, no. 2-3, pp. 591-598, 2004.

[22]. W. H. Chan , R. H. Yang and K. M. Wang, "Development of a mercury ionselective optical sensor based on fluorescence quenching of 5,10,15,20tetraphenylporphyrin," Analytica Chimica Acta, vol. 444, no. 2, pp. 261-269, 2001.

[23]. C. Lakshmi , R. G. Hanshaw and B. D. Smith, "Fluorophore-linked 
zinc(II)dipicolylamine coordination complexes as sensors for phosphatidylserinecontaining membranes," Tetrahedron, vol. 60, no. 49, pp. 11307-11315, 2004.

[24]. H. Sulowska, W. Wiczk, J. Mlodzianowski, M. Przyborowska and T. Ossowski, "Synthesis and fluorescence behaviour of crown and azacrown ethers carrying the dansyl fluorophore as a pendant in acetonitrile solution," Journal of Photochemistry and Photobiology A: Chemistry, vol. 150, no. 1-3, pp. 249-255, 2002.

[25]. R. C. Stringer, S. Gangopadhyay and S. A. Grant, "Detection of nitroaromatic explosives using a fluorescent-labeled imprinted polymer," Analytical Chemistry, vol. 82, no. 10 , pp. $4015-4019,2010$.

[26]. J. Li , C. E. Kendig and E. E. Nesterov, "Chemosensory performance of molecularly imprinted fluorescent conjugated polymer materials," Journal of the American Chemical Society, vol. 129, no. 51, pp. 15911-15918, 2007.

[27]. F. Navarro-Villoslada , J. L. Urraca , M. C. Moreno-Bondi and G. Orellana, "Zearalenone sensing with molecularly imprinted polymers and tailored fluorescent probes," Sensors and Actuators B: Chemical, vol. 121, no. 1, pp. 67-73, 2007.

[28]. E. P. C. Lai , Z. D. Maleki and S. Wu, "Characterization of molecularly imprinted and nonimprinted polymer submicron particles specifically tailored for removal of trace 17 beta-estradiol in water treatment," Journal of Applied Polymer Science, vol. no. pp. NA-NA, 2009.

[29]. Z. DeMaleki , E. P. C. Lai and E. Dabek-Zlotorzynska, "Capillary electrophoresis characterization of molecularly imprinted polymer particles in fast binding with $17 \beta-$ estradiol," Journal of Separation Science, vol. 33, no. 17-18, pp. 2796-2803, 2010. 


\section{Chapter 2}

\section{Spectroscopic Analysis of Poly (Methacrylic Acid-co-Ethylene Glycol Dimethacrylate) Submicron Particles by Fluorescence Emission and Light Scattering upon Binding with 17 $\beta$-Estradiol in Water Treatment}

\subsection{Introduction}

MIP and NIP particles of all sizes have been adopted for cleanup or preconcentration of environmental pollutants $\left[{ }^{1}\right]$. The advantages of using these functional polymers are excellent efficiency on capture of organic pollutants at trace concentration levels, and cost effectiveness, allowing for the fast processing of wastewater effluent in large volumes or at high flow rates $\left[{ }^{2}\right]$. The polymers are synthesized from monomers bearing functional groups (or functional monomers), such as methacrylic acid (MAA), acrylic acid (AA), pyrrole (Py), 4-vinylpyridine (4-VP), and 3-(2-aminoethylamino) propyltrimethoxysilane (APTMS) $\left[^{2,3,4,5,6}\right]$. The most commonly used cross-linkers in MIP and NIP synthesis are EDMA, EGDMA, TRIM, PETRA, TEOS and DVB $[2,7,8,9,10,11]$. An ultra-high specific surface area is a major characteristic of the three dimensional (3-D) cross-linked structure that has become especially important to the development of MIP and NIP submicron particles $\left[{ }^{12}\right]$.

Endocrine disrupting contaminants (EDCs) have a significant impact on ecological systems in the global environment $\left[{ }^{13,14,15}\right]$. Due to their ability to disrupt the central regulatory functions in humans $\left[{ }^{16}\right]$, EDCs have been seen as highly carcinogenic, especially causing breast cancer and human infertility $\left[{ }^{17}\right]$. Among EDCs, estrogenic 
compounds are mainly natural steroids and synthetic compounds with biological metabolisms. Estrone (E1), 17ß-estradiol (E2), 17 $\alpha$-ethinylestradiol (EE2) and bisphenol A (BPA) are among the most potent estrogenic compounds found in environmental water sources.

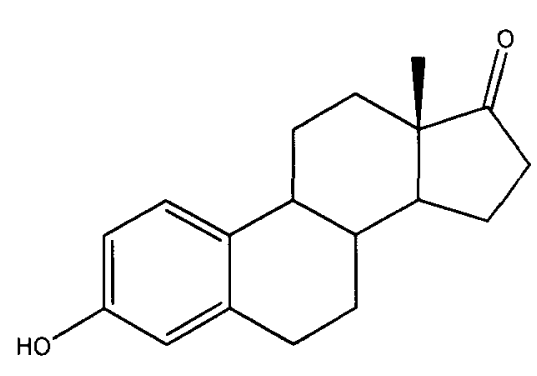

Estrone

(E1)

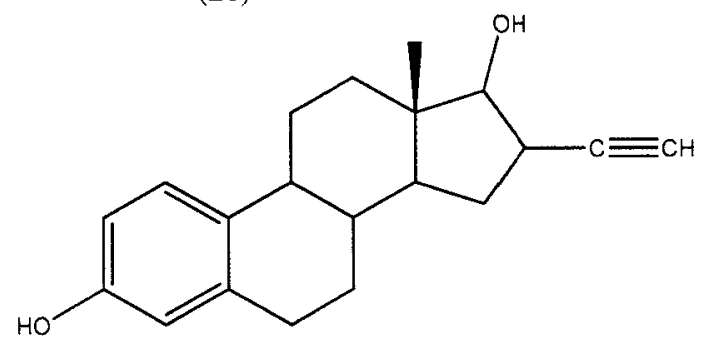

17alpha-ethinylestradıol (EE2)

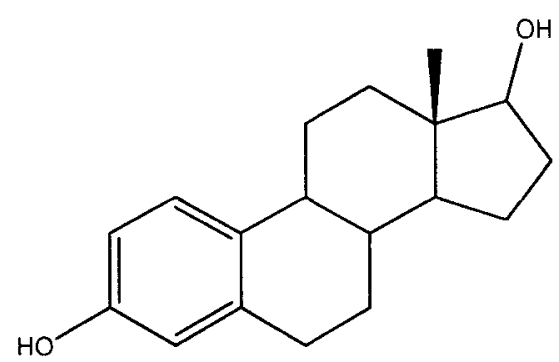

17beta-estradiol

(E2)

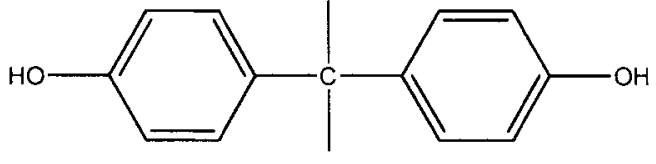

Bisphenol A (BPA)

Figure 2.1 Molecular structures of estrogenic compounds

Selective removal of one model estrogenic compound, E2, by using functional MIPs and NIPs has been investigated by several research groups $\left[{ }^{18,19,20,21}\right]$. The binding between functional MIPs and E2 involves non-covalent molecular interaction $\left[{ }^{7}\right]$ via H-bonding between the carboxyl groups specifically arranged in template cavities and hydroxyl groups in the E2 molecule. The binding of NIPs with E2 molecule is envisaged as nonspecific interaction of its hydroxyl groups with independent carboxyl groups distributed throughout the 3-D structure $\left[{ }^{5}\right]$. 
In the present study, we have used poly (MAA-co-EGDMA) particles to non-covalently bind with E2. As the E2 molecules randomly bound on the surface of NIP particles (in aqueous suspension), an opportunity to preconcentrate them together becomes available. Is the signal coming from free E2 molecules in the sample solution or from E2 molecules bound on NIP particles in aqueous suspension? Our careful investigation of this challenging issue is reported in details below.

\subsection{Experimental}

\subsubsection{Chemicals and reagents}

17ß-Estradiol and bisphenol A were purchased from Sigma-Aldrich (St. Louis, MO, USA). HPLC grade methanol was purchased from Caledon (Georgetown, ON, Canada). 18-M $\Omega . c m$ distilled deionized water (DDW) was obtained from a Millipore Milli-Q water system (Bedford, MD, USA). The procedure for synthesis of polymethacrylic acid NIP submicron particles was based on a previously established method, in the absence of any template molecule $\left[{ }^{22}\right]$. A stock E2 solution was prepared in HPLC grade methanol at a concentration of $1000 \mathrm{ppm}$. A stock aqueous suspension of NIP submicron particles was prepared in DDW at a concentration of $20 \mathrm{ppm}$. All aqueous suspensions of NIP particles were treated by an ultrasonic system (Branson 2510, Danbury, CT, USA) for 10 $\min$ before use.

\subsubsection{Determination of the optimal Mie scattering excitation wavelength for NIP submicron particles in aqueous suspension}


Mie scattering spectra of $0.5 \mathrm{ppm}$ NIP particles in aqueous suspension was measured by a fluorescence spectrophotometer (Varian Cary Eclipse, Palo Alto, CA, USA) using excitation wavelengths in the range from $200 \pm 1 \mathrm{~nm}$ to $750 \pm 1 \mathrm{~nm}$, with both excitation and emission slits equal to $5 \mathrm{~nm}$.

\subsubsection{Determination of light scattering and fluorescence emission intensities of} various concentrations of E2 spiked into aqueous suspension of NIP submicron particles

$2.0 \mu \mathrm{L}$ of $100 \mathrm{ppm} \mathrm{E} 2$ methanol solution was added into a quartz cuvette which contained $2.0 \mathrm{~mL}$ of $0.1 \mathrm{ppm}$ NIP particles in aqueous suspension. The light scattering and fluorescence emission spectra of this mixture, after thorough shaking, was measured at excitation wavelengths of $700 \pm 1 \mathrm{~nm}, 725 \pm 1 \mathrm{~nm}$ and $750 \pm 1 \mathrm{~nm}$ to obtain three light scattering spectra, and at $279 \pm 1 \mathrm{~nm}$ to obtain one fluorescence emission spectrum. Another nine measurements were performed similarly by adding $4.0-20 \mu \mathrm{L}$ of $100 \mathrm{ppm}$ E2 methanol solution. Similarly, light scattering spectra were acquired for a mixture of $0.1 \mathrm{ppm}$ NIP particles and $0.5 \mathrm{ppm}$ BPA.

2.2.4 Determination of light scattering and fluorescence emission intensities of various concentrations of NIP submicron particles in aqueous suspensions spiked with E2 using excitation wavelengths of $279 \pm 1 \mathrm{~nm}$ and $725 \pm 1 \mathrm{~nm}$

$2.0 \mu \mathrm{L}$ of $20 \mathrm{ppm}$ stock NIP particles in aqueous suspension was transferred into a quartz cuvette which contained $2.0 \mathrm{~mL}$ of $1.0 \mathrm{ppm}$ E2 aqueous solution. The light scattering and fluorescence emission spectra of this mixture, after thorough shaking, were measured using excitation wavelengths of $279 \pm 1 \mathrm{~nm}$ and $725 \pm 1 \mathrm{~nm}$. Another five measurements 
were performed similarly by transferring $4.0-12.0 \mu \mathrm{L}$ of 20 ppm stock NIP particles in aqueous suspension.

\subsubsection{FTIR analysis}

All infrared spectra were measured using a Varian 1000 Scimitar Series FTIR spectrometer with Varian resolutions software. Samples were prepared by pressing 1.7$2.0 \mathrm{mg}$ of solid sample and $100 \mathrm{mg}$ of dehydrated $\mathrm{KBr}$ in a die to make transparent pellets.

\subsection{Results and Discussion}

\subsubsection{Optimal Mie scattering wavelength for PMAA-CO-EGDMA NIP submicron particles in aqueous suspension}

Two types of light scattering are usually observed in spectroscopic analysis of a sample solution containing organic compounds. One type is Rayleigh scattering, which has the same wavelength as the incident light $\left[{ }^{23}\right]$. The other type is Raman scattering which appears at longer wavelengths than the incident light $\left[{ }^{24}\right]$. In addition, Mie scattering can show up on top of Rayleigh scattering if the solution contains suspending particles. 


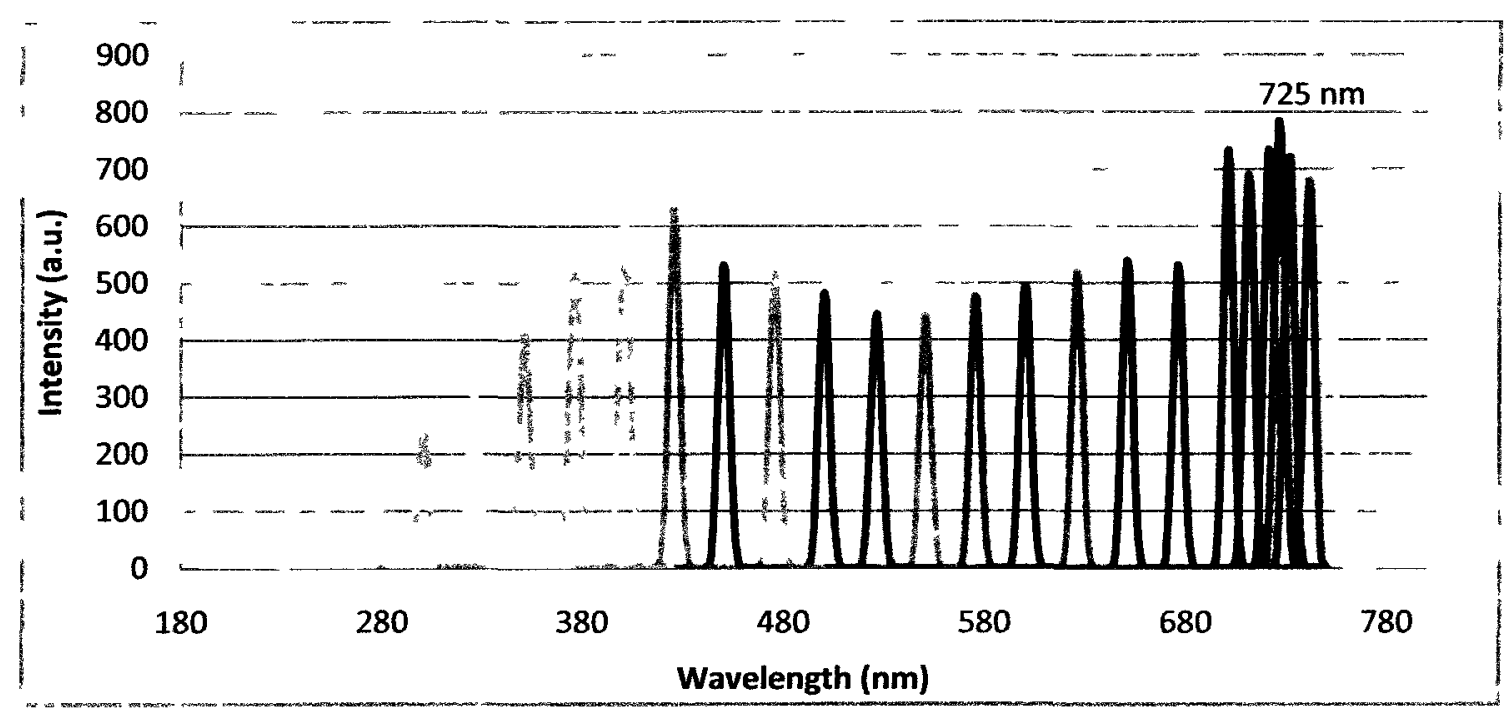

Figure 2.2 Mie scattering spectra of 0.5-ppm NIP particles in aqueous suspension, by scanning the incident light from $750 \pm 1 \mathrm{~nm}$ to $200 \pm 1 \mathrm{~nm}$.

Mie scattering is a perfect method to measure light scattering from spherical submicron particles. The peak intensity can be used to determine the concentration of NIP particles in aqueous suspension $\left[{ }^{25}\right]$. The best excitation wavelength for Mie scattering from NIP particles needed to be found in our research. Figure 2.2 shows that Mie scattering of visible light by NIP submicron particles in aqueous suspension was observed as sharp spectral peaks. All the Mie scattering peaks had the same wavelengths as the incident lights. From $700 \pm 1 \mathrm{~nm}$ to $750 \pm 1 \mathrm{~nm}$, this wavelength range exhibited the most intense Mie scattering $(725 \pm 1 \mathrm{~nm}>700 \pm 1 \mathrm{~nm}>720 \pm 1 \mathrm{~nm}>730 \pm 1 \mathrm{~nm}>710 \pm 1 \mathrm{~nm}>740 \pm 1$ $\mathrm{nm} \approx 750 \pm 1 \mathrm{~nm})$ than all lower wavelengths. The best wavelength for strong Mie scattering from the NIP particles was $725 \pm 1 \mathrm{~nm}$ which gave the highest intensity of $783 \pm 1$ arbitrary units (a.u.). It would provide optimal sensitivity for determining the concentration of NIP particles in aqueous suspension. One plausible explanation for this best wavelength is the size of submicron particles. Another factor is incident light intensity from the spectrofluorometer and spectral response of its detector, which can 
vary with the excitation wavelength setting. Note that Mie scattering has the highest intensity at a detection angle of 180 degrees with respect to the incident light $\left[{ }^{26}\right]$. Using a spectrofluorimeter to measure the Mie scattering from NIP submicron particles permits only the detection of scattering light at 90 degrees to the incident light. Therefore, the most intense Mie scattering from NIP submicron particles was not recorded by the spectrofluorimeter.

\subsubsection{Light scattering from NIP particles in qqueous suspension upon binding with E2}

The best excitation wavelength to determine Mie scattering from our NIP submicron particles in aqueous suspension using the spectrofluorimeter was $725 \pm 1 \mathrm{~nm}$. The wavelength range from $700 \mathrm{~nm}$ to $750 \mathrm{~nm}$ provided nearly optimal results for Mie scattering. Next the effect on light scattering after E2 addition into the NIP particles was further investigated. Figure 2.3 shows the light scattering spectra of 0.1-ppm NIP particles in aqueous suspension, before and after binding with E2 in the concentration range from $0.1 \mathrm{ppm}$ to $1.0 \mathrm{ppm}$. At all three wavelengths of incident light, the scattering peak intensities were distinctly increased by E2 addition. For instance, the peak intensity observed after binding with 0.3-ppm E2 was higher than those with $0.2,0.1$ and 0.0-ppm E2. Note that the wavelengths $725 \pm 1 \mathrm{~nm}$ and $750 \pm 1 \mathrm{~nm}$ exhibited irregularity in peak intensities upon binding with 1.0-ppm E2. Even though the enhancement of light scattering from NIP particles due to E2 binding was of unknown nature until further investigation, its significance could be three-fold. First, the peak intensity was no longer determined by the concentration of NIP particles only. Second, the increase in peak intensity provided a new analytical parameter for the determination of E2 down to 0.1 
ppm or lower. Third, it would not be straightforward any more to determine, by light scattering measurement, the amount of NIP particles that could pass through a syringe filter (after a binding experiment with E2).

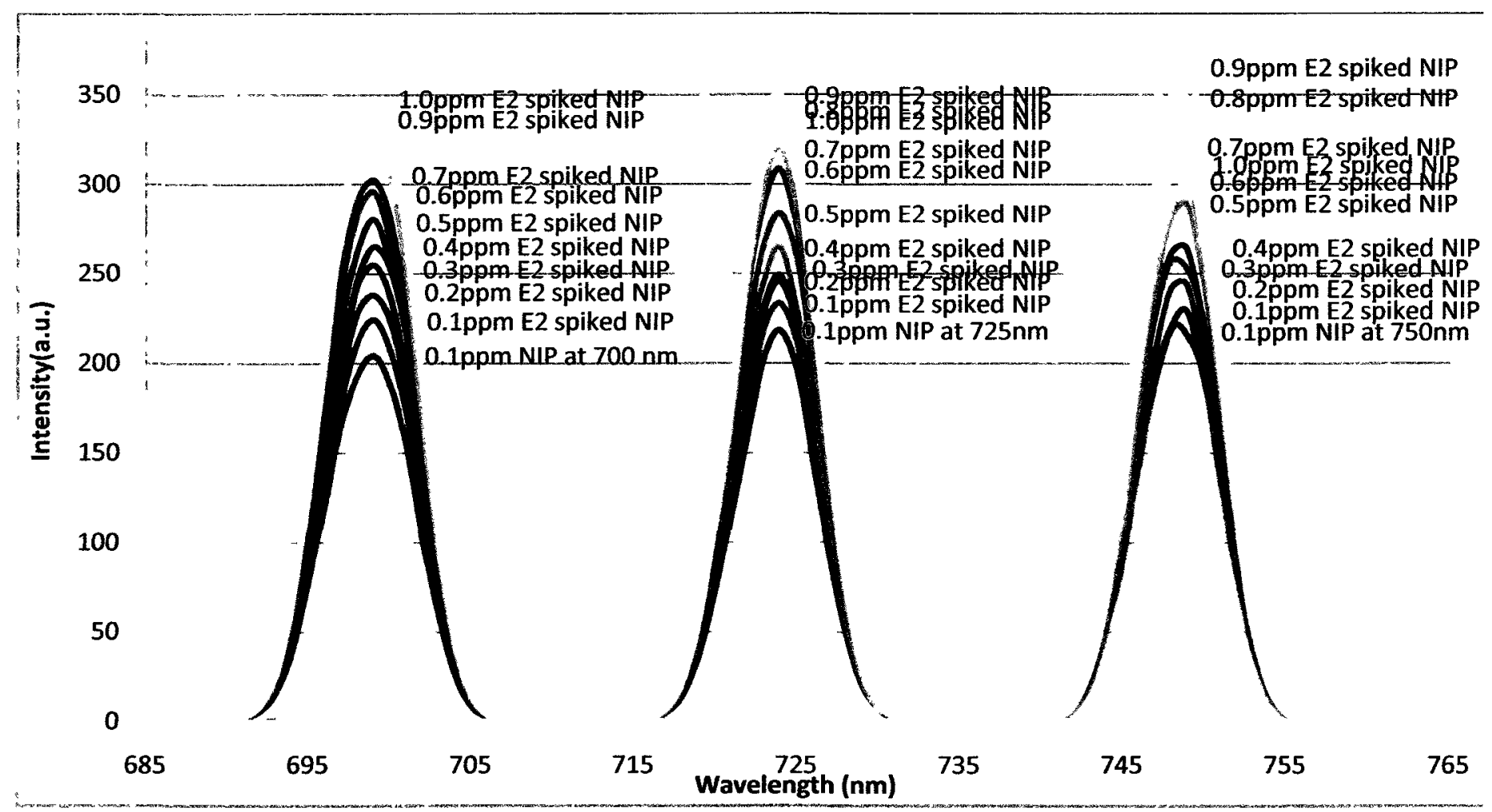

Figure 2.3 Light scattering spectra from 0.1-ppm NIP particles in aqueous suspension upon binding with E2 (from $0.1 \mathrm{ppm}$ to $1.0 \mathrm{ppm}$ ), by scanning the incident light around $700 \mathrm{~nm}, 725 \mathrm{~nm}$ and $750 \mathrm{~nm}$.

In the standard calibration curves of light scattering intensities versus concentration of E2 added to 0.1-ppm NIP particles in aqueous suspension, the $700 \pm 1 \mathrm{~nm}$ wavelength gave the best correlation coefficient of 0.9862 . The sensitivity of light scattering measurement, based on the slope of each calibration curve, increased from 132.6 a.u./ppm at $700 \pm 1 \mathrm{~nm}$ to 160.7 a.u. $/ \mathrm{ppm}$ at $750 \pm 1 \mathrm{~nm}$. Thus, measuring the light scattering intensity is a new alternative method that can be used to determine the concentration of E2 (down to 0.1 
ppm or less) in unknown samples. This method would be valuable especially for organic compounds which do not exhibit strong molecular fluorescence or UV-visible absorbance. In Figure 2.4, a non-fluorescent organic compound, bisphenol A (BPA), was successfully observed to exhibit enhancement in light scattering from the NIP particles after binding BPA and NIP particles together. Fluorescence analysis of 35-ppm BPA using excitation wavelengths of $190,200,250,280,300,350$ and $400 \mathrm{~nm}$ did not detect any emission intensity in the wavelength range from $190-800 \mathrm{~nm}$. Now, using this new method, BPA was detectable at $0.5 \mathrm{ppm}$ with good sensitivity. The only requirement to determine these target molecules is addition of 0.1-ppm NIP particles to all unknown samples and standard solutions. It is probably the sharp profile of the light scattering peak (with a full width at half maximum of $7.9 \pm 0.1 \mathrm{~nm}$ ) that renders this method much more sensitive than conventional UV-visible spectrophotometry.

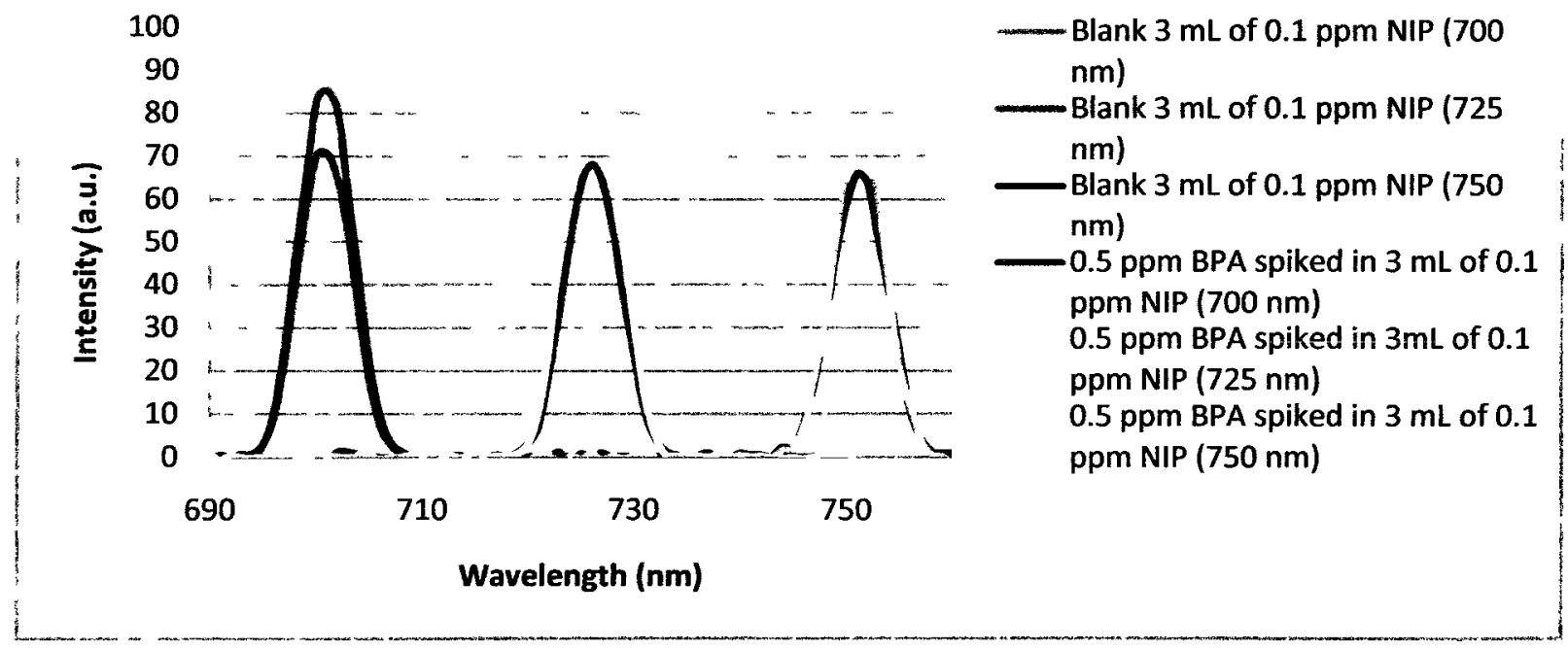

Figure 2.4 Light scattering spectra from 0.1-ppm NIP particles in aqueous suspension upon binding with bisphenol A $(0.5 \mathrm{ppm})$, by scanning the incident light around $700 \mathrm{~nm}, 725 \mathrm{~nm}$ and $750 \mathrm{~nm}$. 


\subsubsection{Comparison of fluorescence emissions from E2 added to NIP particles in aqueous suspension and $E 2$ in aqueous solution}

After E2 was found to significantly enhance the light scattering by NIP particles in aqueous suspension, the reverse effect of NIP particles on E2 fluorescence emission was investigated. Figure 2.5 shows the fluorescence emission spectra of E2 added in various concentrations to 0.1-ppm NIP particles in aqueous suspension, using a fluorescence excitation wavelength of $279 \pm 1 \mathrm{~nm}$. The fluorescence emission intensity at $310 \pm 2 \mathrm{~nm}$ increased successively when the concentration of E2 was raised from $0.1 \mathrm{ppm}$ to $1.0 \mathrm{ppm}$.

A standard calibration curve was constructed to verify a high correlation coefficient of 0.9824 and a sensitivity slope of $25.3 \pm 0.1$ a.u./ppm E2.

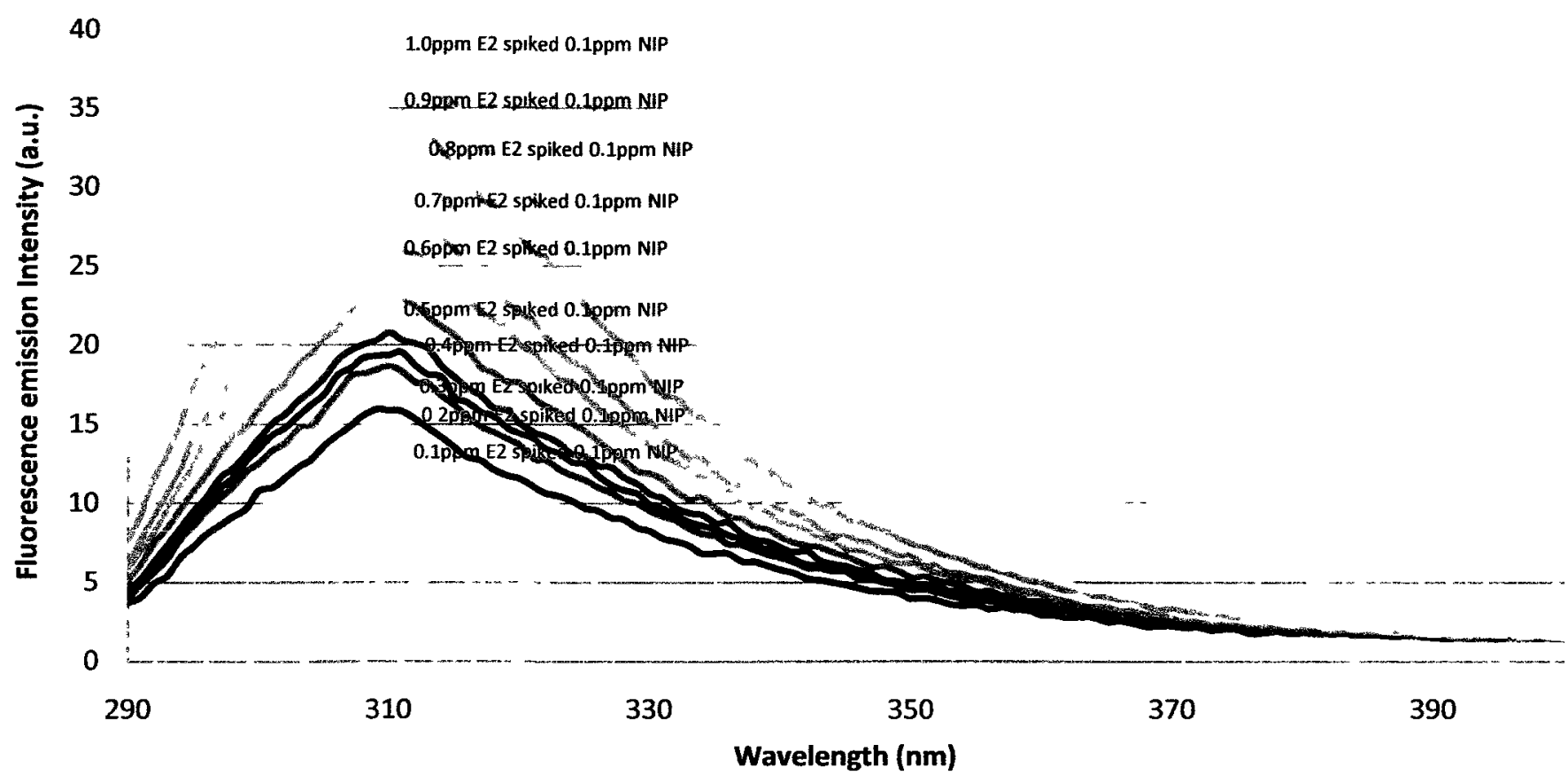

Figure 2.5 Fluorescence emission spectra of 0.1 to $1.0-\mathrm{ppm}$ E2 added to $0.1-\mathrm{ppm}$ NIP particles in aqueous suspension, using excitation wavelength $=279 \pm 1 \mathrm{~nm}$.

Figure 2.6 shows the fluorescence emission spectra of E2 added in various concentrations 
to distilled deionized water (DDW), using a fluorescence excitation wavelength of $279 \pm 1$ $\mathrm{nm}$, without any NIP particles. Similarly to Figure 2.5 , the fluorescence emission intensity at $310 \pm 2 \mathrm{~nm}$ increased with higher concentration of E2. A standard calibration curve of fluorescence emission intensity vs. concentration of E2 added to DDW was constructed to indicate a higher correlation coefficient of 0.9907 and better sensitivity slope of $29.8 \pm 0.1$ a.u./ppm E2 (in comparison to $25.3 \pm 0.1$ a.u./ppm from 0.1 - to $1.0-\mathrm{ppm}$ E2 spiked 0.1-ppm NIP suspension). Such a decrease in sensitivity of $\sim 15 \%$ was attributed to the diminution of excitation light and attenuation of fluorescence emission by the presence of NIP particles in each sample. Note that the fluorescence emission intensities from various concentrations of E2 when added to NIP particles in aqueous suspension were larger than added to DDW merely due to a larger background (or blank).

40

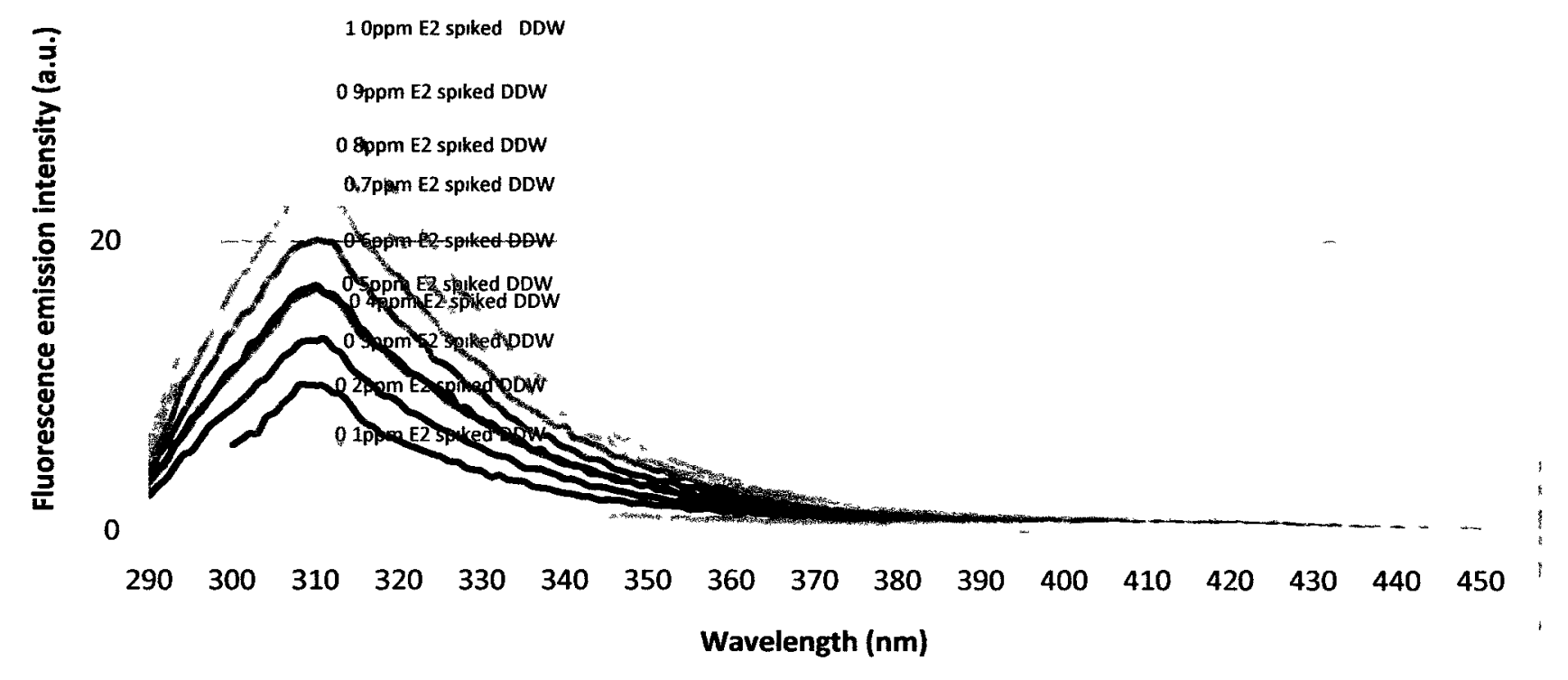

Figure 2.6 Fluorescence emission spectra of 0.1 to $1.0-\overline{p m} \overline{\mathrm{E} 2}$ added to $\overline{\mathrm{DDW}}$, using excitation wavelength $=279 \pm 1 \mathrm{~nm}$. 


\begin{tabular}{|c|c|c|c|}
\hline $\begin{array}{c}\text { Concentration of E2 } \\
\text { spiked DDW (ppm) }\end{array}$ & $\begin{array}{c}\text { Fluorescence emission } \\
\text { intensity (blank } \\
\text { subtracted) } \\
\text { (a.u.) }\end{array}$ & $\begin{array}{c}\text { Concentration of } \\
\text { E2 (ppm) spiked } \\
\text { 0.1-ppm NIP }\end{array}$ & $\begin{array}{c}\text { Fluorescence emission } \\
\text { intensity (blank } \\
\text { subtracted) } \\
\text { (a.u.) }\end{array}$ \\
\hline 0.1 & $\mathbf{3 . 6 0}$ & 0.1 & 3.58 \\
\hline 0.2 & 6.98 & 0.2 & 6.30 \\
\hline 0.3 & 10.16 & 0.3 & 7.18 \\
\hline 0.4 & 13.62 & 0.4 & 8.41 \\
\hline 0.5 & 13.88 & 0.5 & 10.88 \\
\hline 0.6 & 16.99 & 0.6 & 14.13 \\
\hline 0.7 & 20.84 & 0.7 & 16.85 \\
\hline 0.8 & 23.69 & 0.8 & 20.03 \\
\hline 0.9 & 27.42 & 0.9 & 23.15 \\
\hline 1.0 & 31.65 & 1.0 & 26.73 \\
\hline
\end{tabular}

Table 2.1 Net fluorescence intensities of E2 spiked DDW and 0.1-ppm NIP submicron particles aqueous suspension

Table 2.1 shows the net (or blank subtracted) fluorescence emission intensities of E2 added to either DDW or 0.1-ppm NIP submicron particles in aqueous suspension. For instance, the fluorescence emission intensity of 0.1-ppm E2 spiked DDW was $3.60 \pm 0.05$ a.u. while the fluorescence emission intensity of 0.1-ppm E2 spiked 0.1-ppm NIP submicron particles in aqueous suspension was $3.58 \pm 0.05$ a.u. Generally, the fluorescence emission intensities in water (the second column) are higher than the fluorescence emission intensities of E2 spiked NIP particles in aqueous suspension (the fourth column). In other words, the NIP particles $(0.1 \mathrm{ppm})$ distinctly decreased the fluorescence emission intensity of E2 by $15 \pm 1 \%$ (= 1 - ratio of slopes in the standard calibration curves) due to diminution of the excitation light and attenuation of the fluorescence emission. Nonetheless, this spectroscopic property (15\% lower fluorescence emission intensity) of poly (MAA-co-EGDMA) sub-micron particles is acceptable, or tolerable, for environmental monitoring and remediation applications. Most importantly, they can bind E2 molecules on an impressively fast time scale of 
seconds (data not shown) $\left[^{27}\right]$. After using NIP particles to remove trace E2 from a large volume of contaminated water, it would still be possible to estimate the total amount of E2 (bound on suspending NIP particles) by measuring increase of fluorescence emission intensity from the E2 bound on NIP particles.

\subsubsection{Fluorescence emission and light scattering from various concentrations of NIP in aqueous suspension at fixed $E 2$ concentration}

The enhancement of light scattering from NIP particles due to E2 binding (as discussed in Section 2.3.2) was further investigated, by varying the concentration of NIP particles in aqueous suspension with a fixed E2 concentration. Figure 2.7 shows their fluorescence emission and light scattering spectra obtained using two excitation wavelengths, $279 \pm 1$ $\mathrm{nm}$ and $725 \pm 1 \mathrm{~nm}$. The intensities of light scattering at both excitation wavelengths increased with each increment of NIP particles. Two standard calibration curves were constructed for both light scatterings, which showed a better correlation of $0.96 \pm 0.01$ for $725 \pm 1 \mathrm{~nm}$ than $0.89 \pm 0.01$ for $279 \pm 1 \mathrm{~nm}$. The longer wavelength, $725 \pm 1 \mathrm{~nm}$, is obviously better for the determination of NIP particle concentrations by light scattering. Figure 2.7 also shows that, when the concentration of NIP particles increased, the fluorescence emission intensity from E2 stayed essentially constant. Whereas this constant fluorescence emission was totally expected, the enhancement of light scattering (as discussed in Section 2.3.2) became even more fascinating to comprehend because the light scattering intensity produced by 1.0 ppm E2 at excitation wavelength $=725 \pm 1 \mathrm{~nm}$ was only 15-20 a.u. in the standard calibration curve. 


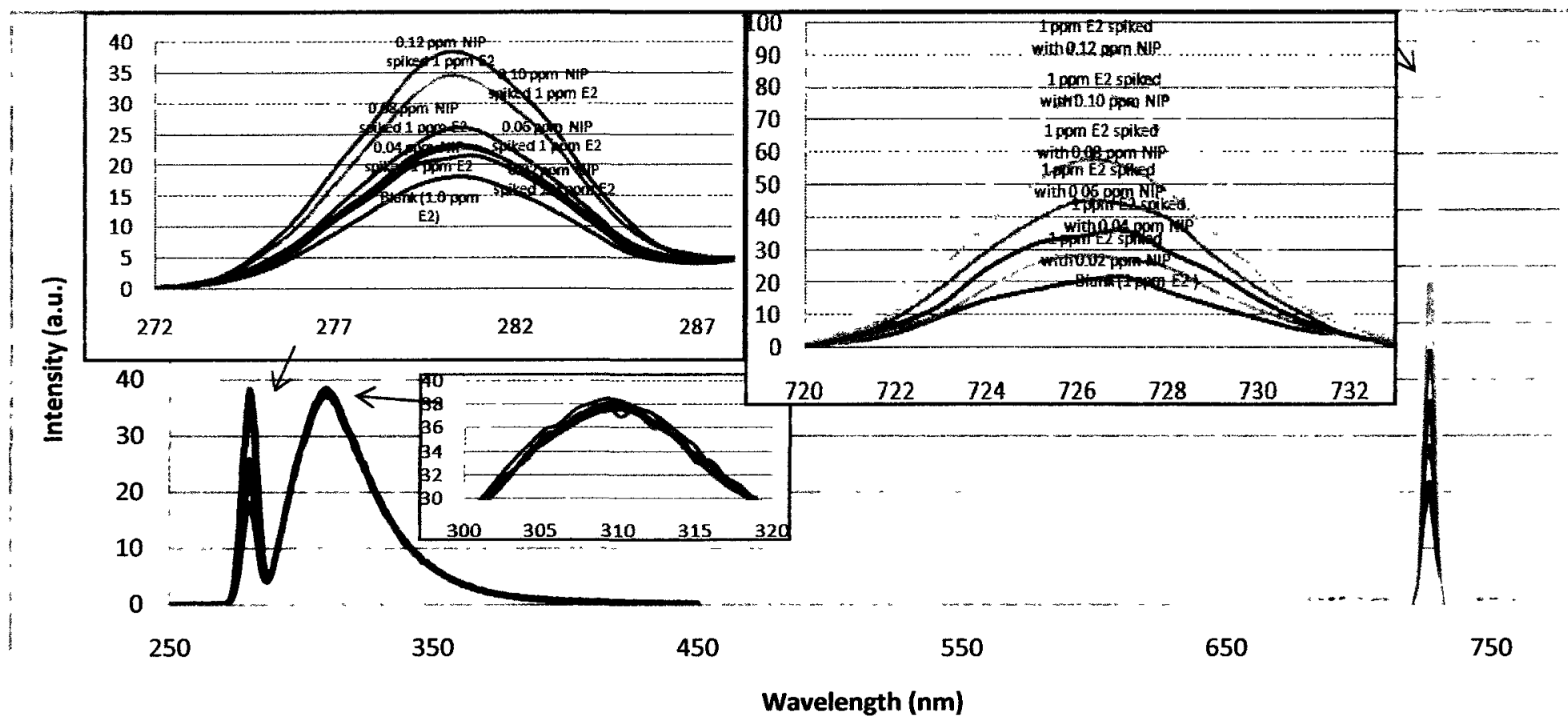

Figure 2.7 Fluorescence emissions and light scattering spectra of 1.0-ppm E2 aqueous solution spiked with various concentrations of NIP submicron particles, using excitation wavelengths of $279 \pm 1 \mathrm{~nm}$ and $725 \pm 1 \mathrm{~nm}$

\subsubsection{Spectroscopic characterization of NIP and E2 bound NIP submicron particles}

The interaction between NIP submicron particles and E2 was characterized by FTIR spectroscopy. In Figure 2.8, spectrum (a) represents NIP submicron particles before E2 binding, spectrum (b) shows NIP submicron particles after binding with E2, spectrum (c) shows NIP submicron particles in mixture with E2 particles, and spectrum (d) shows E2 particles. These FTIR spectra show detailed information on the interaction between the NIP submicron particles and E2 molecules via H-bonding. In the FTIR spectrum of E2 bound NIP submicron particles, the $-\mathrm{OH}$ stretching vibration peak has shifted (from the $3436.7 \mathrm{~cm}^{-1}$ for NIP submicron particles before E2 binding) to a lower wavenumber of $3423.7 \mathrm{~cm}^{-1}$ after binding. To confirm this $-\mathrm{OH}$ stretching vibration shift phenomenon, spectrum (c) was measured for a mixture of NIP submicron particles and E2 particles. 
The $-\mathrm{OH}$ stretching vibration peak is observed at $3439.7 \mathrm{~cm}^{-1}$ which is very close to that for NIP submicron particles (before E2 binding) at $3436.7 \mathrm{~cm}^{-1}$. As no hydrogen bonding can occur between NIP submicron particles and E2 particles, the -OH stretching vibration peak is expected to undergo very limited shift. In general, the spectrum (b) of E2 bound NIP submicron particles shows a $\mathrm{C}=\mathrm{O}$ peak (which belongs to the NIP submicron particles) at a wavenumber of $1729.6 \mathrm{~cm}^{-1}$ and a couple of aromatic $\mathrm{C}=\mathrm{C}$ peaks (which belong to E2) between wave numbers 1610.4 to $1451.5 \mathrm{~cm}^{-1}$.

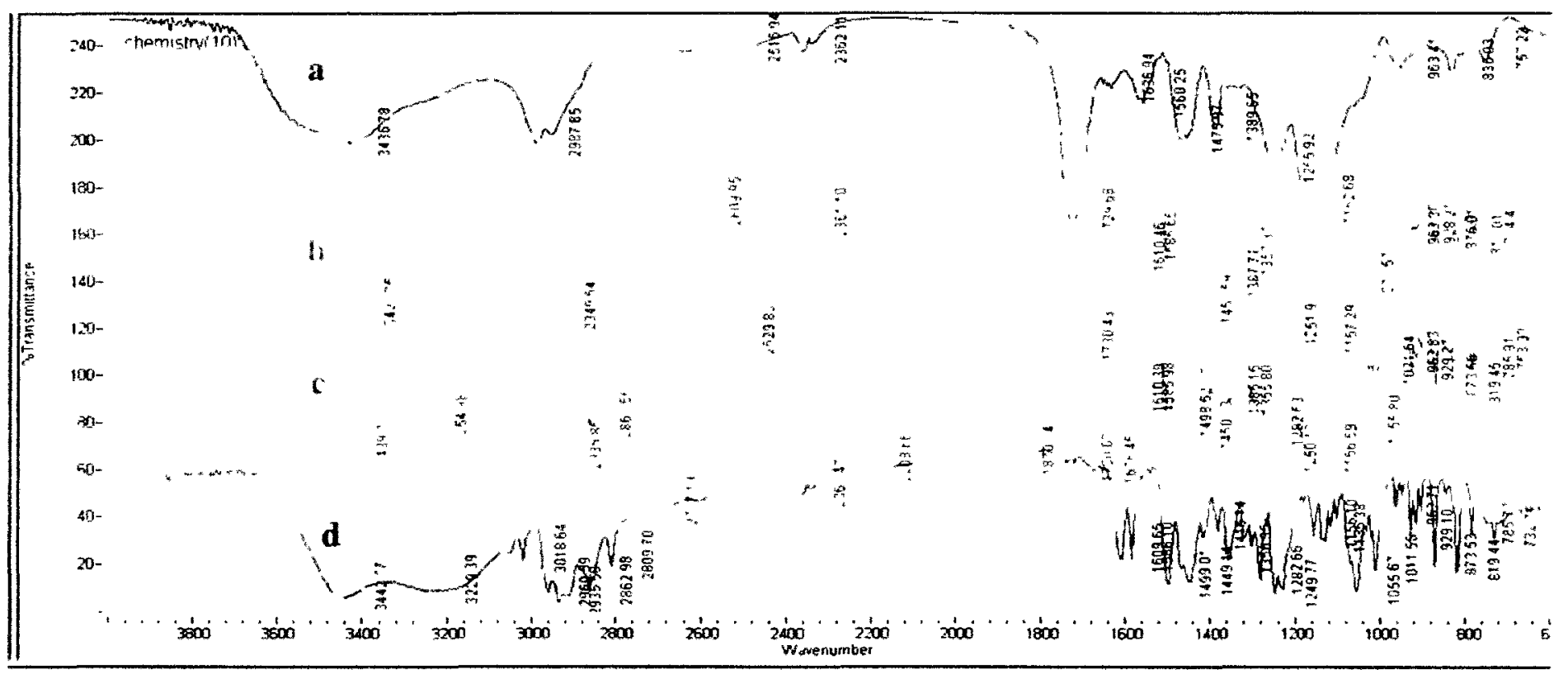

Figure 2.8 FTIR spectra of (a) poly MAA-co-EGDMA particles before E2 binding, (b) poly MAA-co-EGDMA particles after binding with E2, (c) poly MAA-co-EGDMA and E2 particles in mixture, and (d) E2 particles. 


\subsection{Conclusion}

Mie scattering of PMAA-co-EGDMA non-imprinted polymer submicron particles $(300 \pm 5$ $\mathrm{nm}$ ) in aqueous suspension has been studied systematically using various excitation wavelengths from $200 \mathrm{~nm}$ to $750 \mathrm{~nm}$. The optimal excitation wavelength was $725 \pm 1 \mathrm{~nm}$, which provided a sharp peak with the highest intensity for sensitive determination of NIPs in aqueous suspension. The light scattering peak also allowed accurate determination of trace E2 (as low as $0.1 \mathrm{ppm}$ ) in water samples spiked with NIP particles. This new E2 determination method can be attributed to binding between E2 molecules and NIP particles, as characterized by using FTIR spectroscopy. It is also applicable for the determination of bisphenol A (BPA) which is not naturally fluorescent. $700-750 \mathrm{~nm}$ is truly an optimal wavelength range for light scattering measurements because laser diodes of high power are commercially available at a reasonable price. NIP submicron particles have one more advantage of being optically transparent (at least translucent). As such, binding of organic contaminants with these particles will allow on-line spectroscopic monitoring by molecular fluorescence and possibly UV-visible spectrophotometry. This is of great importance because the absorbance value and emission intensity can readily indicate when the particles are saturated with contaminants and hence should be regenerated. Automation of these two steps, monitoring and regeneration, are in principle easy to implement from the engineer's perspective for water treatment applications.

Further investigation will be performed by measuring fluorescence emission and light scattering intensities from molecular imprinted polymer (MIP) submicron particles, before and after binding with E2. MIP particles have a porous structure which can do 
more specific and semi-specific binding with E2 than NIPs. One big challenge is that the fluorescence emission and light scattering from E2 molecules bound inside the cavities can be changed (in intensity and wavelengths) by MIPs porous structure. Future study will examine spectroscopically the mechanisms of competitive binding of E1/E2/EE2/E3 mixture to MIP submicron particles, as previously proposed in the framework of the NICA-Donnan model $\left[{ }^{28}\right]$. The evolution of time-resolved laser-induced fluorescence spectra of MIP with bound E2, for instance, could show two strikingly different environments for the binding. Release into the bulk solution as free E2 could be evidenced both by the shapes of the spectra and by the decrease in the luminescence decay times. 


\section{References:}

[1] V. Pichon, F. Chapuis-Hugon, "Role of molecularly imprinted polymers for selective determination of environmental pollutants-A review," Anal. Chim. Acta, vol. 622, no. 1-2, pp. 48-61, 2008.

[2] M. Le Noir, F. Plieva, T. Hey, B. Guieysse, B. Mattiasson, "Macroporous molecularly imprinted polymer/cryogel composite systems for the removal of endocrine disrupting trace contaminants," J. Chromatogr. A., vol. 1154, no. 1-2, pp. 158-164, 2007.

[3] I. Sanchez-Barragan, K. Karim, J.M. Costa-Fernandez, S.A. Piletsky, A. Sanz-Medel, "A molecularly imprinted polymer for carbaryl determination in water," Sensors \& Actuators: B. Chemical, vol. 123, no. 2, pp. 798-804, 2007.

[4] Y. Wei, L. Qiu, J.C.C. Yu, E.P.C. Lai, "Molecularly imprinted solid phase extraction in a syringe needle packed with Polypyrrole-encapsulated carbon nanotubes for determination of Ochratoxin A in Red Wine," Food Sc. Tec., vol. 13, no. 5, pp. 375$380,2007$.

[5] Z. Zhang, J. Hu, "Selective removal of estrogenic compounds by molecular imprinted polymer (MIP)," Water Res, vol. 42, no. 15, pp. 4101-4108, 2008.

[6] E. Caro, R.M. Marce, P.A.G. Cormack, D.C. Sherrington, F. Borrull, "On-line solidphase extraction with molecularly imprinted polymers to selectively extract substituted 4-chlorophenols and 4-nitrophenol from water," J. Chromatogr. A, vol. 995, no. 1-2, pp. 233-238, 2003.

[7] S. Le Moullec, L. Truong, C. Montauban, A. Begos, V. Pichon, B. Bellier, "Extraction of alkyl methylphosphonic acids from aqueous samples using a conventional polymeric solid-phase extraction sorbent and a molecularly imprinted polymer," J. Chromatogr. A, vol. 1139, no. 2, pp. 171-177, 2007.

[8] C. Michailof, P. Manesiotis, C. Panayiotou, "Synthesis of caffeic acid and phydroxybenzoic acid molecularly imprinted polymers and their application for the selective extraction of polyphenols from olive mill waste waters," J. Chromatogr. A, vol. 1182, no. 1, pp. 25-33, 2008.

[9] R.G. Da Costa Silva, F. Augusto, "Sol-gel molecular imprinted ormosil for solidphase extraction of methylxanthines," J. Chromatogr. A, vol. 1114, no. 2, pp. 216 223, 2006.

[10] S.D. Harvey, "Molecularly imprinted polymers for selective analysis of chemical warfare surrogate and nuclear signature compounds in complex matrices," J. Sep Sci., vol. 28, no. 11, pp. 1221-1230, 2005.

[11] A. Beltran, E. Caro, R.M. Marce, P.A.G. Cormack, D.C. Sherrington, F. Borrull, 
"Synthesis and application of a carbamazepine-imprinted polymer for solid-phase extraction from urine and wastewater," Anal. Chim. Acta, vol. 597, no. 1, pp. 6-11, 2007.

[12] E. Benito-Pena, J.L. Urraca, B. Sellergren, M.C. Moreno-Bondi, "Solid-phase extraction of fluoroquinolones from aqueous samples using a water-compatible stochiometrically imprinted polymer," J. Chromatogr. A, vol. 1208, no. 1-2, pp. 62$70,2008$.

[13] H. Horiguchi, N. Takiguchi, H.S. Cho, M. Kojima, M. Kaya, H. Shiraishi, M. Morita, H. Hirose, M. Shimizu, "Ovo-testis and disturbed reproductive cycle in the giant abalone, Haliotis madaka: possible linkage with organotin contamination in a site of population decline," Mar. Env. Res., vol. 50, no. 1-5, pp. 223-229, 2000.

[14] M.H. Depledge, Z. Billinghurst, "Ecological significance of endocrine disruption in marine invertebrates," Mar. Poll. B., vol. 39, no. 1-12, pp. 32-38, 1999.

[15] L.S. Birnbaum, "Developmental effects of dioxins and related endocrine disrupting chemicals" Tox. Lett., vol. 82, pp. 743-750, 1995.

[16] W. Wuttke, H. Jarry, D. Seidlova, "Endocrine disrupters," Reproduktionsmedizin, vol. 15 , no. 3, pp. 173-178, 1999.

[17] R.J. Golden, K.L. Noller, L. Titus-Ernstoff, R.H. Kaufman, R. Mittendorf, R. Stillman, E.A. Reese, "Environmental endocrine modulators and human health: an assessment of the biological evidence," Cr. R. Toxico., vol. 28, no. 2, pp. 109-227, 1998.

[18] M.L. Noir, A.S. Lepeuple, B. Guieysse, B. Mattiasson, "Selective removal of 17ßestradiol at trace concentration using a molecularly imprinted polymer," Water Res., vol. 41 , no. 12, pp. 2825-2831, 2007.

[19] Q. Zhu, L. Wang, S. Wu, W. Joseph, X. Gu, J. Tang, "Selectivity of molecularly imprinted solid phase extraction for sterol compounds," Food Chem., vol. 113, no. 2, pp. 608-615, 2009.

[20] Y. Watabe, T. Kubo, T. Nishikawa, T. Fujita, K. Kaya, K. Hosoya, "Fully automated liquid chromatography-mass spectrometry determination of $17 \beta$-estradiol in river water," J. Chromatogr. A, vol. 1120, no. 1-2, pp. 252-259, 2006.

[21] A. Rachkov, S. McNiven, A. El'skaya, K. Yano, I. Karube, "Fluorescence detection of $\beta$-estradiol using a molecularly imprinted polymer," Anal. Chim. Acta., vol. 405, no. 1-2, pp. 23-29, 2000.

[22] S. Wei, A. Molinelli, B. Mizaikoff, "Molecularly imprinted micro and nanospheres for the selective recognition of 17ß-estradiol," Biosens. Bioelectron., vol. 21, no. 10, pp. 1943-1951, 2006. 
[23] H. Horvath, "Gustav Mie and the scattering and absorption of light by particles: Historic developments and basics," J. Quan. Spectrosc. Radiat. Transfer, vol. 110, no. 11, pp. 787-799, 2009.

[24] C. Gendrin, Y. Roggo, C. Collet, "Pharmaceutical applications of vibrational chemical imaging and chemometrics: A review," J. Pharm. B., vol. 48, no. 3, pp. 533-553, 2008.

[25] M.J. Costello, S. Johnsen, K.O. Gilliland, C.D. Freel, W.C. Fowler, "Predicted light scattering from particles observed in human age-related nuclear cataracts using Mie scattering theory," Invest Ophthalmol Vis Sci., vol. 48, no. 1, pp. 303-312, 2007.

[26] W. Cai, L. Ma, "Information content of scattering measurements and characterization of spheroids," J.Aerosol Sci., vol. 39, no. 12, pp. 1032-1039, 2008.

[27] Z.D. Malki, E.P.C. Lai, E. Dabek-Zlotorzynska, "Characterization of molecularly imprinted polymer submicron particles by capillary electrophoresis," Electrophor. (submitted)

[28] L. Marang, S. Eidner, M.U. Kumke, M.F. Benedetti, P.E. Reiller, "Spectroscopic characterization of the competitive binding of $\mathrm{Eu}(\mathrm{III}), \mathrm{Ca}$ (II), and $\mathrm{Cu}$ (II) to a sedimentary originated humic acid," Chem. Geol., vol. 264, no. 1-4, pp. 154-161, 2009. 


\section{Chapter 3}

\section{An investigation of porous structure in molecularly imprinted polymer for sensor development: non-linear fluorescence quenching of $17 \beta$-estradiol bound inside MIP submicron particles by sodium nitrite and methacrylamide}

\subsection{Introduction}

MIP is increasingly recognized as a selective separation material ever since 1990 s the growth in the number of published articles $\left[^{1}\right]$. Every MIP consists of a highly crosslinked polymer matrix and one target compound as the template. After the template is eluted, binding cavities become available in the MIP with high affinity for the target compound as analyte. The advantages of MIP technology are high selectivity for the analyte, and hence low detection limits due to less matrix interference effects. MIPs can be used in sample solutions over a broad $\mathrm{pH}$ or temperature range. They can also be prepared at both high cost- and time- efficiencies. Nowadays MIPs are broadly benefiting the sensor and separation technologies. They are commonly used in thermometric sensors for amino acids and carbohydrates $\left[{ }^{2}\right]$, optical sensors for biologically active molecules $\left[{ }^{3}\right]$, ionic sensor $\left[{ }^{4}\right]$, biomimetic electrochemical sensors $\left[{ }^{5}\right]$, enantiomer separations $\left[{ }^{6}\right]$, and solid phase extractions $\left[{ }^{7}\right]$.

Estrogens are naturally produced female sex steroid hormones. They were first described by Stockard and Papanicolaou in $1917\left[{ }^{8}\right]$. Then, Doisy and Allen isolated estrogens and tested the estrogenic activities in $1923\left[^{9}\right]$. As shown in Figure 3.1, estrone (E1) is the primary estrogenic hormone in the post-menopausal woman. $17 \beta$-estradiol (E2) is the 
primary estrogen of ovarian origin and the major estrogenic hormone in the premenopausal woman. E2 has a relative strong estrogenic effect that is twelve times greater than E1, and eighty times higher than estriol (E3). E3 is a relatively weak estrogen which yields from the metabolism of estrone; it reaches the highest level in women only during pregnancy.

Estrogens can cause major impact on reproduction, sex characteristics and regulation of female development, and infertility $\left[{ }^{10,11,12,13,14,15}\right]$. Moreover, estrogens are carcinogenic compounds especially toward women breast and endometrial cancers.<smiles>[Z17]Cc1cc(O)ccc1C1CCC2C1CCC1C2CC[C@@]2(C)C(=O)CC[C@]12C</smiles>

Figure 3.1 Molecular structures of estrone (E1), $\beta$-estradiol (E2) and estriol (E3)

One sensing method for determination of the most naturally abundant estrogen E2 in water by spectrofluorimetry is undergoing rapid development in our lab. It involves (a) addition of MIP particles to bind E2 in a water sample, (b) modification of the water sample to release non-specifically bound E2 (and other compounds) from MIP particles, (c) quenching of fluorescence emission from E2 (and other compounds) in the water by methacrylamide, (d) preconcentration of MIP particles into a small cell volume, (e) measurement of fluorescence emission intensity from E2 specifically bound inside MIP particles, (f) quenching of fluorescence emission from E2 inside MIP particles by sodium nitrite, and (g) blank measurement of fluorescence emission intensity from MIP particles. After subtracting (g) from (f), the concentration of E2 can be determined from a standard 
calibration curve. This E2 concentration will be divided by the preconcentration factor to obtain a final result.

The objective of this work was to investigate the porous structure of MIP particles for non-linear fluorescence quenching of E2 (bound inside them) by sodium nitrite and methacrylamide. Our goal was to determine whether any larger quenchers would be needed to fulfill step (c) in the method described above.

\subsection{Experimental}

\subsubsection{Chemicals}

17ß-Estradiol (E2) and sodium nitrite were purchased from Sigma-Aldrich (St. Louis, MO, USA). Methacrylic acid and methacrylamide were purchased from Aldrich (Milwaukee, WI, USA). 2,2-Azobisisobutyronitrile (AIBN) was purchased from Pfaltz \& Bauer (Waterbury, CT, USA). HPLC grade methanol, HPLC grade acetonitrile and Spectro grade acetone were purchased from Caledon (Georgetown, ON, Canada). 18MS.cm distilled deionized water (DDW) was obtained from a Millipore Milli-Q water system (Bedford, MD, USA).

\subsubsection{Preparation of E2-MIP and NIP submicron particles}

The method for preparation of E2-molecularly imprinted polymer (E2-MIP) and nonimprinted polymer (NIP) submicron particles had previously been described $\left[{ }^{16}\right]$. The freshly prepared MIP and NIP particles in suspension were separately placed in five 15$\mathrm{mL}$ polypropylene tubes (Greiner Bio-One, Frickenhausen, Germany), and then spun by a centrifuge (Hamilton Bell VanGuard Centrifuge, Montvale, NJ, USA) for $60 \mathrm{~min}$ at 4000 rpm to help remove the supernatants. 


\subsubsection{MIP particles}

The E2-MIP particles were washed in $15 \mathrm{~mL}$ of DDW with ultrasonication (Branson 2510, Danbury, CT, USA) for 30 min to remove free E2 and pre-polymerization residues. After more than 25 times of washing, the $\mathrm{pH}$ was $5.5 \pm 0.1$ in the supernatant and the free E2 concentration was lower than $0.2 \mathrm{ppm}$ (the detection limit of our HPLC-FD instrument).

\subsubsection{NIP particles}

The NIPs particles were washed by methanol, acetonitrile and DDW, three times each, to obtain a final $\mathrm{pH}$ of $5.5 \pm 0.1$ in the supernatant. $50 \mathrm{mg}$ of NIP particles were then suspended in $15 \mathrm{~mL}$ of $3.5 \mathrm{ppm} \mathrm{E} 2$ aqueous solution. The suspension was sonicated for 1 hr, allowing binding between the NIP particles and E2 to form E2-NIP particles.

\subsubsection{Characterization of particles}

\subsubsection{Particle size measurements by dynamic light scattering (DLS)}

The washed MIP and NIP particles were suspended in $10 \mathrm{M} \mathrm{KNO}_{3}$ at a concentration of $40 \mathrm{~g} / \mathrm{mL}$. The suspensions were sonicated for $15 \mathrm{~min}$ before measurement on a NanoDLS particle size analyzer (Brookhaven Instruments, Holtsville, New York, USA). The instrument had been calibrated by $92 \pm 4 \mathrm{~nm}$ Nanosphere ${ }^{\mathrm{TM}}$ size standards (Duke Scientific, Palo Alto, CA, USA). A total of 10 measurements were run after $5 \mathrm{~min}$, and the laser beam intensity was automatically optimized by the instrument before each run. 


\subsubsection{Fluorescence binding measurements}

\subsection{MIP particles}

Fluorescence emission of the last washing from Section 3.2.2.1 was measured by a fluorescence spectrophotometer (Varian Cary Eclipse, Palo Alto, CA, USA) using excitation wavelength of $279 \pm 1 \mathrm{~nm}$ and emission wavelength of $310 \pm 1 \mathrm{~nm}$ (or scanning from $290 \mathrm{~nm}$ to $450 \mathrm{~nm}$ ). Both the excitation and emission slits were set at $5 \mathrm{~nm}$. Fluorescence emission of the washed E2-MIP particles suspension was measured using the same spectrophotometer settings. All fluorescence experiments were carried out at room temperature $\left(20 \pm 1^{\circ} \mathrm{C}\right)$.

\subsection{NIP particles}

Fluorescence emissions of the $3.5 \mathrm{ppm} \mathrm{E2}$ aqueous solution and the supernatant after binding from Section 3.2.2.2 were measured using the same spectrophotometer settings as in Section 3.2.3.2.1.

\subsubsection{Fluorescence quenching measurements}

Fluorescence emission spectra of $0.5-4.5 \mathrm{ppm}$ E2 aqueous solutions and $0.1-2.5 \mathrm{mg} / \mathrm{mL}$ E2-MIP and E2-NIP particles, suspended in DDW, were measured using the same spectrophotometer settings as in Section 3.2.3.2. All these fluorescence measurements were carried out in a 3-mL quartz cuvette cell with a PTFE stopper. Next, these E2 solutions and E2-MIP and E2-NIP particle suspensions were successively spiked with 1 mg of quencher (sodium nitrite or methacrylamide) before the fluorescence emission spectra were measured again. The inner filter effect for right-angle illumination, introduced by the absorption of exciting light $(\lambda \mathrm{ex}=280 \pm 1 \mathrm{~nm})$ and absorption of

fluorescence emission ( $\lambda \mathrm{em}=310 \pm 1 \mathrm{~nm}$ ) by quenchers, were corrected as described 
elsewhere $\left.{ }^{17}\right]$. All light absorptions from quenchers were measured on a UV-visible spectrophotometer (Varian Cary 3, Palo Alto, CA, USA) by scanning from $350 \mathrm{~nm}$ to 250 $\mathrm{nm}$ at room temperature $\left(20 \pm 1^{\circ} \mathrm{C}\right)$

\subsection{Results and Discussion}

\subsubsection{Fluorescence property of E2-MIP and E2-NIP particles}

The spherical MIP particles were determined by DLS to have an average diameter of 477 $\pm 11 \mathrm{~nm}$. The spherical NIP particles were smaller, with an average diameter of $373 \pm 21$ $\mathrm{nm}$. According to the general theory of molecular imprinting, MIP bound E2 via specific, semi-specific and non-specific interactions, whereas NIP bound E2 via non-specific interaction only $\left[{ }^{18}\right]$. Both MIP and NIP particles prepared with MAA and EGDMA were not naturally fluorescent. However, once the MIP and NIP particles bound some E2 molecules, the bound E2 was detectable by a fluorescence spectrophotometer. Figure 3.2(a) and (b) shows the fluorescence emission peak at 310 $\pm 1 \mathrm{~nm}$ from E2-MIP and E2NIP particles, when using an excitation wavelength of $280 \pm 1 \mathrm{~nm}$. Note that the emission spectra from E2-MIP and E2-NIP particles were very similar to that obtained from 3.5 ppm E2 in aqueous solution (Figure 3.2c) except for two light scattering peaks at $380 \pm 1$ $\mathrm{nm}$ and $423 \pm 1 \mathrm{~nm}$ from the particles. 


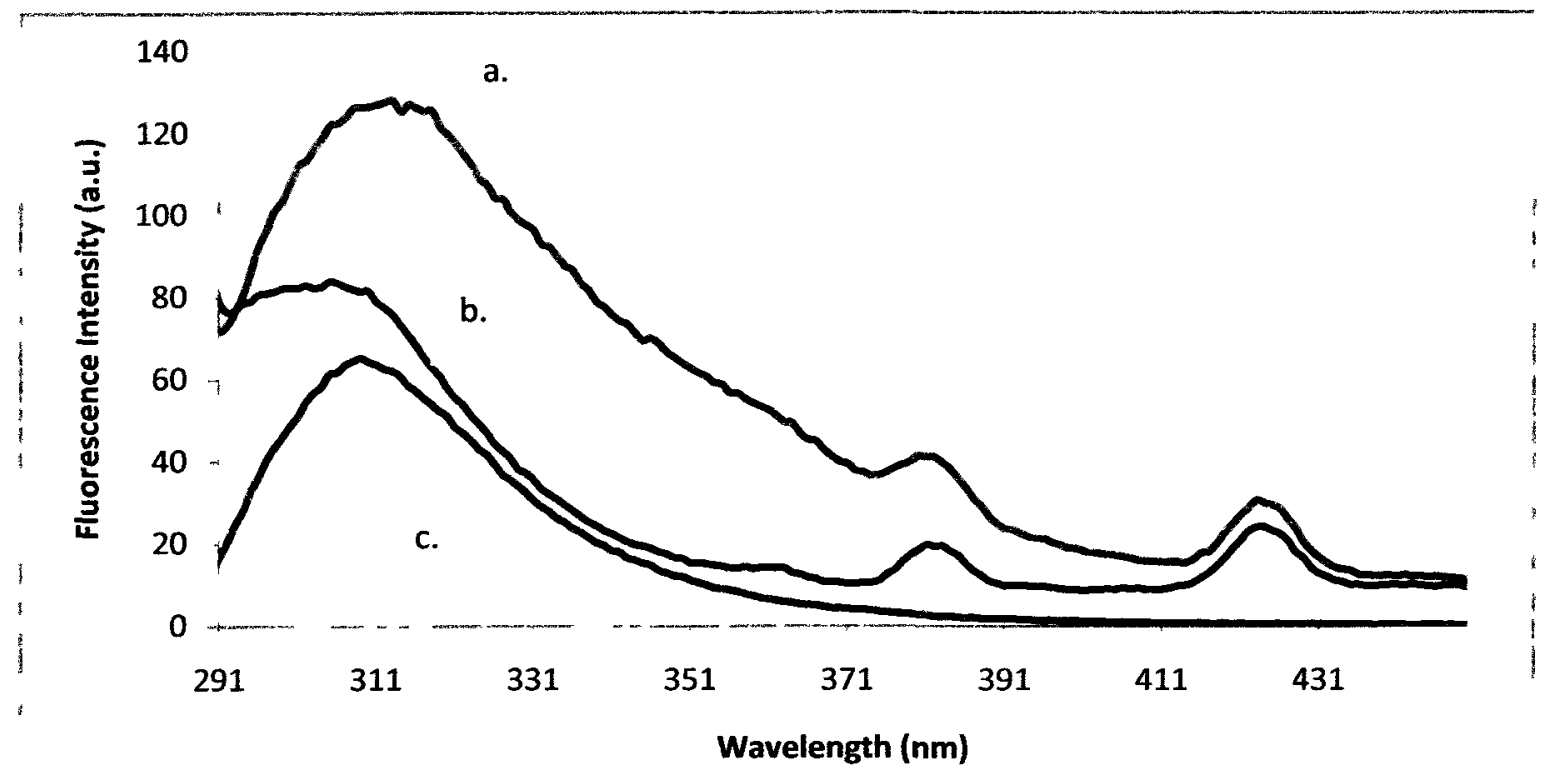

Figure 3.2 Fluorescence determination of E2 binding with MIP and NIP particles $\left(\lambda_{\mathrm{ex}}=\right.$ $280 \pm 1 \mathrm{~nm}$ ): (a) fluorescence emission of E2-MIP particles suspended in DDW, (b) fluorescence emission of E2-NIP particles suspended in DDW, (c) fluorescence emission of $3.5 \mathrm{ppm} \mathrm{E} 2$ in aqueous solution.

The detection sensitivity for E2-MIP/NIP fluorescence was not significantly decreased by the physical and chemical properties of particles. The fluorescence emission intensity of $3.5 \mathrm{ppm}$ E2 was $65 \pm 1$ a.u. before binding with NIP particles. After binding with $50 \mathrm{mg}$ of NIP particles the fluorescence emission intensity in the same solution (supernatant) decreased to $5 \pm 1$ a.u. Apparently $92 \pm 1 \%$ of E2 $(48.4 \pm 0.1 \mu \mathrm{g})$ in the original aqueous solution was bound by NIP particles.

\subsubsection{Fluorescence quenching analysis}

Fluorescence quenching of the E2 molecules bound inside MIP and NIP particles is significant to study for clarifying the binding site environment between E2 and MIP/NIP. The results, as detailed below, will show some essential differences between MIP and NIP when they bound with E2 molecules. 
The process of fluorescence quenching is described by the Stern-Volmer equation:

$$
F_{0} / F=1+K_{\text {sv }}[Q]
$$

Where $\mathrm{F}_{0}$ and $\mathrm{F}$ are the fluorescence emission intensities from $\mathrm{E} 2$ detected in the absence and presence of a quencher, respectively. $\mathrm{K}_{\mathrm{sv}}$ is Stern-Volmer florescence quenching constant (dynamic or collisional quenching constant) and [Q] is the concentration of quencher. Sodium nitrite and methacrylamide were selected for comparison of their quenching properties $[3,4]$. These two quenchers represent different types of chemical species. One is an ionic quencher; sodium nitrite exists in aqueous solution in the form of (positively charged sodium ions and) negatively charged nitrite ions. This nitrite anion interacted with E2 to result in fluorescence quenching. The other one is a molecular quencher; methacrylamide with specific functional groups (acryl and amide) has good water solubility for fluorescence quenching. No attempt was made in this study to analyze these two factors (size and ionic charge) separately. 

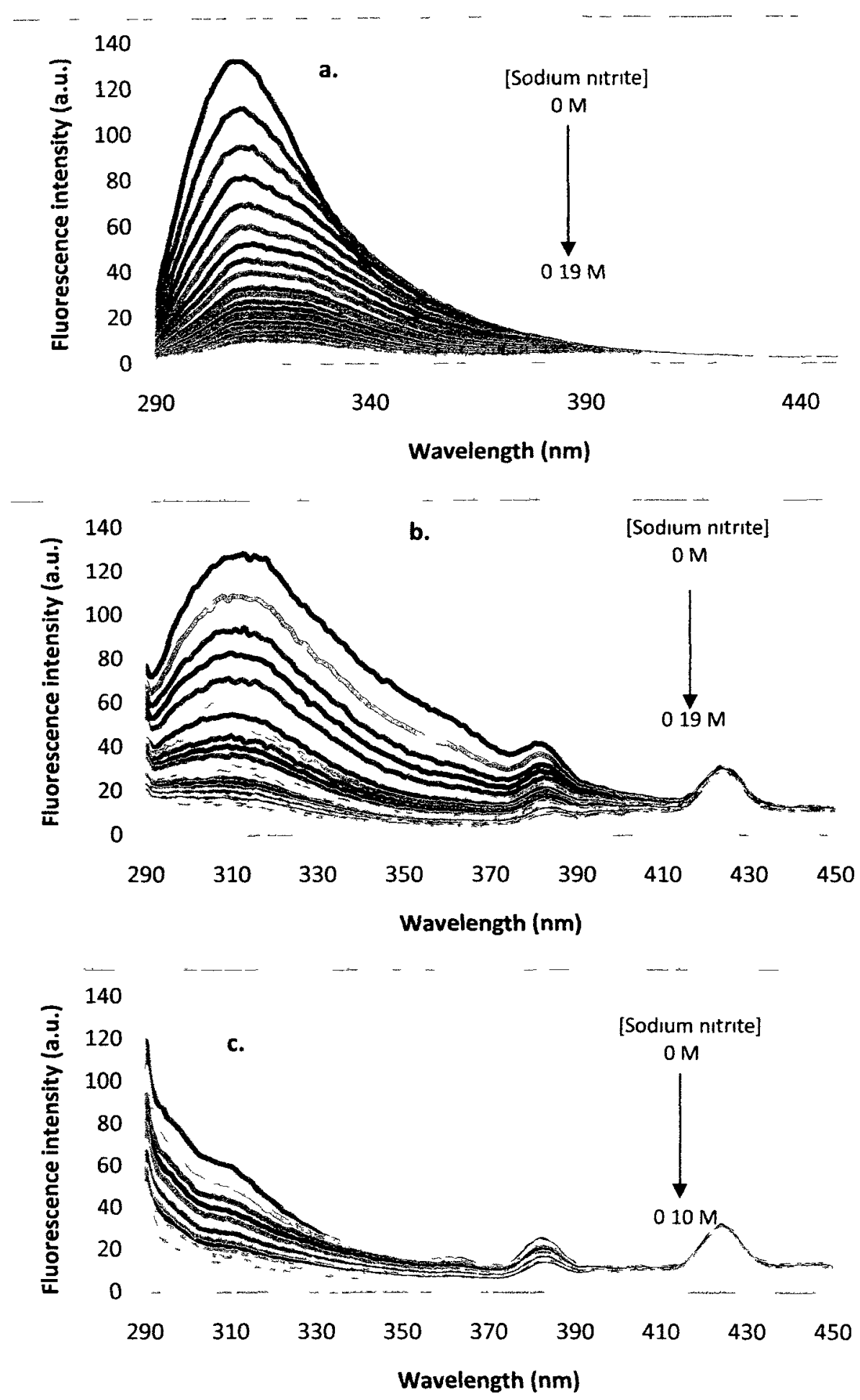

Figure 3.3 Fluorescence emission spectra of (a) $4.5 \mathrm{ppm}$ E2 aqueous solution, (b) 2.5 $\mathrm{mg} / \mathrm{mL}$ E2-MIP particles in aqueous suspension, and (c) $2.5 \mathrm{mg} / \mathrm{mL}$ E2-NIP particles in aqueous suspension, during titration with sodium nitrite up to a final concentration of $0.19 \mathrm{M}$ (without causing any significant dilution effects, $\sim 6 \%$ ). 
Figure 3.3(a) shows the fluorescence emission spectra of 4.5 ppm E2 aqueous solution progressively quenched by titration with sodium nitrite. The concentration of sodium nitrite titrated into $3 \mathrm{~mL}$ of $4.5 \mathrm{ppm} \mathrm{E} 2$ aqueous solution increased from 0.00 to $0.19 \mathrm{M}$, with each titration increment amounting to $1 \mathrm{mg}(10 \mu \mathrm{L}$ of $100 \mathrm{ppm})$ of sodium nitrate. The fluorescence emission intensity was obviously decreased, after 45 titration increments, by $99 \%$ from the initial intensity. During the quenching titration, the fluorescence peak shape changed from sharp to broad. Figure 3.3(b) and (c) show how progressively the fluorescence emissions of $2.5 \mathrm{mg} / \mathrm{mL}$ E2-MIP particles and E2-NIP particles in aqueous suspensions were quenched by titration with sodium nitrite. The lower fluorescence intensity scale in Figure 3.3(c) was dictated by a lower E2 binding capacity of the NIP particles. According to our previous results, the MIP/NIP submicron particles scattered the excitation light (at $279 \pm 1 \mathrm{~nm}$ ) $\left[{ }^{19}\right]$. The fluorescence emission peaks (at $310 \pm 1 \mathrm{~nm}$ ) from E2-MIP and E2-NIP particles were slightly disturbed by the tail of this Mie scattering peak, but the fluorescence emission intensities after background subtraction were still valid for constructing Stern-Volmer plots (in Figure 3.4). Two Raman scattering peaks were found at wavelengths around $380 \mathrm{~nm}$ and $425 \mathrm{~nm}$; these light scattering peaks had no significant effects on the fluorescence emission intensities at $310 \pm 1 \mathrm{~nm}$. 


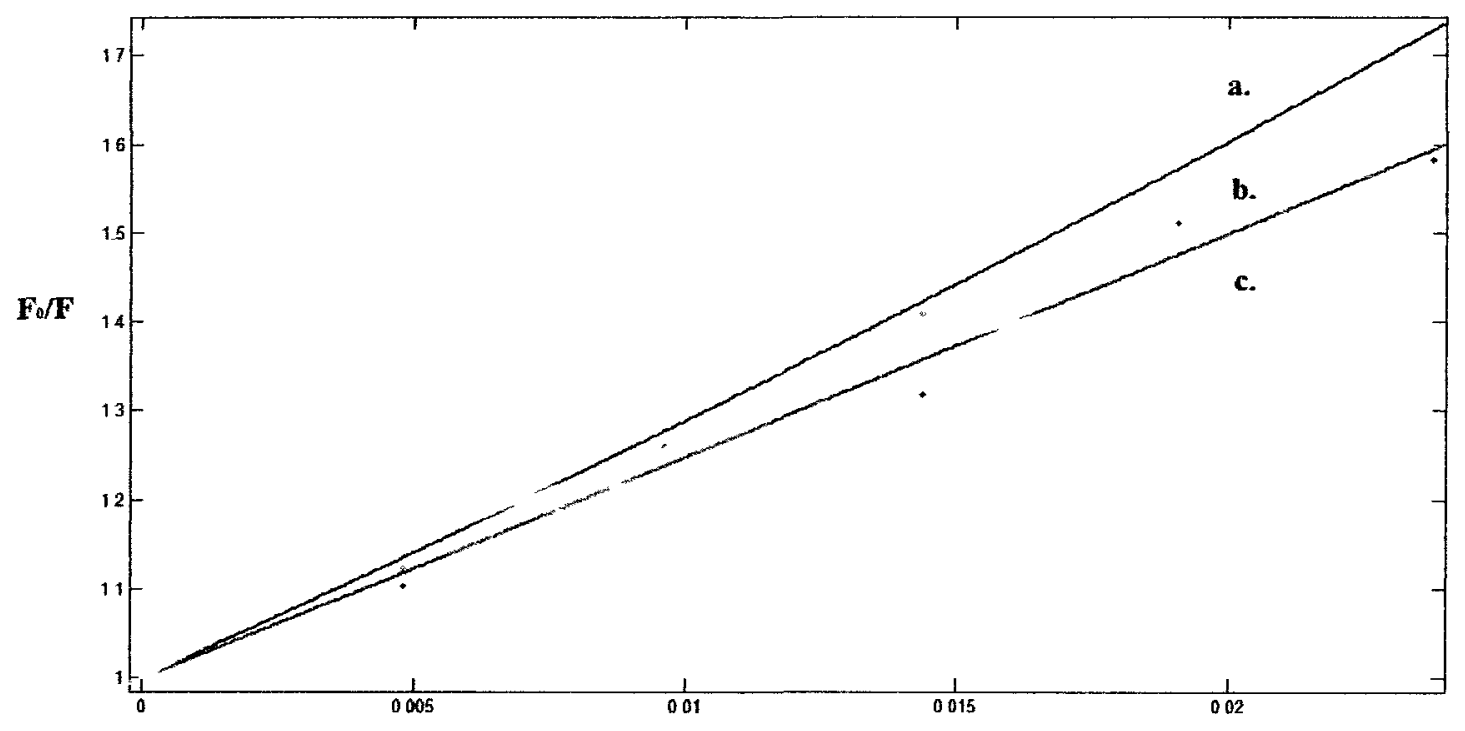

[Sodium nitrite] (M)

Figure 3.4 Stern-Volmer plots of $F_{0} / F$ versus concentration of sodium nitrite for (a) 4.5 ppm E2 aqueous solution, (b) $2.5 \mathrm{mg} / \mathrm{mL}$ E2-MIP particles in aqueous suspension, and (c) $2.5 \mathrm{mg} / \mathrm{mL}$ E2-NIP particles in aqueous suspension. The solid lines indicate the best fittings from nonlinear regression up to $0.025 \mathrm{M}$.

Stern-Volmer (S-V) plots for fluorescence quenching usually exhibit a linear relationship between $\mathrm{F}_{0} / \mathrm{F}$ vs. [Q] (see equation 1). If the $\mathrm{S}-\mathrm{V}$ plots show an upward-curving trend as evidenced by the data points in Figure 3.4, the positive deviations from linearity represent a combined result from both static and dynamic (or collisional) quenching $\left[{ }^{20}\right]$.

$$
F_{0} / F=\left(1+K_{\mathrm{sv}}[Q]\right) \exp ^{(V[Q])}
$$

where $\mathrm{V}$ is the static quenching constant.

The S-V plots for fluorescence quenching by sodium nitrite are shown in Figure 3.4. Nonlinear regression fitting, presented as solid lines through the data points, had correlation coefficients as high as 0.9836 . The black line (a) is a non-linear regression 
curve for the S-V plot of 4.5 ppm E2 aqueous solution. The quenching constants were simulated with $\mathrm{Matlab}^{\circledR}$ (R2008b) to obtain $\mathrm{K}_{\mathrm{sv}}=23.0 \pm 1.3 \mathrm{M}^{-1}$ and $\mathrm{V}=4.7 \pm 2.5 \mathrm{M}^{-1}$. The quenching constants for $2.5 \mathrm{mg} / \mathrm{mL}$ E2-MIP particles were $\mathrm{K}_{\mathrm{sv}}=21.8 \pm 1.3 \mathrm{M}^{-1}$ and $\mathrm{V}<1.00 \mathrm{M}^{-1}$. For E2-NIP particles, $\mathrm{K}_{\mathrm{sv}}=19.4 \pm 1.2 \mathrm{M}^{-1}$ and $\mathrm{V}<1.00 \mathrm{M}^{-1}$. Apparently, the MIP/NIP particles disturbed the static quenching process. This may be attributed to the binding mechanisms between E2 and MIP/NIP particles. As proposed by $\mathrm{Hu}$ and coworker, non-specific interaction (called surface binding) occurred between MIP particles and E2 molecules especially in water due to their hydrophobic nature, via hydrogen binding $\left[{ }^{18}\right]$. The static quenching constant for E2 aqueous solution was larger than those for E2-MIP/NIP particles. This means the E2 molecules were protected inside the particles. Some functional groups of the E2 molecule were no longer available to interact with the quencher and form a non-fluorescent complex. The $\mathrm{K}_{\mathrm{sv}}$ and $\mathrm{V}$ results for E2-MIP and E2-NIP particles were not very distinguishable due to the small size of nitrite anions. These small ions could easily infiltrate the porous MIP/NIP particles and quench the fluorescence of E2 molecules inside. Another disadvantage of using sodium nitrite as a quencher to investigate the porous structure of MIP particles by fluorescence quenching of E2 bound inside was that sodium nitrite exhibited a fluorescence emission peak (at $335 \pm 1 \mathrm{~nm}$ ) that interfered with the E2 fluorescence peak, especially at lower concentrations of E2 inside the particles. 

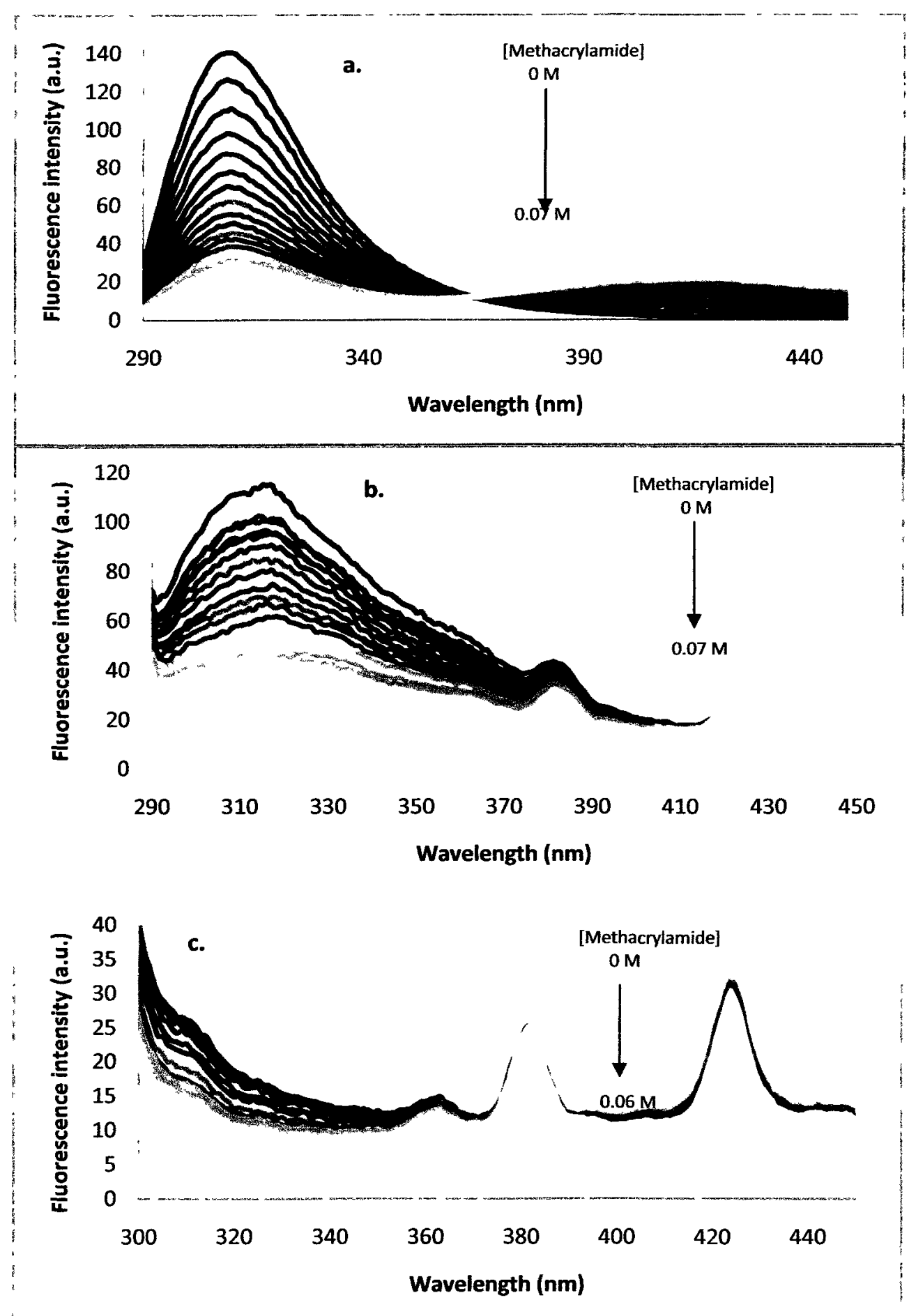

Figure 3.5 Fluorescence emission spectra of (a) $4.5 \mathrm{ppm}$ E2 aqueous solution, (b) 2.5 $\mathrm{mg} / \mathrm{mL}$ E2-MIP particles in aqueous suspension, and (c) $2.5 \mathrm{mg} / \mathrm{mL}$ E2-NIP particles in aqueous suspension, during titration with methacrylamide up to a final concentration of $0.07 \mathrm{M}$ (without causing any significant dilution effects). 
Unlike the ionic quencher (sodium nitrite), the molecular quencher methacrylamide has a larger size and more steric conformation. Figure 3.5 (a) shows the fluorescence emission spectra of $4.5 \mathrm{ppm}$ E2 aqueous solution progressively quenched by titration with methacrylamide. After $0.07 \mathrm{M}$ of methacrylamide was titrated into $3 \mathrm{~mL}$ of the E2 aqueous solution, approximately $86 \%$ of fluorescence emission from E2 was quenched. A broad fluorescence emission peak from methacrylamide was observed at $418 \pm 3 \mathrm{~nm}$ (but of low intensity (even for $0.07 \mathrm{M}$ ). Figures $3.5(\mathrm{~b})$ and (c) show the fluorescence quenching spectra of E2-MIP and E2-NIP particles, respectively. The increasing intensity at wavelengths below $300 \mathrm{~nm}$ was caused by Mie scattering (of the $279 \pm 1 \mathrm{~nm}$ excitation light) from the particles. This Mie scattering peak did not cause any significant interference with the measurement of E2 fluorescence emission intensity in this study. Apparently, $76 \%$ of fluorescence emission from the E2-MIP particles (in aqueous suspension) was quenched by $0.07 \mathrm{M}$ of methacrylamide, as well as $54 \%$ of fluorescence emission from the E2-NIP particles. 


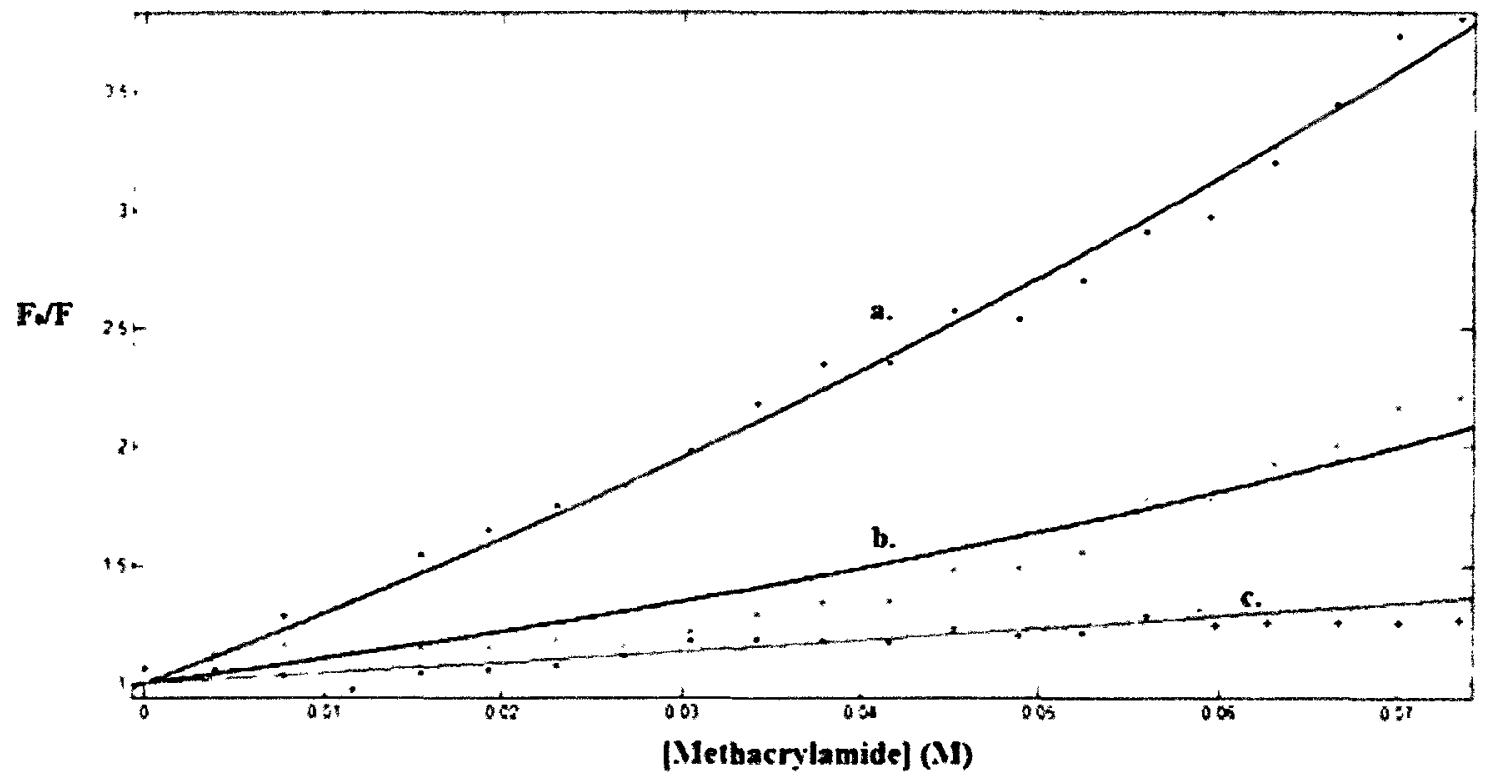

Figure 3.6 Stern-Volmer plots of $\mathrm{F}_{0} / \mathrm{F}$ versus concentration of methacrylamide for (a) 4.5 ppm E2 aqueous solution, (b) $2.5 \mathrm{mg} / \mathrm{mL}$ E2-MIP particles in aqueous suspension, and (c) $2.5 \mathrm{mg} / \mathrm{mL}$ E2-NIP particles in aqueous suspension. The solid lines indicate the best fittings from nonlinear regression.

The S-V plots for fluorescence quenching by methacrylamide are shown in Figure 3.6, nonlinear regression fitting, presented as solid lines through the data points had correlation coefficients as high as 0.9914 . The dynamic and static quenching constants for $4.5 \mathrm{ppm}$ E2 aqueous solution were $24.5 \pm 2.4 \mathrm{M}^{-1}$ and $4.0 \pm 1.0 \mathrm{M}^{-1}$, respectively. In comparison with sodium nitrite, methacrylamide exhibited quite similar dynamic and static quenching abilities. Both E2-MIP and E2-NIP particles exhibited very low dynamic quenching constants $\left(<1.00 \mathrm{M}^{-1}\right.$ for both E2-MIP and E2-NIP) but strong static quenching constants $\left(\mathrm{V}=9.9 \pm 2.0 \mathrm{M}^{-1}\right.$ for E2-MIP and $4.1 \pm 1.1 \mathrm{M}^{-1}$ for E2-NIP). One plausible explanation is that methacrylamide molecules are too large in size to be an effective dynamic quencher for collision with E2 molecules, bound inside the particles, under diffusion control. In this situation, static quenching became the dominant quenching mechanism for the E2. No significant steric hindrance existed for 
methacrylamide molecules to infiltrate the porous structure of MIP/NIP particles.

The MIP particles had a porous structure consisting of imprinted cavities to selectively bind with E2 molecule. These cavities were unique in size, shape and functional groups that matched the 3-D molecular structure of E2. Other molecules would not be able to bind with the MIP, or to disrupt the E2-MIP binding of strong affinity. For quenching of the fluorescence emission from E2 (bound inside the imprinted cavities), methacrylamide might not suitable because it is sterically hindered in penetrating the imprinted cavities of MIP particles. However, the nitrite anions have a small size and planar 2-D structure, which facilitated their infiltration of MIP particles and get into the imprinted cavities with minimal resistance. This allowed the nitrite anions to penetrate the imprinted cavities and collide with the bound E2 molecules (which resulted in dynamical quenching of the fluorescence emission from E2 molecules). Contrarily, the methacrylamide molecules are too large to have this penetration capability for dynamic quenching the fluorescence emission from E2 inside of MIP cavities. The dynamic quenching constants of methacrylamide for E2-MIP particles (in aqueous suspension) were reasonably small ( $\mathrm{K}_{\mathrm{sv}}$ $<1.0 \mathrm{M}^{-1}$ ). In fact, E2 aqueous solutions exhibited decreasing dynamic quenching constant values, with lower concentrations of E2 aqueous solution because the chance of collision between E2 molecules and quenchers would become smaller. Low E2 concentrations also caused decreasing static quenching constant values for both quenchers. The static quenching constant is based on the formation of 1:1 dark complex. When the concentration of E2 got lower, the rate of complex formation would be reduced and thus the static quenching constant values would decrease concomitantly. The static quenching constants for different concentrations of E2-MIP particles are interesting to 
examine. The quenching constant values for methacrylamide decreased with decreasing E2-MIP concentrations, which was the same with E2 aqueous solutions. For nitrite, the increasing static quenching constants with decreasing E2-MIP concentrations were caused by the artifact of fluorescence emission interference by the nitrite anion (around $335 \mathrm{~nm}$ ). This presents a major disadvantage of using sodium nitrite in step (f) of the method described in the Introduction section, especially during the sensing of E2 at trace levels.

The NIP particles had similarly a porous structure like the MIP particles. A major difference was that, during the NIP preparation, E2 was not present as template molecules in the polymerization. Due to the absence of template molecules, the NIP particles lacked the 3-D imprinted cavities for selective binding with E2. However, the observed quenching constants for E2-NIP were remarkably different from those of E2 aqueous solution. The dynamic quenching constant for E2-NIP particles with sodium nitrite decreased its value from $19.4 \mathrm{M}^{-1}$ to less than $1.0 \mathrm{M}^{-1}$ when the concentration of particles was reduced from $2.5 \mathrm{mg} / \mathrm{mL}$ to $0.1 \mathrm{mg} / \mathrm{mL}$. This also can be explained with the less opportunity to have collision between E2-NIP particles and nitrite ions. When methacrylamide was used to quench the fluorescence emission from E2-NIP particles, the dynamic quenching constant values were mostly less than $1.0 \mathrm{M}^{-1}$. This phenomenon may be explained by the interaction between the MAA-based NIP particles with methacrylamide due to similarity in molecular structure. Nonetheless, this interaction prevented collision between the bound E2 and methacrylamide.

\subsection{Conclusion}

Several interesting physico-chemical results were obtained from our experiments: (1) the 
particle sizes of MIP and NIP are $477 \pm 11 \mathrm{~nm}$ and $373 \pm 21 \mathrm{~nm}$ in diameter, possibly as the result of adding E2 as a template in the former; (2) the fluorescence emission peaks of E2-MIP and E2-NIP are both found at $\lambda_{\mathrm{em}}=310 \pm 1$ when using $\lambda_{\mathrm{ex}}=280 \pm 1 \mathrm{~nm}$. No difference is observed between the excitation and emission spectra of E2-MIP and E2NIP; (3) the non-linear fluorescence quenching model is properly elucidating the porous structure of MIP and NIP particles. The small 2-D planar nitrite ions penetrate the pores and quench the fluorescence emission from E2 inside by collision; a significant decrease of the dynamic quenching constant is obtained. Contrarily, the large 3-D stearic methacrylamide molecules are hindered in penetrating the pores, resulting in much smaller dynamic quenching constant values than those for the nitrite ion. Further research will be carried out in our lab to find a larger quencher molecule (than methacrylamide) to fulfill step (c) in the method described in the Introduction section. Metal nano-particles with a size hundreds of times larger than organic quenchers will be adopted in our further E2-MIP/E2-NIP fluorescence quenching research. For instance, Au nano-particles with a diameter ranging from 5-50 $\mathrm{nm}$ are an ideal large-size quencher for step (c) $\left[^{21,22,23}\right]$. A better quencher ion (than nitrite) will also be needed for step (f) of the method, especially during the sensing of $\mathrm{E} 2$ at trace levels.

Nevertheless, methacrylamide is a functional monomer that has previously used to prepare MIP particles $\left[{ }^{24}\right]$. All methacrylamide-based MIP particles have a fluorescence quencher built in them. It can directly quench the fluorescence emission from any template molecules bound inside imprinted cavities $\left[{ }^{25}\right]$. These particles can serve in the quick monitoring of E2 concentration in a water sample, by easily measuring the reduction of fluorescence emission from the sample (due to quenching) after E2 
molecules bind with the particles with strong affinity and high selectivity. In our future work, an E2 biochemical sensor will be constructed of methacrylamide-based MIP. It can quickly determine the unknown E2 concentration in environmental water samples, or the E2 level in pre-menopausal woman's body fluids for her health care. 


\section{References:}

[1] C.J. Allender, "Molecularly imprinted polymers: technology and applications Preface," Adv. Drug Deliver Rev., vol. 57, no. 12, pp. 1731-1732, 2005.

[2] R. Rajkumar, M. Katterle, A. Warsinke, H. Moehwald, F.W. Scheller, "Thermometric MIP sensor for fructosyl valine," Biosensors \& Bioelectronics, vol. 23, no. 7, pp. 11951199, 2008.

[3] K. Yano, I. Karube, "Molecularly imprinted polymers for biosensor applications," Trac-Trend Anal Chem, vol. 18, no. 3, pp. 199-204, 1999.

[4] K. Uezu, H. Nakamura, J. Kanno, T. Sugo, M. Goto, F. Nakashio, "Metal ionimprinted polymer prepared by the combination of surface template polymerization with postirradiation by gamma-rays," Macromolecules, vol. 30, no. 13, pp. 3888-3891, 1997.

[5] N. Gao, Z. Xu, F. Wang, S.J. Dong, "Sensitive biomimetic sensor based on molecular imprinting at functionalized indium tin oxide electrodes," Electroanal, vol. 19, no. 16, pp. 1655-1660, 2007.

[6] L. Schweitz, L.I. Andersson, S. Nilsson, "Rapid electrochromatographic enantiomer separations on short molecularly imprinted polymer monoliths," Anal Chim Acta, vol. 435, no. 1, pp. 43-47, 2001.

[7] E. Caro, R.M. Marce, F. Borrull, P.A.G. Cormack, D.C. Sherrington, "Application of molecularly imprinted polymers to solid-phase extraction of compounds from environmental and biological samples," Trac-Trend Anal Chem, vol. 25, no. 2, pp. 143$154,2006$.

[8] C.S.A.G. Papanicolaou, "The existence of a typical oestrous cycle in the guinea pig; with a study of its histological and physiological changes," Am. J. of Anat., vol. 22, no. 2, pp. 225-283, 1917.

[9] E. Allen, A.E. Doisy, "An ovarian hormone: Preliminary report on its localization, extraction, and partial purification and actions in test animals," J. Am. Med. Assoc., vol. 81, no. 10, pp. 819-821, 1923.

[10] M. Luconi, G. Forti, E. Baldi, "Genomic and nongenomic effects of estrogens: molecular mechanisms of action and clinical implications for male reproduction," $J$. Steroid Biochem Mol Biol, vol. 80, no. 4-5, pp. 369-381, 2002.

[11] N.B. Ojeda, D. Grigore, E.B. Robertson, B.T. Alexander, "Estrogen protects against increased blood pressure in postpubertal female growth restricted offspring," Hypertension, vol. 50, no. 4, pp. 679-685, 2007.

[12] B. Brunstrom, J. Axelsson, A. Mattsson, K. Halldin, "Effects of estrogens on sex 
differentiation in Japanese quail and chicken," Gen Comp Endocrinol, vol. 163, no. 1-2, pp. 97-103, 2009.

[13] G.J. Pepe, E.D. Albrecht, "Actions of placental and fetal adrenal steroid hormones in primate pregnancy," Endocr Rev, vol. 16, no. 5, pp. 608-648, 1995.

[14] E.D. Albrecht, G.W. Aberdeen, G.J. Pepe, "The role of estrogen in the maintenance of primate pregnancy," Am J Obstet Gynecol, vol. 182, no. 2, pp. 432-438, 2000.

[15] R.J. Golden, K.L. Noller, L. Titus-Ernstoff, R.H. Kaufman, R. Mittendorf, R. Stillman, E.A. Reese, "Environmental endocrine modulators and human health: an assessment of the biological evidence," Crit Rev Toxicol, vol. 28, no. 2, pp. 109-227, 1998.

[16] S. Wei, A. Molinelli, B. Mizaikoff, "Molecularly imprinted micro and nanospheres for the selective recognition of 17beta-estradiol," Biosens Bioelectron, vol. 21, no. 10, pp. 1943-1951, 2006.

[17] R.A. Leese, E.L. Wehry, "Corrections for inner-filter effects in fluorescence quenching measurements via right-angle and front-surface illumination," Anal Chem, vol. 50, no. 8, pp. 1193-1197, 1978.

[18] Z. Zhongbo, J. Hu, "Selective removal of estrogenic compounds by molecular imprinted polymer (MIP)," Water Res, vol. 42, no. 15, pp. 4101-4108, 2008.

[19] Y. Yang, E.P.C. Lai, M. Liu, "Spectroscopic analysis of poly (methacrylic acid-coethylene glycol dimethacrylate) submicron particles by fluorescence emission and light scattering upon binding with 17ß-estradiol in water treatment," The Open Colloid Science Journal, vol. 3, no. 8, pp. 1-8, 2010.

[20] J.R. Lakowicz, Principles of fluorescence spectroscopy, third ed., Springer, 2006.

[21] J. Zhang, R. Badugu, J.R. Lakowicz, "Fluorescence quenching of CdTe nanocrystals by bound gold nanoparticles in aqueous solution," Plasmonics, vol. 3, no. 1, pp. 3-11, 2008 .

[22] S.Y. Lim, J.H. Kim, J.S. Lee, C.B. Park, "Gold nanoparticle enlargement coupled with fluorescence quenching for highly sensitive detection of analytes," Langmuir. vol. 25, no. 23, pp. 13302-13305, 2009.

[23] S. Mayilo, M.A. Kloster, M. Wunderlich, A. Lutich, T.A. Klar, A. Nichtl, K.K. rzinger, F.D. Stefani, J. Feldmann, "Long-range fluorescence quenching by gold nanoparticles in a sandwich immunoassay for cardiac troponin T," Nano letters, vol. 9, no. 12, pp. 4558-4563, 2009.

[24] V. Pichon, F. Chapuis-Hugon, "Role of molecularly imprinted polymers for selective 
determination of environmental pollutants-A review," Anal. Chim. Acta, vol. 622, no. 12, pp. 48-61, 2008.

[25] C.I. Lin, A.K. Joseph, C.K. Chang, Y.D. Lee, "Synthesis and photoluminescence study of molecularly imprinted polymers appended onto CdSe/ZnS core-shells," Biosensor and Bioelectronics, vol. 20, no. 1, pp. 127-131, 2004 


\section{Chapter 4}

\section{Molecularly Imprinted Polymer Particles for Rapid Determination of $17 \beta$-Estradiol in Water by Fluorescence Quenching}

\subsection{Introduction}

MIPs exhibiting high selectivity and affinity to the target molecule are well recognized as a fast growing research field $\left[{ }^{1,2}\right]$. They have been successfully applied in various novel methods of chemical analysis $[3,4]$, including potentiometric sensors $\left[{ }^{5,6,7}\right]$, amperometric detection $\left[{ }^{8}\right]$ and differential pulse cathodic stripping voltammetry $\left[{ }^{9}\right]$. An optical sensor was fabricated with a MIP film for the determination of formaldehyde molecules that induced measurable optical reflectivity shifts $\left[{ }^{10}\right]$. For surface plasmon resonance spectroscopy, MIP particles were spin-coated onto a gold surface to detect theophylline $\left[{ }^{11}\right]$. MIP fibers were used in a sensing device to determine folic acid $\left[{ }^{12}\right]$.

A novel sensing scheme based on non-linear fluorescence quenching of $17 \beta$-estradiol (E2) was recently developed in our lab $\left[{ }^{13}\right]$. Small nitrite ions penetrated the porous structure of MIP particles and quenched the fluorescence emission from E2 molecules inside imprinted cavities. On the contrary, large methacrylamide molecules (3-D stearic diameter $=0.536 \mathrm{~nm}$ ) were hindered when penetrating the pores to access the imprinted cavities, resulting in low dynamic quenching. Research was continued in our lab to evaluate larger quenchers, such as gold nano-particles (AuNPs) that could readily be synthesized with a diameter of $43 \pm 5 \mathrm{~nm}\left[{ }^{14,15,16}\right]$. Their effectiveness was studied with regard to quenching the fluorescence of only non-specifically bound E2 molecules throughout the porous MIP particles, but not those specifically bound inside the imprinted cavities, as illustrated in Scheme 4.1. The objective of this work was to 
develop a rapid method (hopefully under $5 \mathrm{~min}$ ) for the determination of trace E2 in water (down to $0.1 \mathrm{ppb}$ ).

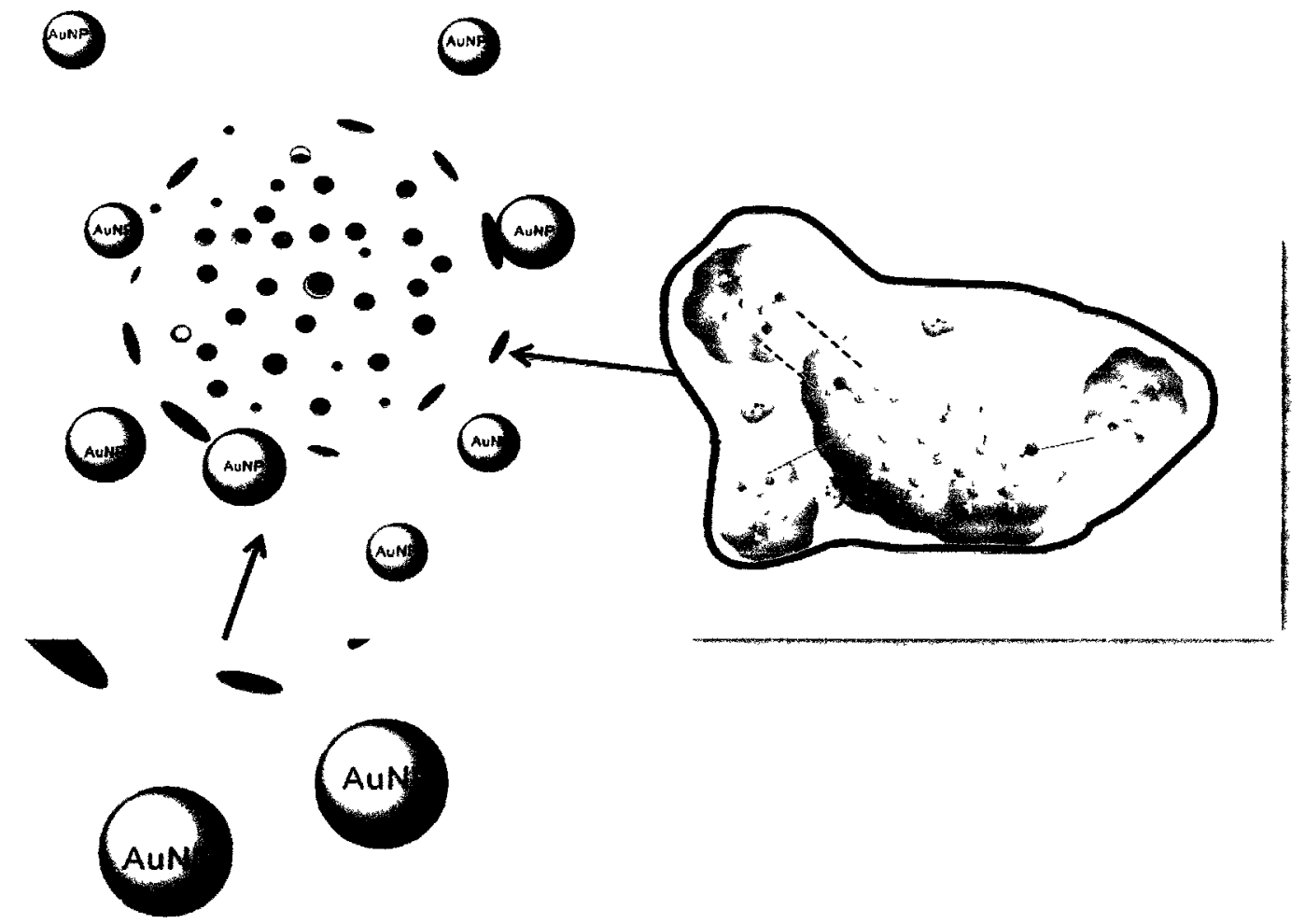

Scheme 4.1: Larger AuNPs were used in the first step of fluorescence quenching to quench E2 molecules non-specifically bound throughout the porous MIP particle, while small nitrite anions were easily penetrate the MIP particle to quench the fluorescence emission from E2 molecules specifically bound inside imprinted cavities in the second step of fluorescence quenching. The attenuated fluorescence emission intensity between step 1 and step 2 varies as a function of $\mathrm{E} 2$ concentration.

\subsection{Experimental Section}

\subsubsection{Chemicals.}

Sodium citrate tribasic dihydrate, gold (III) chloride trihydrate, sodium nitrite and E2 were purchased from Sigma-Aldrich (St. Louis, MO, USA). Methacrylic acid and methacrylamide were purchased from Aldrich (Milwaukee, WI, USA). 2,2- 
Azobisisobutyro-nitrile (AIBN) was purchased from Pfaltz \& Bauer (Waterbury, CT, USA). Methanol (HPLC grade), acetonitrile (HPLC grade) and acetone (spectro grade) were purchased from Caledon (Georgetown, ON, Canada). Acetic acid (reagent grade) was purchased from Anachemia (Montreal, QC, Canada). 18-M $2 . \mathrm{cm}$ distilled deionized water (DDW) was obtained from a Millipore Milli-Q water system (Bedford, MD, USA).

\subsubsection{Preparation of MIP submicron particles and AuNPs.}

The method for preparation of E2 MIP submicron particles had previously been described $\left[{ }^{17}\right]$. These particles $(80 \mathrm{~mL})$ were washed with $15 \%$ acetic acid in methanol $(\mathrm{v} / \mathrm{v})$, methanol, acetonitrile and DDW three times. Each washing was combined with $1 \mathrm{hr}$ of sonication and $1 \mathrm{hr}$ of centrifugation to completely extract template E2 molecules from the particles and remove polymerization reagent residues. After the last washing with $\mathrm{DDW}$, the $\mathrm{pH}$ was $5.5 \pm 0.1$ in the supernatant and the free $\mathrm{E} 2$ concentration was below the detection limit of HPLC-FD instrument. These washed MIP submicron particles were dried at $70^{\circ} \mathrm{C}$. Another batch of freshly prepared MIP submicron particles was washed only with DDW for 25 times. These washed E2-MIP particles would contain the

maximum E2 loading $\left[{ }^{13}\right]$. AuNPs were synthesized by adapting a previously reported method $\left[{ }^{18}\right]$. No washing was applied to these AuNPs.

\subsubsection{Particle size analysis.}

The AuNPs, MIP and E2-MIP particles were suspended in $10 \mathrm{M} \mathrm{KNO}_{3}$ at a concentration of $40 \mathrm{mg} / \mathrm{mL}$. The suspensions were sonicated for $15 \mathrm{~min}$ before measurement on a NanoDLS particle size analyzer (Brookhaven Instruments, Holtsville, New York, USA). 
The instrument had been calibrated by $92 \pm 4 \mathrm{~nm}$ Nanosphere ${ }^{\mathrm{TM}}$ size standards (Duke Scientific, Palo Alto, CA, USA). A total of 10 measurements were run after 5 min of quiescence time, and the laser beam intensity was automatically optimized by the analyzer before each run.

\subsubsection{Fluorescence quenching.}

$3.5 \mathrm{ppm} \mathrm{E2}(2 \mathrm{~mL})$ and $2.5 \mathrm{mg} / \mathrm{mL}$ E2-MIP particles $(2 \mathrm{~mL})$ were added into two $3-\mathrm{mL}$ quartz cuvette cells, each equipped with a polytetrafluoroethylene (PTFE) stopper. Then 1 $\mathrm{mL}$ of AuNPs aqueous suspension with elemental concentrations from $0 \mathrm{M}$ to $5.88 \times 10^{-4}$ M was used to quench the E2 and E2-MIP particles fluorescence emission intensities. All emission intensities were measured at room temperature $\left(20 \pm 1^{\circ} \mathrm{C}\right)$ by a spectrofluorometer (Varian Cary Eclipse, Palo Alto, CA, USA) using excitation wavelength of $280 \pm 1 \mathrm{~nm}$ and emission wavelength of $310 \pm 1 \mathrm{~nm}$ (or scanning from 290 $\mathrm{nm}$ to $450 \mathrm{~nm}$ ). Both the excitation and emission slits were set at $5 \mathrm{~nm}$. To test for inner filter effect, $1 \mathrm{~mL}$ of $1 \%(\mathrm{w} / \mathrm{w})$ trisodium citrate dihydrate was used instead of AuNPs. Similarly, E2 and E2-MIPs fluorescence quenching experiments with sodium nitrite were accomplished under exactly the same experimental conditions.

Two-step fluorescence quenching by first AuNPs and then sodium nitrite was performed. $7.7 \pm 0.1 \mathrm{mg}, 5.5 \pm 0.1 \mathrm{mg}, 3.3 \pm 0.1 \mathrm{mg}$ and $1.1 \pm 0.1 \mathrm{mg}$ of template-removed MIP submicron particles were added into $2.2 \mathrm{~mL}$ of E2 aqueous solution with concentrations from $0.0001 \mathrm{ppm}$ to $3.5 \mathrm{ppm}$. The blank and E2-templated MIP particles were prepared by using the same amount of template-removed MIPs and E2-MIP particles suspended in $2.2 \mathrm{~mL}$ of DDW. All of these suspensions were incubated under sonication for 5-35 min 
at room temperature $\left(20 \pm 1^{\circ} \mathrm{C}\right)$. Then, $2.0 \mathrm{~mL}$ of E2-bound NIP or E2-MIP submicron particle suspension was transferred into a 3-mL quartz cuvette cell and spiked with $1 \mathrm{~mL}$ of $5.88 \times 10^{-4} \mathrm{M}$ AuNPs aqueous suspension. After the fluorescence emission intensity was recorded, $100 \mu \mathrm{L}$ of $150 \pm 1 \mathrm{mg} / \mathrm{mL}$ sodium nitrite was added to perform the second step of fluorescence quenching.

All light absorption spectra by quenchers were measured on a UV-visible spectrophotometer (Varian Cary 3, Palo Alto, CA, USA) by scanning from $250 \mathrm{~nm}$ to 350 $\mathrm{nm}$ at room temperature $\left(20 \pm 1^{\circ} \mathrm{C}\right)$ to investigate the inner filter effect. The absorption of both exciting light $\left(\lambda_{\mathrm{ex}}=280 \pm 1 \mathrm{~nm}\right)$ and fluorescence emission $\left(\lambda_{\mathrm{em}}=310 \pm 1 \mathrm{~nm}\right)$ by quenchers was corrected, for right-angle illumination, as described elsewhere $\left[{ }^{19}\right]$.

\subsection{Results and Discussion}

\subsubsection{Fluorescence quenching.}

E2 is a naturally fluorescent compound. After it interacts with non-fluorescent MIP particles both specifically and non-specifically $\left[{ }^{20}\right]$, the bound E2 molecules can be determined by spectrofluorimetry $\left(\lambda_{\mathrm{ex}}=280 \mathrm{~nm}\right.$ and $\left.\lambda_{\mathrm{em}}=310 \mathrm{~nm}\right)\left[{ }^{21}\right]$. Figure 1 shows the fluorescence emission spectra of E2, E2-MIP particles and E2-bound NIP particles during their quenching by AuNPs. Without particles, a 3.5 ppm E2 aqueous solution exhibited decreasing fluorescence intensities when AuNPs were added stepwise as shown in Figure 4.1(a). The fluorescence intensity decreased by almost $82 \%$ from the initial level as the concentration of AuNPs reached $5.88 \times 10^{-4} \mathrm{M}$. Similarly, the quenching effects of AuNPs on E2-MIP particles and E2-bound NIP particles are evidenced in Figures 4.1(b) and 1(c), decreasing the fluorescence intensity by $76 \%$ and $77 \%$. The strong Mie 
scattering peak (at $280 \mathrm{~nm}$ ) from particles slightly enhanced all E2 fluorescence emission peaks at $310 \mathrm{~nm}$, which can be considered meritorious for the determination of E2 at trace levels. Two Raman scattering peaks (at $380 \mathrm{~nm}$ and $425 \mathrm{~nm}$ ) were characteristic of particles when an excitation wavelength of $280 \mathrm{~nm}$ was used. Luckily, they did not have any significant impact on the fluorescence quenching results. 

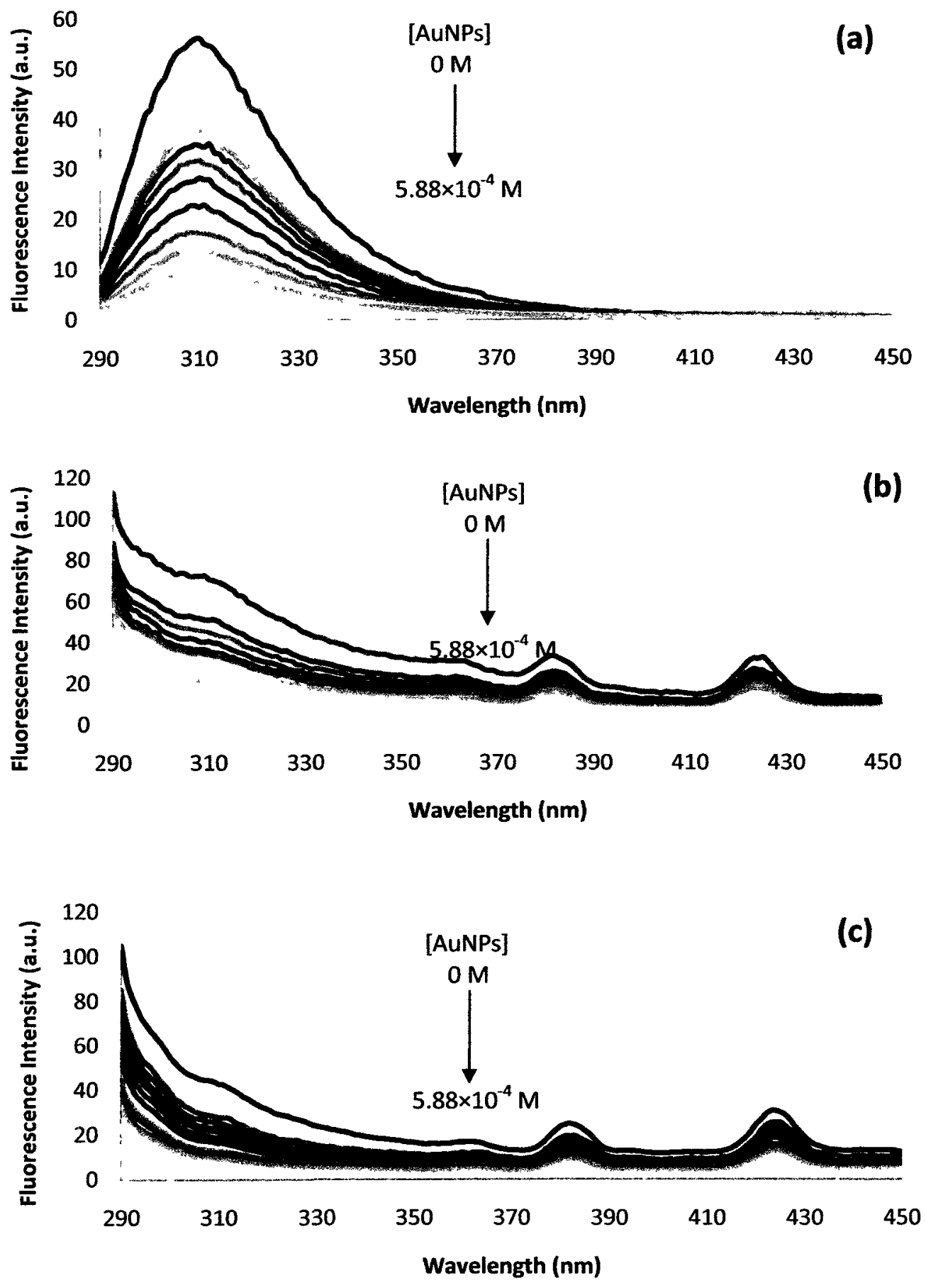

Figure 4.1 Fluorescence emission spectra of (a) 3.5 ppm E2 aqueous solution, (b) 2.5 $\mathrm{mg} / \mathrm{mL}$ E2-MIP particles in aqueous suspension, and (c) $2.5 \mathrm{mg} / \mathrm{mL} \mathrm{E2-}$ bound NIP particles in aqueous suspension, during fluorescence quenching by AuNPs from $0 \mathrm{M}$ to $5.88 \times 10^{-4} \mathrm{M}$. $\left(\lambda_{\mathrm{ex}}=280 \mathrm{~nm}\right)$ 
The fluorescence properties of AuNPs were studied before they were used as a large fluorescence quencher in all subsequent experiments. When $5.88 \times 10^{-4} \mathrm{M}$ of AuNPs were examined by scanning the excitation wavelength in Figure 4.2(a) and using an emission wavelength of $310 \mathrm{~nm}$, only one Mie scattering peak was observed at $310 \mathrm{~nm}$. When the emission wavelength was scanned in Figure 4.2(b) using an excitation wavelength of 280 $\mathrm{nm}$, only two Mie scattering peaks were found at $280 \mathrm{~nm}\left(1^{\text {st }}\right.$ order$)$ and $570 \mathrm{~nm}\left(2^{\text {nd }}\right.$ order). Therefore the AuNPs were non-fluorescent, making them ideal for use as fluorescence quencher in this work. Figure 4.2(c) shows the fluorescence emission spectrum of 3.5 ppm E2 aqueous solution while Figure 4.2(d) shows the same spectrum after addition of trisodium citrate dehydrate $(1 \% \mathrm{w} / \mathrm{w})$. No significant inner filter effect was observed from $1 \%$ trisodium citrate dihydrate, which was present in the synthesis of AuNPs.

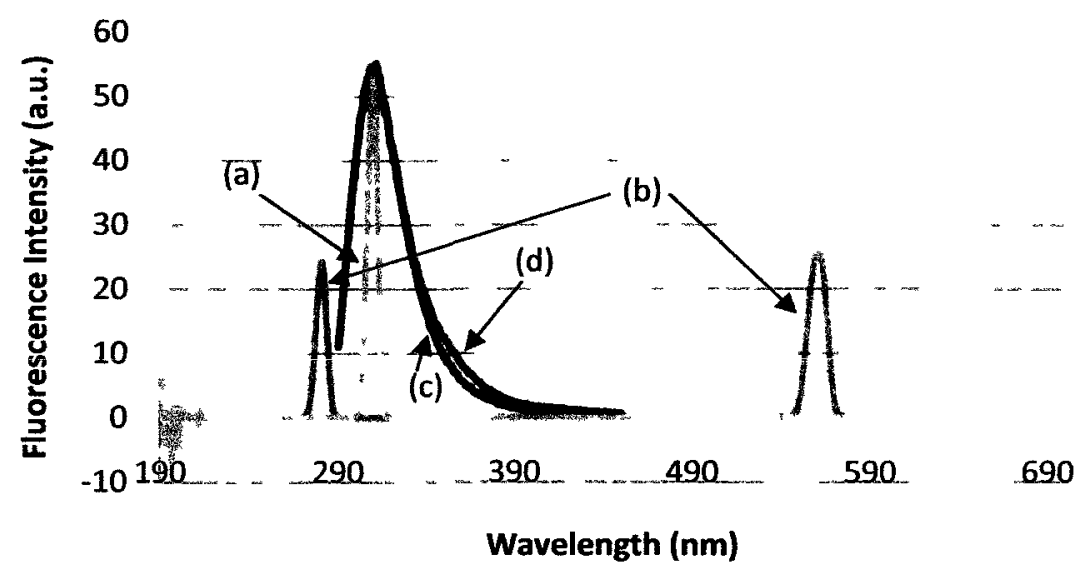

Figure 4.2 (a) Fluorescence excitation spectrum of AuNPs aqueous suspension $\left(\lambda_{\mathrm{em}}=\right.$ $310 \mathrm{~nm}$ ), (b) fluorescence emission spectrum ( $1^{\text {st }}$ and $2^{\text {nd }}$ orders) of AuNPs aqueous suspension $\left(\lambda_{\mathrm{ex}}=280 \mathrm{~nm}\right.$ ), (c) fluorescence emission spectrum of E2 aqueous solution $\left(\lambda_{\mathrm{ex}}=280 \mathrm{~nm}\right)$, and (d) fluorescence emission spectrum of $\mathrm{E} 2$ aqueous solution in presence of trisodium citrate dihydrate $(1 \% \mathrm{w} / \mathrm{w})$ $\left(\lambda_{\mathrm{ex}}=280 \mathrm{~nm}\right)$. 
In our previous study $\left[{ }^{13}\right]$, sodium nitrite was able to quench the fluorescence emissions from E2 aqueous solution, E2-MIP aqueous suspension, and E2-bound NIP aqueous suspension. Hence, it was used in this work to finish the fluorescence quenching job after AuNPs quenched only the fluorescence emission from E2 that were non-specifically bound inside particles. As shown in Figure 4.3, the residual fluorescence emission from $2.5 \mathrm{mg} / \mathrm{mL}$ E2-MIP particles in aqueous suspension, after quenching with $5.88 \times 10^{-4} \mathrm{M}$ AuNPs, was an intensity of $14.2 \pm 0.2$ arbitrary units (a.u.) coming from E2 specifically bound inside the MIP cavities. Sodium nitrite was then titrated, stepwise from $0 \mathrm{M}$ to $6.5 \times 10^{-2} \mathrm{M}$, into the mixture of E2-MIP particles and AuNPs. Due to its small size, the nitrite anion penetrated through the porous MIP particles and quenched the fluorescence emission from the specifically bound E2 molecules. At the end of titration, the emission intensity was reduced to $5.5 \pm 0.2$ a.u. This result clearly demonstrated how simple it was to determine the amount of specifically bound E2 molecules.

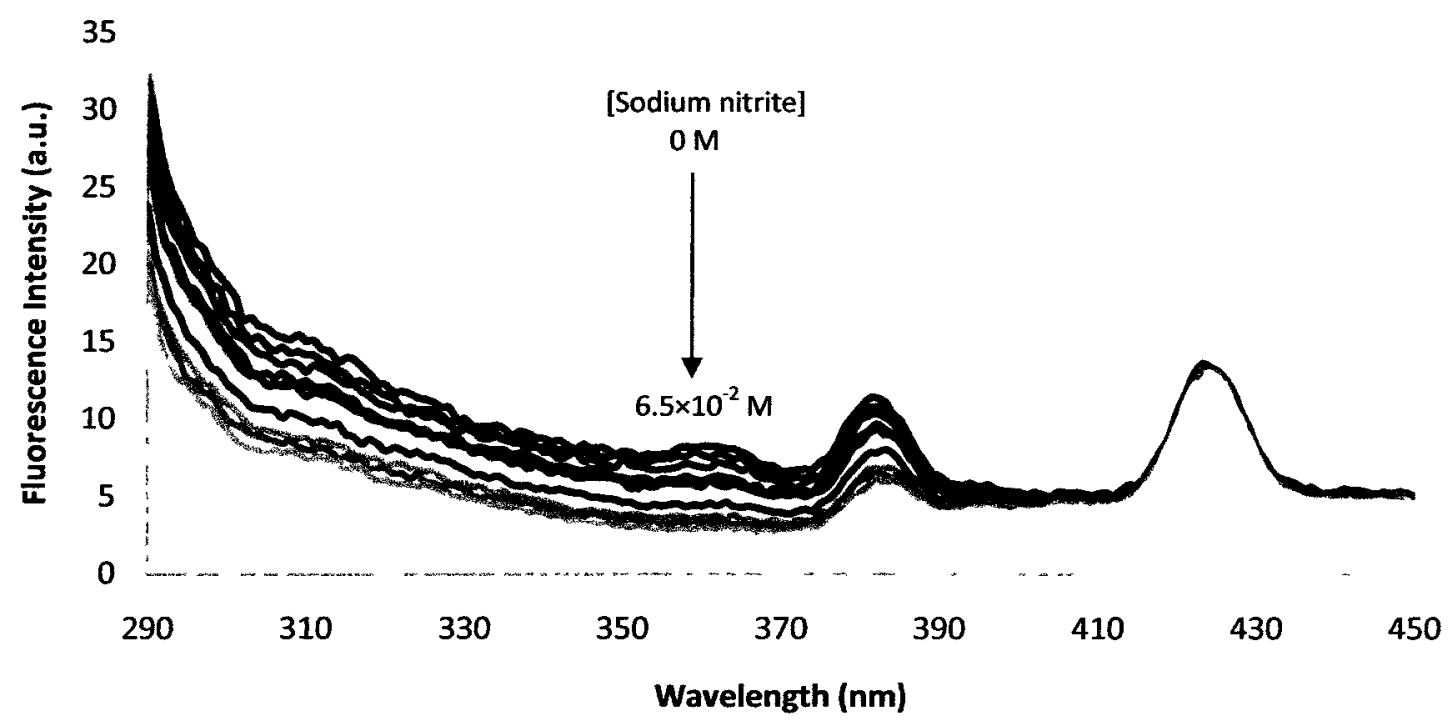

Figure 4.3 Fluorescence emission spectra during titration of sodium nitrite (up to a final concentration of $6.5 \times 10^{-2} \mathrm{M}$ ) into a mixture of $2.5 \mathrm{mg} / \mathrm{mL}$ E2-MIP particles and $5.88 \times 10^{-4} \mathrm{M}$ AuNPs. The titration consisted of fifteen $10-\mu \mathrm{L}$ spikes of $100 \mathrm{mg} / \mathrm{mL}$ sodium nitrite to minimize any dilution effect $(\sim 6 \%)$. 
Figure 4.4 plots all the fluorescence emission intensities measured (at $310 \mathrm{~nm}$ ) from Figure 4.1 and Figure 4.3. Intuitively, both free E2 molecules in aqueous solution and non-specifically bound E2 molecules in NIP particles (which had no imprinted cavities) in aqueous suspension were all accessible by AuNPs to undergo collisional quenching. If there were no imprinted cavities in MIP particles to protect the specifically bound E2 molecules (from quenching by AuNPs), the final emission intensity in 4.4(a) would probably be as low as the $\sim 10$ a.u. in 4.4(b) and 4.4(c) plots when the AuNPs quencher concentration reached $38.7 \mathrm{ppm}\left(=5.88 \times 10^{-4} \mathrm{M}\right)$. In reality, the E2-MIP particles contained some inaccessible E2 molecules that contributed to a higher final emission intensity of $\sim 18$ a.u. 


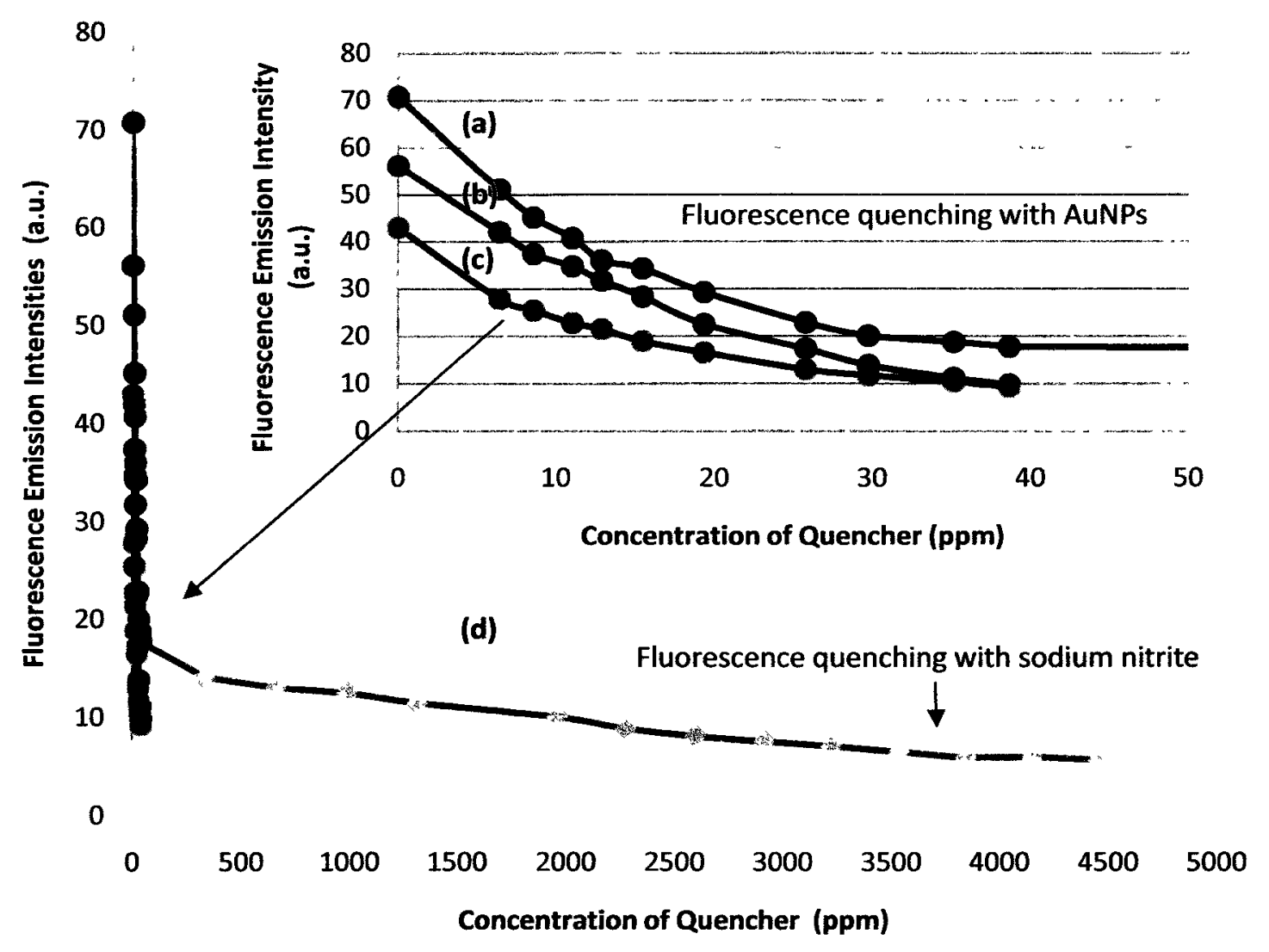

Figure 4.4 Fluorescence emission intensity at $310 \mathrm{~nm}$ versus concentration of quencher: (a) $2.5 \mathrm{mg} / \mathrm{mL}$ E2-MIP particles in aqueous suspension quenched with AuNPs, (b) $3.5 \mathrm{ppm}$ E2 aqueous solution quenched with AuNPs, (c) $2.5 \mathrm{mg} / \mathrm{mL}$ E2bound NIP particles in aqueous suspension quenched with AuNPs, (d) 2.5 $\mathrm{mg} / \mathrm{mL}$ E2-MIP particles in aqueous suspension going through two steps of fluorescence quenching, first with AuNPs and next with sodium nitrite. (Standard error bars, approximately three times the size of each data point symbol, are omitted here for the sake of clarity).

\subsubsection{Quencher sizes and efficiencies.}

The MIP and NIP particles studied in this work had diameters, as measured by a nanoDLS particle size analyzer, of $477 \pm 11 \mathrm{~nm}$ and $373 \pm 21 \mathrm{~nm}$, respectively. E2 molecules were specifically bound inside the MIP cavities that were complementary in size, shape and arrangement of functional groups. Small nitrite anions could easily penetrate the porous MIP particles and quench the fluorescence from the E2 molecules by 
dynamic collisions. The large AuNPs used in this study had a diameter of $43 \pm 5 \mathrm{~nm}$. Figure 4.5 shows the correlation of light scatting intensity with time, as obtained for AuNPs during a particle size measurement. Over 10 runs, the particle size readings varied between $33 \mathrm{~nm}$ and $85 \mathrm{~nm}$ with a polydispersity of 0.3 (moderate dispersion). The size range seemed to be suited for fluorescence quenching of E2 molecules that were non-specifically bound to MIP particles.

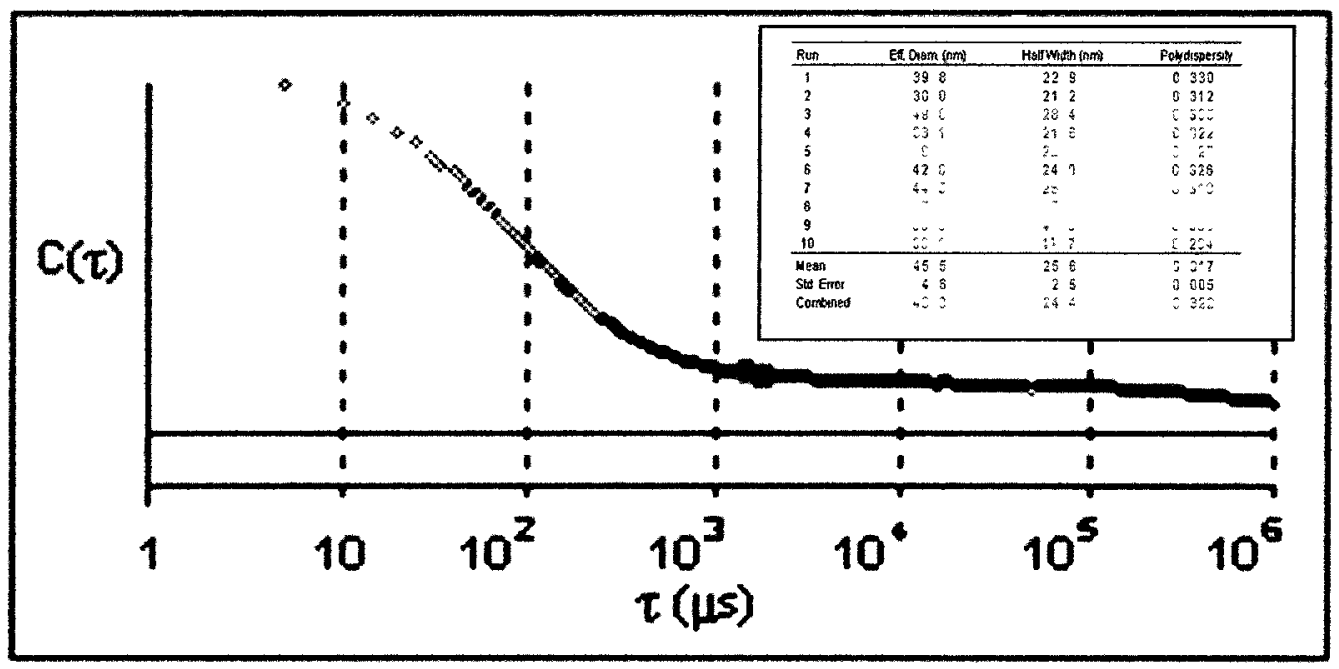

Figure 4.5 Correlation of light scatting intensity with time for measuring the size of AuNPs on a nanoDLS particle size analyzer.

Figure 4.6 plots the fluorescence quenching efficiency $\left(\theta=1-F / F_{0}\right.$, where $F$ and $F_{0}$ are the fluorescence emission intensities measured in the presence and absence of quencher) versus the concentration of quencher. With AuNPs, similar quenching efficiencies were observed for both particles and E2 in figure 4.6(a), (b) and (c). By comparison, sodium nitrite exhibited significantly lower quenching efficiency in figure 4.6(d) and (e). Approximately $4500 \mathrm{ppm}$ sodium nitrite was needed in figure $4.6(\mathrm{e})$ to quench $80 \%$ of fluorescence emission from E2-MIP particles although only $38.7 \mathrm{ppm}$ AuNPs was needed in figure 4.6(b). Interestingly a lesser amount of sodium nitrite was needed in the 
presence of AuNPs in figure 4.6(d) to quench E2-MIP particles, from $80 \%$ to $90 \%$, than in figure 4.6(e).

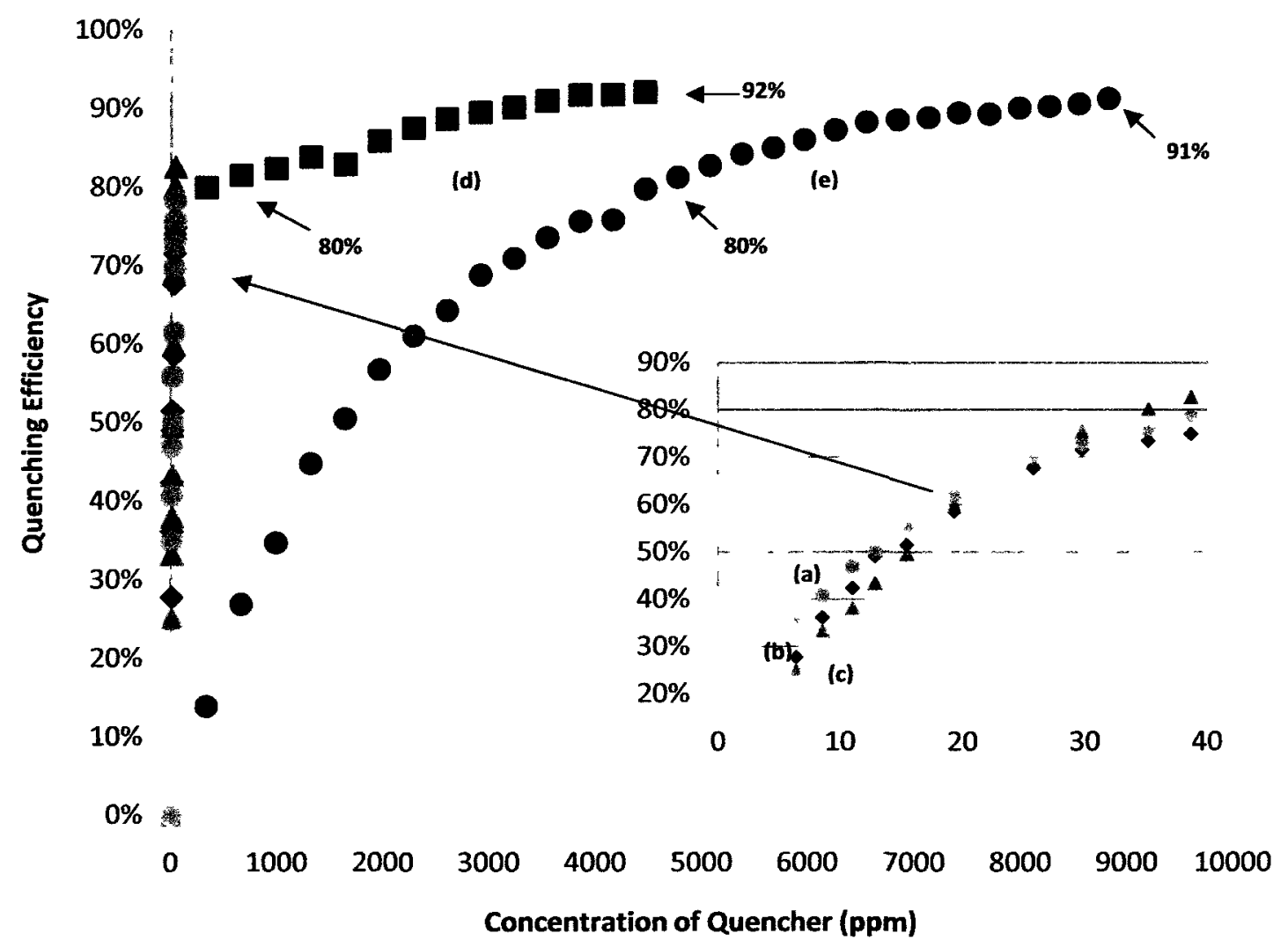

Figure 4.6 Quenching efficiency ( $\theta$ ) versus concentration of quencher: (a) $2.5 \mathrm{mg} / \mathrm{mL}$ E2-bound NIP particles in aqueous suspension quenched with AuNPs, (b) 2.5 $\mathrm{mg} / \mathrm{mL}$ E2-MIP particles in aqueous suspension quenched with AuNPs, (c) $3.5 \mathrm{ppm}$ E2 aqueous solution quenched with AuNPs, (d) $2.5 \mathrm{mg} / \mathrm{mL}$ E2-MIP particles in aqueous suspension quenched first with AuNPs and next with sodium nitrite. (e) $2.5 \mathrm{mg} / \mathrm{mL}$ E2-MIP particles in aqueous suspension quenched with sodium nitrite (up to $0.128 \mathrm{M}$ ).

\subsubsection{Stern-Volmer plots.}

All fluorescence quenching data were analyzed further by applying the Stern-Volmer (SV) equations that examine different quenching mechanisms $\left[{ }^{18,22}\right]$ :

$$
\frac{F_{0}}{F}=1+K_{s v}[Q]
$$




$$
\frac{F_{0}}{F}=\left(1+K_{s v}[Q]\right) \exp (V[Q])
$$

$\mathrm{F}_{0}$ and $\mathrm{F}$ are the fluorescence emission intensities in the absence and presence of quencher. $\mathrm{K}_{\mathrm{sv}}$ denotes the dynamic quenching constant, and $\mathrm{V}$ denotes the static quenching constant. [Q] is the concentration of quencher. Equation 4.1 represents a linear function between dynamic quenching and quencher concentration, where quencher collision with the excited fluorophore $\left(\mathrm{E} 2^{*}\right)$ returns it to the ground state without fluorescence emission $\left[{ }^{23}\right]$. Figure 4.7 shows the linear S-V plots for AuNPs, which were best analyzed using equation 4.1. The $\mathrm{K}_{\mathrm{sv}}$ for $\mathrm{E} 2$ is $2.6( \pm 0.1) \times 10^{4} \mathrm{M}^{-1}\left(\mathrm{R}^{2}=0.9478\right)$, the $\mathrm{K}_{\mathrm{sv}}$ for E2-MIP particles is $2.9( \pm 0.1) \times 10^{4} \mathrm{M}^{-1}\left(\mathrm{R}^{2}=0.9566\right)$, and the $\mathrm{K}_{\mathrm{sv}}$ for E2-bound NIP particles is $3.3( \pm 0.1) \times 10^{4} \mathrm{M}^{-1}\left(\mathrm{R}^{2}=0.9678\right)$. Due to their large size, AuNPs could hardly penetrate the porous structures of E2-MIP and E2-NIP particles. Consequently, their $\mathrm{K}_{\mathrm{sv}}$ values were in the same order of magnitude as that obtained for E2 in aqueous solution.

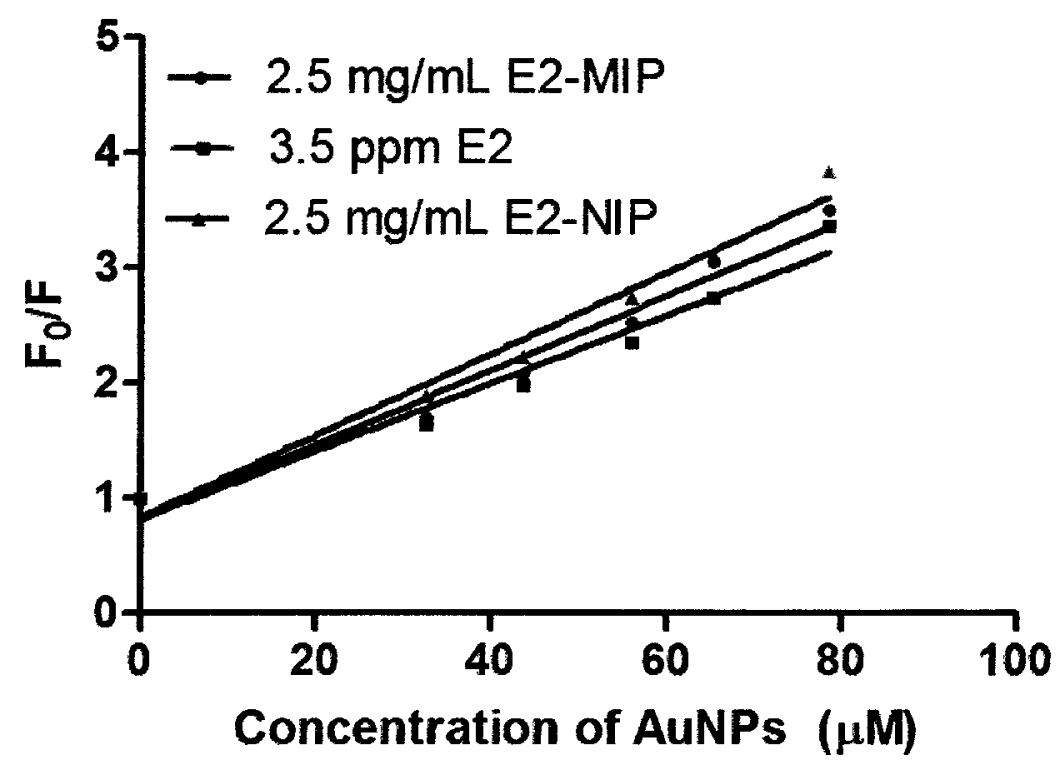

Figure 4.7 Stern-Volmer plots of $\mathrm{F}_{0} / \mathrm{F}$ versus concentration of AuNPs for $3.5 \mathrm{ppm}$ E2 aqueous solution, $2.5 \mathrm{mg} / \mathrm{mL}$ E2-MIP particles in aqueous suspension, and $2.5 \mathrm{mg} / \mathrm{mL}$ E2-bound NIP particles in aqueous suspension. Each solid line indicates the best possible linear regression. 
The S-V plots for sodium nitrite was found to be non-linear (with an upward-curving trend), as shown in Figure 8. Non-linear S-V plots had been discussed by Zhao and Swager $\left[{ }^{22}\right]$ as a combined result from dynamic and static quenching. In contrast to dynamic quenching, the mechanism of static quenching involves interaction between the quencher and fluorophore to form a non-fluorescent complex $\left[{ }^{23}\right]$. Analysis using equation 4.2 obtained $\mathrm{K}_{\mathrm{sv}}=2.1 \times 10^{2} \mathrm{M}^{-1}$ and static quenching constant (V) below $1.0 \mathrm{M}^{-1}$ $\left(\mathrm{R}^{2}=0.9220\right)$ for $2.5 \mathrm{mg} / \mathrm{mL}$ E2-MIPs in aqueous suspension containing $5.88 \times 10^{-4} \mathrm{M}$ AuNPs. Since MIP cavities did not facilitate complex formation between E2 molecules and nitrite anions due to space constraints, the V value turned out to be very small. A higher $\mathrm{V}$ value of $4.7 \mathrm{M}^{-1}$ was obtained for $4.5 \mathrm{ppm} \mathrm{E} 2$ in aqueous solution, which signifies the complexation of E2 molecules with nitrite anions in the absence of steric hindrance.

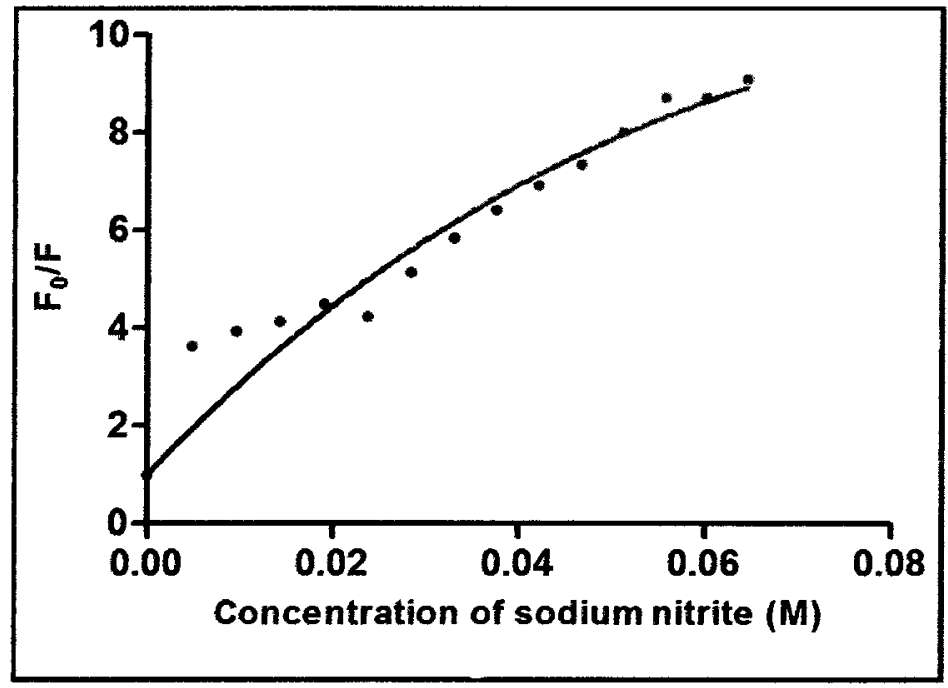

Figure 4.8 Stern-Volmer plots of $\mathrm{F}_{0} / \mathrm{F}$ versus concentration of sodium nitrite. Sodium nitrite was titrated stepwise into $2.5 \mathrm{mg} / \mathrm{mL}$ E2-MIPs in aqueous suspension containing $5.88 \times 10^{-4} \mathrm{M}$ AuNPs. Each solid line indicates the best possible linear regression. 


\subsubsection{Determination of E2 in water.}

Various concentrations (from $0.1 \mathrm{ppb}$ up to $3.5 \mathrm{ppm}$ ) of E2 in aqueous solution were used to validate MIP particles for rapid E2 determination by fluorescence quenching. MIP particles were added in these E2 solutions to form $0.5-3.5 \mathrm{mg} / \mathrm{mL}$ suspensions. Two incubation times ( $5 \mathrm{~min}$ and $35 \mathrm{~min}$ ) were tested to investigate binding equilibrium between E2 molecules and MIP particles. The fluorescence emission intensity from E2 specifically bound with MIP particles was determined by measuring the fluorescence emission intensities after two quenching steps, as summarized by:

$I_{E 2 \text { inside MIP cavities }}=I_{\text {After quenching with AuNps }}-I_{\text {After quenching with sodium nitrite }}$

Essentially, the first quenching with AuNPs would eliminate the fluorescence emission from E2 molecules on non-specific binding sites throughout the porous MIP particles. Then, sodium nitrite would quench the fluorescence emission from E2 molecules inside the specific imprinted cavities. The normalized \% binding of E2 with imprinted cavities was determined as:

$$
\text { Normalized } \% E 2 \text { binding }=\frac{I}{I_{\max }}
$$

where I is the fluorescence intensity from E2 bound specifically inside imprinted cavities for an E2 standard solution, and $I_{\max }$ is the maximum fluorescence intensity from E2 bound specifically inside all imprinted cavities. Both $I$ and $I_{\max }$ were calculated according to equation 4.3, in parallel measurements. To determine $\mathrm{I}_{\max }$, E2-MIP particles were prepared by washing only with DDW to remove all non bound E2 molecules. Normalization was deemed necessary because $I_{\max }$ is not linearly dependent on the concentration of E2-MIP particles in aqueous suspension, as shown in Figure 4.9, due to 
inner filter effects.

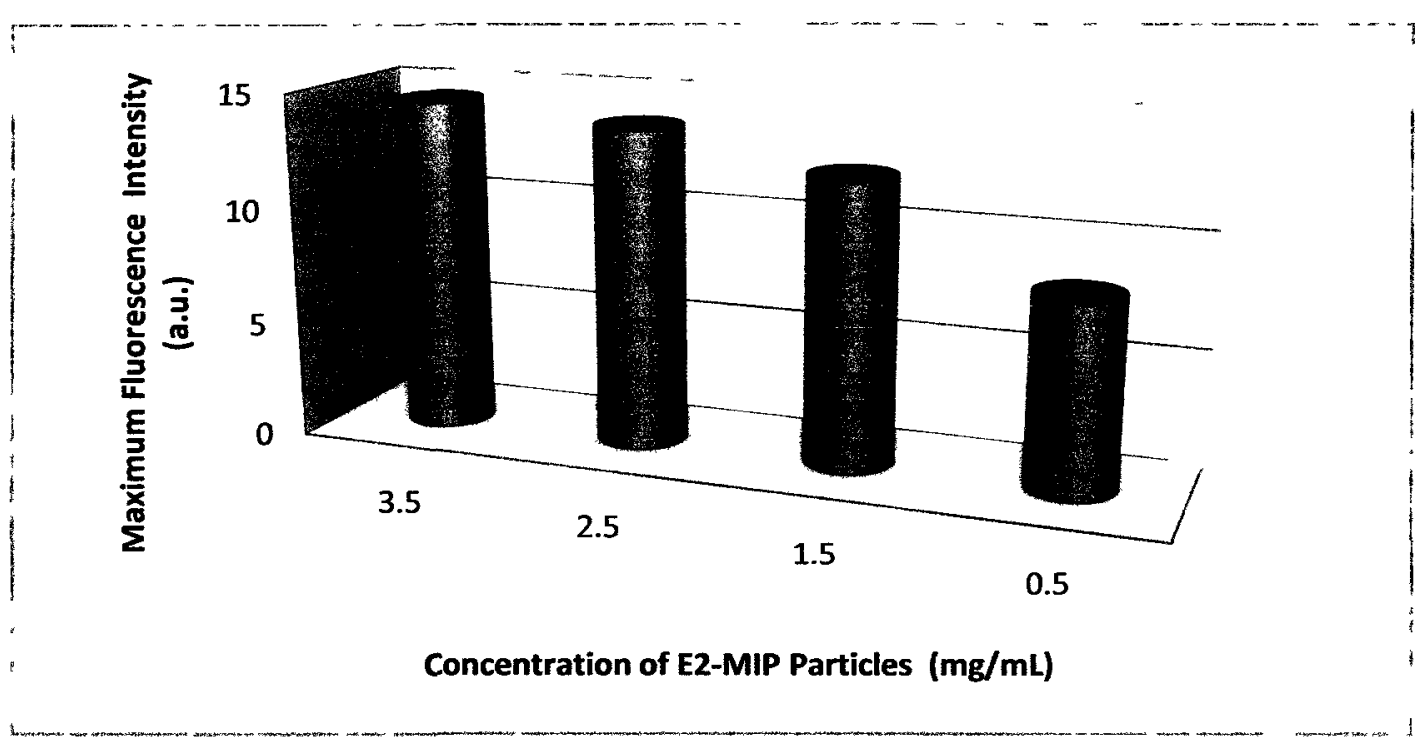

Figure $4.9 \mathrm{I}_{\max }$ for $3.5 \mathrm{mg} / \mathrm{mL}, 2.5 \mathrm{mg} / \mathrm{mL}, 1.5 \mathrm{mg} / \mathrm{mL}$ and $0.5 \mathrm{mg} / \mathrm{mL}$ E2-MIP particles in aqueous suspension.

Figure 4.10 shows \% E2 binding (with imprinted cavities) as a function of E2 concentration after incubation for (a) $5 \mathrm{~min}$ and (b) $35 \mathrm{~min}$. A comparison of figure 4.10(a) with (b) indicates that \% E2 binding exhibited no significant difference. This suggests that binding equilibrium was reached in $5 \mathrm{~min}$ or less, in agreement with the $\sim 2$ min previously reported $\left[{ }^{24}\right]$. As $0.5 \mathrm{mg} / \mathrm{mL}$ E2-MIP particles had the smallest number of imprinted cavities and hence the lowest $I_{\max }$ value, it produced the highest $\%$ E2 binding among the three concentrations studied. As the method involved binding of the analyte with MIP particles for the best possible selectivity (only second to natural antibodies), Scatchard plots were constructed in accordance with the following equation $\left[{ }^{25}\right]:$

$$
\% \text { E binding }=\frac{[E 2]}{\left(K_{d}+[E 2]\right)}
$$

where $\mathrm{K}_{\mathrm{d}}$ is the equilibrium binding constant. The best calibration curves, fitted using 
Graphpad Prism ${ }^{\circledR}$, are shown as solid lines in Figure 4.10. The best correlation coefficients were obtained for $2.5 \mathrm{mg} / \mathrm{mL}$ MIP particles, being $\mathrm{R}^{2}=0.9716$ for $5 \mathrm{~min}$ of incubation and 0.9937 for $35 \mathrm{~min}$ of incubation. Table 4.1 shows that the equilibrium binding constant $\left(\mathrm{K}_{\mathrm{d}}\right)$ for $2.5 \mathrm{mg} / \mathrm{mL}$ of MIP particles, using $5 \mathrm{~min}$ of incubation, was the highest among the three MIP concentrations studied as expected. 

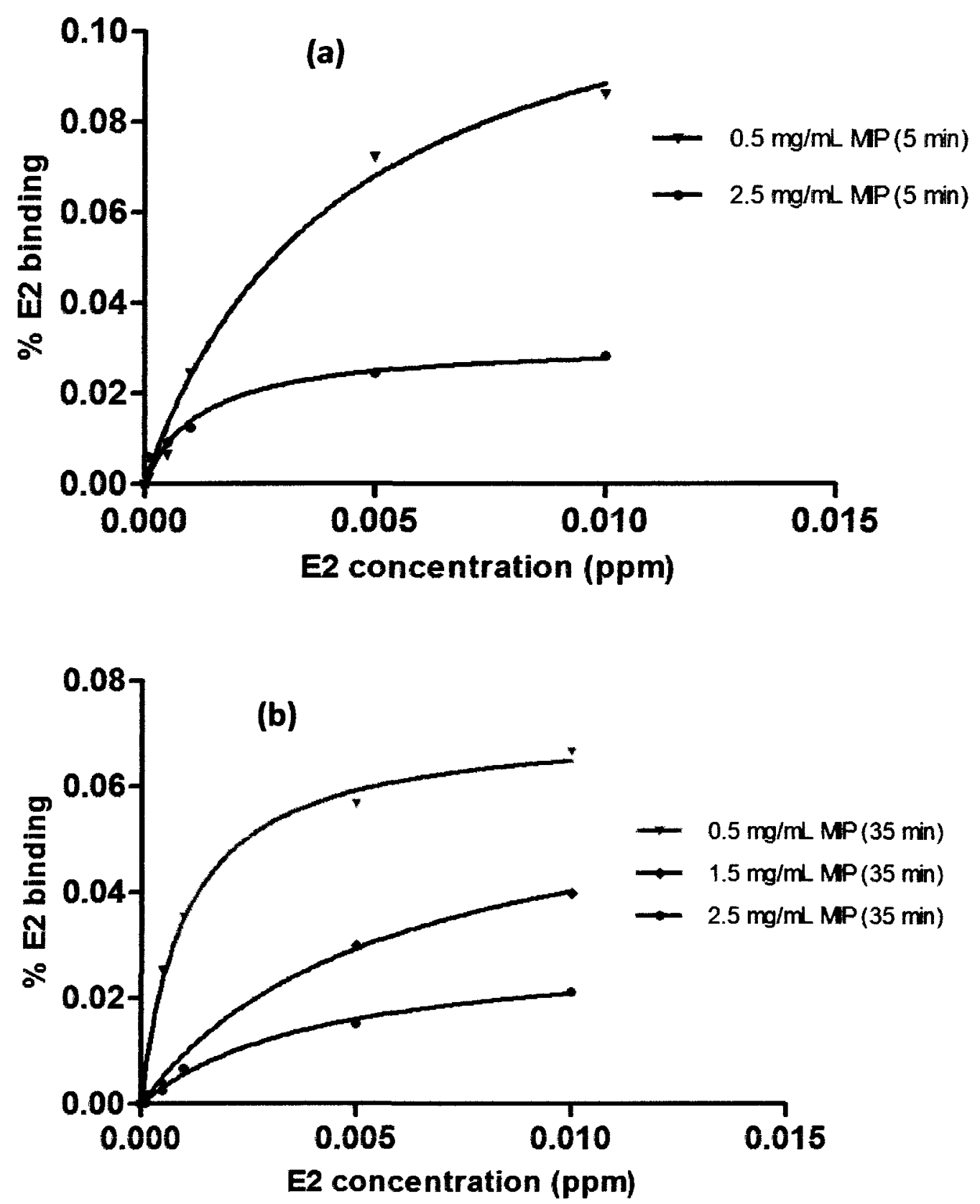

Figure $4.10 \%$ E2 binding (with imprinted cavities) as a function of E2 concentration after incubation for (a) $5 \mathrm{~min}$, and (b) $35 \mathrm{~min}$. (Standard error bars, approximately three to five times the size of each data point symbol, are omitted here for the sake of clarity). 


\begin{tabular}{|c|c|c|}
\hline Incubation time $(\mathrm{min})$ & Concentration of MIP particles $(\mathrm{mg} / \mathrm{mL})$ & $\mathrm{K}_{\mathrm{d}}(\mathrm{ppm})$ \\
\hline \multirow{3}{*}{$5 \mathrm{~min}$} & 0.5 & 0.7 \\
\cline { 2 - 3 } & 1.5 & 1.4 \\
\cline { 2 - 3 } & 2.5 & 2.9 \\
\hline
\end{tabular}

Table 4.1 Equilibrium binding constant $\left(\mathrm{K}_{\mathrm{d}}\right)$ values determined for three concentrations of MIP particles in aqueous suspension, after 5 min of incubation.

\subsection{Conclusion}

AuNPs $(43 \pm 5 \mathrm{~nm})$ were efficient in quenching the fluorescence emission from E2 molecules in aqueous solution, or non-specifically bound with porous particles. For E2 molecules specifically bound inside imprinted cavities, fluorescence quenching by sodium nitrite was successful. A rapid method has been developed for E2 determination by measuring the change in fluorescence emission intensities between these two fluorescence quenching steps, using first AuNPs and then sodium nitrite. One major advantage of this method is the high selectivity of MIP particles for E2, as previously demonstrated using molecules with similar structures (estrone, ethynylestradiol) $\left[{ }^{2 !}\right]$ and dissimilar structures (bisphenol A) $\left.{ }^{26}\right]$. Other fluorescent molecules would not interfere with the E2 determination because they can only bind non-specifically to be readily quenched by AuNPs. Highly correlated Scatchard plots $\left(\mathrm{R}^{2}>0.97\right)$ serve well as a standard calibration curve. The detection limit for E2 is low, at the ultra-trace level of 0.1 ppb. The method is also promising for use on a portable spectrofluorimeter in field studies. Further work is underway to verify that no potential interference by common 
anions $\left(\mathrm{CO}_{3}{ }^{2-}, \mathrm{NO}_{3}{ }^{-}, \mathrm{PtCl}_{4}{ }^{2-}, \mathrm{SCN}^{-}, \mathrm{N}_{3}^{-}\right.$present in environmental waters) exists after an extra centrifugation step is added (to precipitate the MIP particles out for transfer into a cuvette of deionized water) before the two fluorescence quenching measurements. 


\section{References}

[1]. H. Y. Yan and K. H. Row, "Characteristic and synthetic approach of molecularly imprinted polymer," International Journal of Molecular Sciences, vol. 7, no. 5-6, pp. 155-178, 2006.

[2]. W. H. Zhou, C. H. Lu , X. C. Guo, F. R. Chen, H. H. Yang and X. R. Wang, "Mussel-inspired molecularly imprinted polymer coating superparamagnetic nanoparticles for protein recognition," Journal of Materials Chemistry, vol. 20, no. 5, pp. 880-883, 2010.

[3]. N. D. Zakaria, N. A. Yusof, J. Haron and A. H. Abdullah, "Synthesis and evaluation of a molecularly imprinted polymer for 2,4-dinitrophenol," International Journal of Molecular Sciences, vol. 10, no. 1, pp. 354-365, 2009.

[4]. P. Kueseng , M. L. Noir , B. Mattiasson, P. Thavarungkul and P. Kanatharana, "Molecularly imprinted polymer for analysis of trace atrazine herbicide in water," Journal of Environmental Science and Health B, vol. 44, no. 8, pp. 772-80, 2009.

[5]. K. Prasad , K. P. Prathish , J. M. Gladis , G. R. K. Naidu and T. P. Rao, "Molecularly imprinted polymer (biomimetic) based potentiometric sensor for atrazine," Sensors and Actuators B-Chemical, vol. 123, no. 1, pp. 65-70, 2007.

[6]. K. P. Prathish , K. Prasad , T. P. Rao and M. V. S. Suryanarayana, "Molecularly imprinted polymer-based potentiometric sensor for degradation product of chemical warfare agents - Part I. Methylphosphonic acid," Talanta, vol. 71, no. 5, pp. 1976-1980, 2007.

[7]. T. Alizadeh and M. Akhoundian, "A novel potentiometric sensor for promethazine based on a molecularly imprinted polymer (MIP): The role of MIP structure on the sensor performance," Electrochimica Acta, vol. 55, no. 10, pp. 3477-3485, 2010.

[8]. J. Zhang, Y. Q. Wang, R. H. Lv and L. Xu, "Electrochemical tolazoline sensor based on gold nanoparticles and imprinted poly-o-aminothiophenol film," Electrochimica Acta, vol. 55, no. 12, pp. 4039-4044, 2010.

[9]. A. K. Patel , P. S. Sharma and B. B. Prasad, "Trace-level sensing of creatine in real sample using a zwitterionic molecularly imprinted polymer brush grafted to sol-gel modified graphite electrode," Thin Solid Films, vol. 518, no. 10, pp. 2847-2853, 2010.

[10]. N. Wu , L. Feng, Y. Tan and J. Hu, "An optical reflected device using a molecularly imprinted polymer film sensor," Analytica chimica acta, vol. 653, no. 1, pp. 103-8, 2009.

[11]. B. K. Lavine, D. J. Westover, N. Kaval, N. Mirjankar , L. Oxenford and G. K. 
Mwangi, "Swellable molecularly imprinted polyN-(N-propyl)acrylamide particles for detection of emerging organic contaminants using surface plasmon resonance spectroscopy," Talanta, vol. 72, no. 3, pp. 1042-1048, 2007.

[12]. B. B. Prasad, M. P. Tiwari , R. Madhuri and P. S. Sharma, "Development of a highly sensitive and selective hyphenated technique (molecularly imprinted micro-solid phase extraction fiber-molecularly imprinted polymer fiber sensor) for ultratrace analysis of folic acid," Analytica chimica acta, vol. 662, no. 1, pp. 14-22. 2010.

[13]. Y. Yang and E. P. C. Lai, "An investigation of porous structure in molecularly imprinted polymer for sensor development: non-linear fluorescence quenching of $17 \beta$ cstradiol bound inside MIP submicron particles by sodium nitrite and methacrylamide," "Journal of Photochemistry and Photohiology A: Chemistry, vol. 213, no. 2-3, pp. 123128. 2010.

[14]. J. Zhang, R. Badugu and J. R. Lakowicz, "Fluorescence quenching of CdTe nanocrystals by bound gold nanoparticles in aqueous solution," Plasmonics, vol. 3, no. 1, pp. 3-11, 2008.

[15]. S. Y. Lim , J. H. Kim, J. S. Lee and C. B. Park, "Gold nanoparticle enlargement coupled with fluorescence quenching for highly sensitive detection of analytes." Langmuir, vol. 25, no. 23, pp. 13302-13305, 2009.

[16]. S. Mayilo, M. A. Kloster, M. Wunderlich, A. Lutich, T. A. Klar, A. Nichtl, K. Kurzinger, F. D. Stefani and J. Feldmann, "Long-range fluorescence quenching by gold nanoparticles in a sandwich immunoassay for cardiac troponin T," Nano Letters, vol. 9, no. 12. pp. 4558-63. 2009.

[17]. S. Wei . A. Molinelli and B. Mizaikoff, "Molecularly imprinted micro and nanospheres for the selective recognition of 17beta-estradiol," Biosensors Bioelectronics, vol. 21, no. 10, pp. 1943-51. 2006.

[18]. S. K. Ghosh, A. Pal . S. Kundu, S. Nath and T. Pal, "Fluorescence quenching of 1-methylaminopyrene near gold nanoparticles: size regime dependence of the small metallic particles," C'hemical Physics Letters, vol. 395, no. 4-6, pp. 366-372. 2004.

[19]. R. A. Leese and E. L. Wehry, "Corrections for inner-filter effects in fluorescence quenching measurements via right-angle and front-surface illumination," Analytical Chemistry, vol. 50. no. 8, pp. 1193-1197, 1978.

[20]. Z. B. Zhang and J. Y. Hu, "Selective removal of estrogenic compounds by molecular imprinted polymer (MIP)," Water Research, vol. 42, no. 15, pp. 4101-4108, 2008.

[21]. Y. Yang, E. P. C. Lai and M. Liu, "Spectroscopic analysis of poly (methacrylic acid-co-ethylene glycol dimethacrylate) submicron particles by fluorescence emission 
and light scattering upon binding with $17 \beta$-estradiol in water treatment," Open Colloid Science Journal, vol. 3, no. 8, pp. 1-8, 2010.

[22]. D. Zhao and T. M. Swager, "Sensory responses in solution vs solid state: A fluorescence quenching study of poly(iptycenebutadiynylene)s," Macromolecules, vol. 38, no. 22 , pp. 9377-9384, 2005.

[23]. J. R. Lakowicz, Principles of Fluorescence Spectroscopy, Springer, New York, NY, USA, 3rd edition, 2006.

[24]. E. P. C. Lai , Z. D. Maleki and S. Wu, "Characterization of molecularly-imprinted and non-imprinted polymer submicron particles specifically tailored for removal of trace $17 \beta$-estradiol in water treatment," Journal of Applied Polymer Science, vol. 116, no. 3, pp. 1499-1508, 2010.

[25]. T. A. Sergeyeva , S. A. Piletsky, A. A. Brovko , E. A. Slinchenko , L. M. Sergeeva, T. L. Panasyuk and A. V. El'skaya, "Conductimetric sensor for atrazine detection based on molecularly imprinted polymer membranes," Analyst, vol. 124, no. 3, pp. 331-334, 1999.

[26]. Z. DeMaleki, E. P. Lai and E. Dabek-Zlotorzynska, "Capillary electrophoresis characterization of molecularly imprinted polymer particles in fast binding with 17 betaestradiol," Journal of Separation Science, vol. 33, no. 17-18, pp. 2796-803, 2010. 


\section{Chapter 5}

\section{Conclusion and Future work}

Spectrofluorimetry for trace chemical analysis has been successfully demonstrated in this thesis, using NIP and MIP particles as potential sensor materials for basic research in light scattering and fluorescence quenching. The intensity of NIP light scattering was correlated with the concentration of E2 in water down to $0.1 \mathrm{ppm}$. Advantages of this method include easy operation of the instrument, rapid steps in a simple procedure, and low costs of the NIP particles. A consentaneous explanation of the increase in light scattering from fine particles is increasing particle size $\left[{ }^{1}\right]$. However, the NIP particle size did not change significantly after binding with different concentrations of E2 (appendix I). The real reason is still under investigation in our lab. One limitation of this method is that NIP does not have selectivity and an extra sample preparation step will be needed to separate the target analyte in real-sample applications.

The second spectrofluorimetric method, based on fluorescence quenching, provides a useful two-step scheme for the investigation of specific binding between E2 molecules and MIP imprinted cavities. Determination of trace E2 levels is selective by judicious choices of the quencher size. Sodium nitrite due to its small size is used to penetrate the porous MIP particle to quench the fluorescence emission intensity from E2 molecules bound inside the MIP imprinted cavities. Methacrylamide was tested as a large quencher that would be sterically hindered in penetrating the pores of MIP particles. However, the S-V plots indicated that methacrylamide still could penetrate the porous MIP matrix. AuNPs, which is $\sim 120$ times larger than methacrylamide, can be used as a large-size quencher to eliminate fluorescence emission from non-specifically bound E2 molecules 
located on both the surfaces of MIP particles and inner walls of their porous matrices. Delightfully, the S-V plots indicated there AuNPs could not reach the E2 molecules bound inside MIP imprinted cavities. Thus, sodium nitrite and AuNPs are a good combination of fluorescence quenchers for two-step fluorescence quenching to determine trace levels of E2. The advantages of this method are selective, sensitive, simple and rapid. This analytical approach is also valuable in examining the specific binding sites in newly developed MIP materials.

In the future work, this robust sensing method to detect E2 by using two steps of fluorescence quenching with AuNPs and sodium nitrite will use in real sample analysis. The samples from environment (fresh water and sea water) and health care (urine and other body fluid) are major targets to apply with this E2 sensing method. Depending on the rapid E2 binding characteristic, MIPs can be applied directly into the real sample and then testing the E2 level. The real samples with lower E2 concentration (less than $0.1 \mathrm{ppb}$ ) also can be performed by this sensing method due to the excellent preconcentration ability of MIPs $\left[{ }^{2,3}\right]$. Further studies would examine the possible interferences from real sample matrix. The interference from fluorescent compounds in real sample can be avoided by the specific binding cavities. Further in real samples, the interferences from potential small size ionic quenchers need our careful investigation.

The fluorescence quenching properties of sodium nitrite has shown in fluorescence quenching of E2 in this research. Sodium nitrite is used widely as a preservative in the processing of cured meat products mainly for its antimicrobial properties against Clostridium botulinum $\left[{ }^{4,5}\right]$. The risk of sodium nitrite consumption from cured meat products are incidence of childhood leukemia and brain tumors. In the future work, a 
fluorophore modified membrane sensor will be designed to determination of sodium nitrite in cured meat product. Theoretically, this sensor is based on two results from chapter 3 and 4 . First, a fluorophore bound substrate is a valuable fluorescent molecule sensor material. Second, sodium nitrite is a remarkable fluorescence quencher.

Nylon filter membrane will be an excellent carrier for chemosensory applications in ultratrace analysis. Due to nylon filter membrane shows stronger relative fluorescence after binding with fluorophore and better retention with analyte than other type of filter membranes (i.e. cellulose acetate, immobilon, teflon, mixed esters and filter papers) $\left[{ }^{6}\right]$. Proflavine was used for fluorescence quenching by nitrite in hydrochloric acid $[7]$. The diazotation of proflavine (fluorophore) by using sodium nitrite is rapidly produce acridine-3,6-diol and fluorescence quenching the proflavine fluorescence.

Ideally, in the future, we can build a fluorescent sensing substrate by using nylon filter membrane binding with proflavine (fluorophore). The optimal conditions to making the fluorescent sensing substrate will be carefully tested by fluorescence quenching via Stern-Volmer plots and fluorescence quenching efficiency plots. Further studies would specially focus on proflavine concentration, contact time and $\mathrm{pH}$. A calibration method will built on Stern-Volmer plots to detection sodium nitrite in real cured meat samples. This fluorescent sensing substrate can sense sodium nitrite by direct contact with meat juice and it also can be attached into the packing material of cured meat product. 


\section{References}

[1]. E. L. Weiss and H. N. Frock, "Rapid analysis of particle size distributions by laser light scattering," Powder Technology, vol. 14, no. 2, pp. 287-293, 1975.

[2]. T. Jiang , L. Zhao , B. Chu , Q. Feng , W. Yan and J.-M. Lin, "Molecularly imprinted solid-phase extraction for the selective determination of 17[beta]-estradiol in fishery samples with high performance liquid chromatography," Talanta, vol. 78, no. 2, pp. 442-447, 2009.

[3]. F. Canale , C. Cordero , C. Baggiani , P. Baravalle , C. Giovannoli and C. Bicchi, "Development of a molecularly imprinted polymer for selective extraction of bisphenol A in water samples," J Sep Sci, vol. 33, no. 11, pp. 1644-51, 2010.

[4]. N. P. Sen and P. A. Baddoo, "Trends in the levels of residual nitrite in canadian cured meat products over the past 25 years," Journal of Agricultural and Food Chemistry, vol. 45, no. 12 , pp. 4714-4718, 1997.

[5]. R. B. Tompkin, L. N. Christiansen and A. B. Shaparis, "Enhancing nitrite inhibition of Clostridium botulinum with isoascorbate in perishable canned cured meat," Appl Environ Microbiol, vol. 35, no. 1, pp. 59-61, 1978.

[6]. M. C. Talio , M. O. Luconi , A. N. Masi and L. P. Fernández, "Solid surface spectroscopic methodology for ultra-trace urinary nickel monitoring in smokers and nonsmokers' subjects," Journal of Pharmaceutical and Biomedical Analysis, vol. 52, no. 5, pp. 694-700, 2010.

[7]. M. T. Fernandez-Arguelles, B. Canabate , J. M. Costa-Fernandez, R. Pereiro and A. Sanz-Medel, "Flow injection determination of nitrite by fluorescence quenching," Talanta, vol. 62, no. 5, pp. 991-995, 2004. 


\section{Appendix}

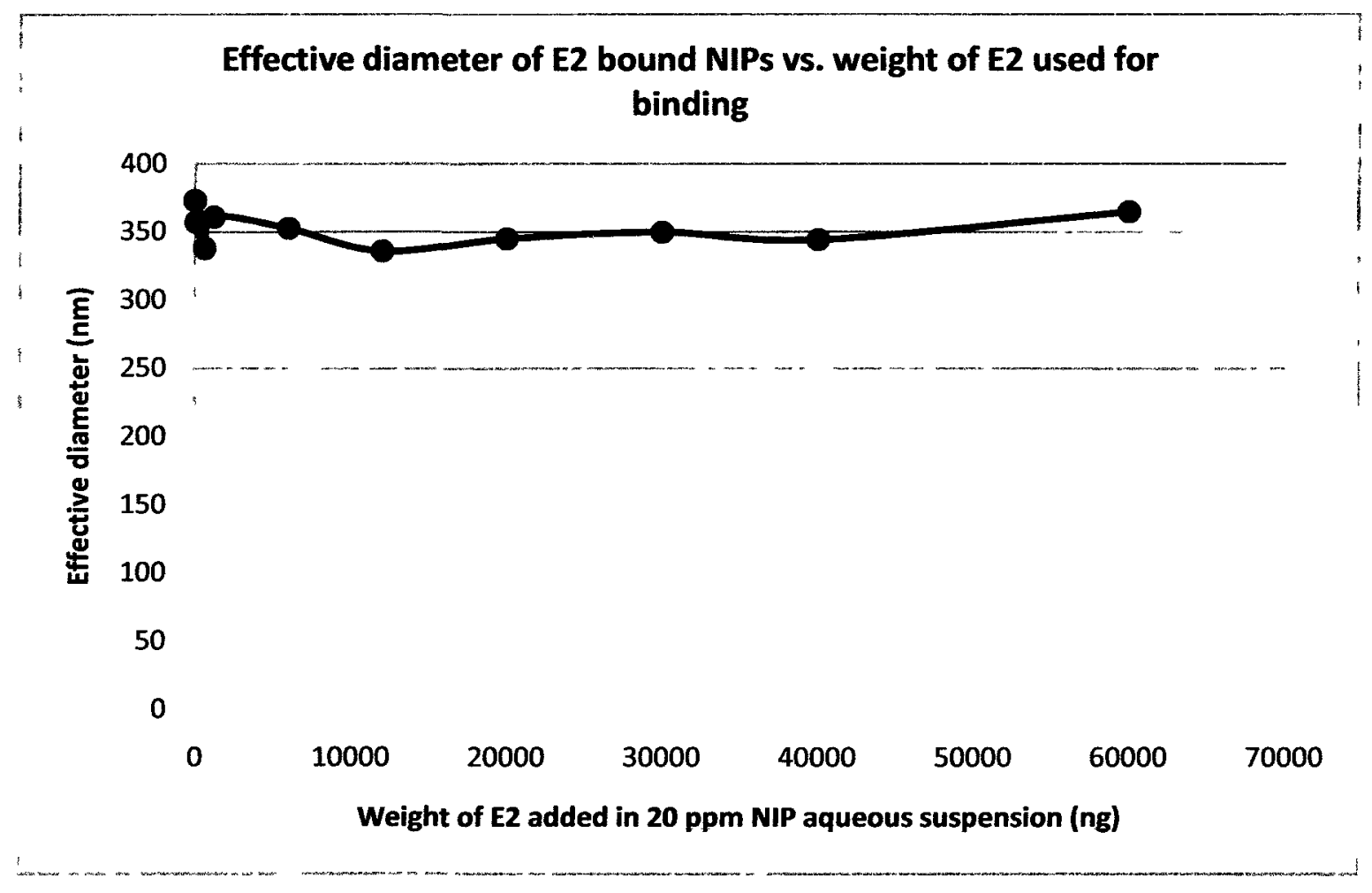

Appendix I. Influence of E2 concentration (0 - 60000 ng or $0-20 \mathrm{ppm})$ on NIP particle size after binding. 